\section{Danser anglais}

Danser selon la mode, la coutume anglaise Intransitif

1926 La rumeur des causeries se mêlait au bruit des instruments, piano, violons et cuivres. Tout ce monde, - deux cents personnes peut-être, - parlait anglais, buvait anglais, dansait anglais (Paul Bourget, Le Danseur mondain)

\section{CORPUS WEB :}

Parler anglais, manger anglais, danser anglais, boire anglais ; viens vivre l'Angleterre ce samedi à La Cartonnerie de Reims avec The Mouse Outfit et Lady Leshurr Support Page !!! [https://www.facebook.com/cartonnerie.reims. fanpage/posts/584840864936233?stream_ref=10] (19.1.2015)

La montagne écossaise dansant (également appelé l'épée d'Scottish dansant) est aussi différente du pays écossais dansant que danser de Morris est de danser anglais de pays [http:// wikipedia.qwika.com/en2fr/Talk:Folk_dance] (19.1.2015)

Si l'envie vous prenait de danser anglais pendant une semaine, ou bien autre chose ou ne rien faire dans les Cévennes. C'est tellement beau. et sympa ! [https://larondedherblay. wordpress.com/2013/03/20/divers-stages-autresgroupes-manifestations] (19.1.2015)

REMARques : Danser anglais désigne le fait de danser comme un Anglais, et, par extension, de danser selon la mode anglaise. L'exemple met en évidence l'effet analogique à partir du modèle parler anglais. Le CW confirme ce phénomène. Notons l'emploi de boire anglais.

\section{Danser classique}

Pratiquer la danse classique

Intransitif

1982 « Il est évident que je ne pourrais plus danser classique » (Antenne 2, 19.12.1982 / Hagège 1987 : 45)

\section{Danser contemporain}

Pratiquer la danse contemporaine (opposé à

'pratiquer la danse classique')

Intransitif

2003 Paul fait danser contemporain (Paris Match)

\section{Danser utile}

Danser dans le but d'obtenir un avantage

$\lambda$ baiser utile

\section{Dater faux}

Donner une date erronnée

Emploi absolu

1833 L'Hercule des Persans est le fameux Roustan antérieur à Arsace $\mathrm{I}^{\mathrm{er}}$, qui fonda en 256 avant J. C. l'empire de Parthie. Ceux qui prétendent en savoir davantage, datent faux (Louis Capello, comte de Sanfranco, Mythologie de tous les peuples)

\section{Décapiter net}

Couper la tête d'un seul coup

Transitif

1857 Le chef de dépôts, le malheureux Miau (d'Auch), à été décapité net, et son corps tellement maltraité que les restes ont pu tenir dans un sac d'une médiocre grandeur (La Presse)

1913 «Porfire doit nous y attendre avec l'automobile... voici ma « vorace » d'été, pour aller et venir entre Moscou et Pétrovskoïé. Les deux grands sabres à l'avant ? C'est pour couper les fils de fer que nos révolutionnaires tendent en travers des routes, depuis quelque temps. Le chauffeur de mon cousin Constantin a été décapité net, le mois dernier, sur la route d'Oranienbaum » (Valery Larbaud, Journal intime / A.O. Barnabooth)

2009 Les loups connaissent les coutelas, pas les sabres. Il ne s'est pas méfié. Tu l'as décapité net (Hubert de Maximy, La Rebouteuse de Champvieille)

\section{Déchaumer droit}

Enlever le chaume du sol, comme il faut

त labourer droit 


\section{Déchevaucher dur}

Faire tomber violemment de cheval

Transitif

1275 Se ne fust une estache, Limbanors fust noiiés,

Dont Sarrazin avoient mains poissons engingniés.

Ahi ! Mahonmet sire, fait il, et car m'aidiés!

Malement est sor moi retornés li meschiés, Quant par un François sui si dur deschevauchiés

(Adenet le Roi, Buevon de Conmarchis, 2618)

REMARQUES : En ancien français, déchevaucher dur désigne le fait de faire tomber quelqu'un de cheval avec force.

\section{Déchirer menu}

Déchirer en petits morceaux

Transitif

1874 Il était tellement absorbé dans ses méditations que, certainement, il ne s'apercevait pas du travail de ses doigts. Ce travail consistait à déchirer si menu, si menu, les confidences de sa belle cousine, que ce monument de la papeterie moderne s'en alla joncher la terre en atomes (Arthur de Gobineau, Les Pléiades)

1932 Le colonel ne bronchait toujours pas, je le regardais recevoir, sur le talus, des petites lettres du général qu'il déchirait ensuite menu, les ayant lues sans hâte, entre les balles (Louis-Ferdinand Céline, Voyage au bout de la nuit)

1947 Comment pouvait-elle être assez vulgaire, assez basse... Elle qui avait le besoin de la voix de cet homme, comme d'une chanson. Elle écrivait son nom sur des petits bouts de papier, qu'elle déchirait ensuite, patiemment, тепи, тепи, comme une souris, avec ses ongles (Louis Aragon, Les Voyageurs de l'impériale)

1960 Lucie déchire menu la feuille de carnet, en flambe les fragments comme par jeu dans le cendrier, en allumant une cigarette. Quatre cent sept mille ! c'est pas des pous- sières ! (Albert Simonin, Du mouron pour les petits oiseaux)

1969 Le morceau de journal contenait encore autre chose : déchirés menu, vingt billets de banque irrémédiablement gâchés par mes retouches maladroites. Les grands seigneurs jettent l'argent par les fenêtres (Léo Malet, Sueur aux tripes)

\section{CORPUS WEB :}

Apprennez à déchirer menu menu vos papiers ;). L'opération recollage sera plus fastidueuse et à force il n'aura peut être plus assez de temps !! [http://forum-juridique.net-iris.fr/ travail/83504-pdg-eboueur.html] (19.1.2015)

pour le reste un super concert samedi soir (grace au « Stephanois ») avec Classic and trouble comme groupe, de la caillette aussi du sauss a en pleuvoir, du tres bon picodon, certainement la crique ou la bombine ! je suis parré pour vous réjouir le gosier en fin de soirée. ça va dechirer тепи, тепи...... [http://www.voxanclubdefrance. com/forum/viewtopic.php?t=12561] (19.1.2015)

après avoir trouvé l'origine du mal, le patient doit l'écrire (ah, les vertus cathartiques de l'écriture !), puis déchirer menu la feuille chargée désormais de toutes les misères (autrefois c'était un bouc qui portait tous les maux) et enterrer les morceaux (le bouc, lui, était chassé dans le désert) [http://www.pseudo-sciences.org/spip. php?article680] (19.1.2015)

REMARQUES : Déchirer menu réfère au fait de mettre quelque chose (souvent du papier) en pièces, en petits morceaux sans se servir d'un instrument tranchant. Menu reste invariable et est modifié par si, ensuite, patiemment. Notons la réduplication menu, menu. Le second exemple du CW, en emploi absolu, renvoie par métaphore à un impact de la musique qui va « déchirer » le public, en jouant sur le sens argotique de déchirer « être génial».

\section{Décider juste}

Juger, prendre une décision juste Intransitif

1694 Mais où sont ceux qui décident juste en leur propre affaire, qui prononcent contre eux-mesmes, et qui veulent bien preferer une condamnation équitable à un gain de 
cause sans appel ? (Recueil de quelques sermons prononcez par monsieur l'abbé de Pezenne)

1736 Si vous le prenez mal, il vous conduira à deux défauts que vous ne sçauriez trop éviter dans vos jugemens, l'entêtement et la prévention. Quand vous avez décidé juste, à la rigueur, vous êtes quitte (Charles-François-Nicolas Le Maître de Claville, Traité du vrai mérite de l'homme)

1784 j'ai vu admirer les défauts de l'acteur, et honnir ses qualités, la sagesse, la finesse, la raison de son jeu senti. Mais, me direz-vous, ce publiq décide juste cependant ! Oui : deux ou trois têtes au-plûs, quelquefois une, qui donnent le branle à cette grosse bête qu'on appelle le publiq (Nicolas Rétif de la Bretonne, La Paysanne pervertie ou Les Dangers de la ville)

1911 Il en sera toujours ainsi quand le commandement supérieur, manquant à lui-même, par insuffisance de vue ou de volonté, voudra se substituer à ses subordonnés, penser et décider pour eux ; il faudrait, pour qu'il pensât droit et décidât juste, qu'il vît par leurs yeux, du point où ils sont, qu'il pût être à la fois partout

(Ferdinand Foch, Des principes de la guerre)

1997 Il contient deux dimensions qui s'entre-détruisent : le savoir pour décider juste et l'ignorance pour permettre aux équipes de travailler en équipe (Bruno Jarrosson, Le savoir, le pouvoir et la formation)

CORpus WeB :

Des Repères pour décider « juste » Dans la désolation, je ne change pas de cap... [http:// www.dioceseauxarmees.catholique.fr/statutaumonier/2-uncategorised/458-des-reperes-pourdecider-juste.html] (19.1.2015)

Bien se connaître pour décider juste - comprendre ses modes de fonctionnement et ses mécanismes de pensée - identifier ses freins et ses croyances [http://maison-equilibres.ch/wpcontent/uploads/2014/12/Decider-vite-et-juste. pdf] (18.5.2016)
Comprendre pour décider juste

En raison de la diversité des origines, des cultures et des croyances des communautés composant la population réunionnaise, celle-ci n'est comparable à aucune autre [http://www. lequotidien.re/opinion/le-courrier-des-lecteurs/ 134772-comprendre-pour-decider-juste.html] (18.5.2016)

REMARques : Décider juste réfère au fait de prendre une décision moralement correcte, le sujet prenant soin de le faire comme il convient, sans erreur. Décider est un verbe transitif/intransitif qui tend à l'emploi intransitif ou absolu dans décider juste. Notons l'emploi de penser droit.

\section{Déclarer bas}

Déclarer à voix basse

Transitif

1635 Ce grand Prince entretient ses langoureuses plaintes,

Promene son esprit dans ses passions saintes,

Et reschauffe tantost ses timides froideurs De l'espoir du retour de ses Ambassadeurs ; Lors qu'un prompt Messager s'en vient à grosse haleine

Luy declarer tout bas le sujet qui le meine (Pierre Le Hayer Du Perron, Les Palmes du juste)

1735 Huascar, prêt d'éclater, se modere pour remplir ses fonctions à la Fête du Soleil. Il declare bas ses intentions à un des complices de sa fureur (Mercure de France)

1787 Quand cette précaution a été prise, nous ordonnons aux curieux de nous déclarer tout bas quel est le mort dont ils veulent que les mânes se presentent aux regards de la personne isolée (Les Historiettes du jour ou Paris tel qu'il est)

1863 Lui que jamais ici l'on ne vit en défaut,

A déclaré tout bas que ces marques récentes

Annonçaient la démarche et les griffes puissantes

De deux grands loups-cerviers et de deux louveteaux (Alfred de Vigny, Les Destinées) 
2011 Ensommeillée, Hermine se redressa. Elle eut un regard rêveur avant de déclarer tout bas :

- En effet, je reste au sanatorium, ce matin, je prendrai un autre train, mais pour rentrer à Chambord (Marie-Bernadette Dupuy, Le Rossignol de Val-Jabert)

CoRpus Web :

Problématique car la laïcité sert ici de prétexte à Marine Le Pen pour ne pas dire tout haut ce que les français déclarent tout bas lorsqu'ils sont interrogés dans le cadre de sondages [http:// www.dreuz.info/2014/04/dans-les-villes-fnmarine-le-pen-supprime-les-menus-halal-descantines] (19.1.2015)

N'oublies pas le frais de douane $(-)+<150$ euros :o ils déclarent bas. J'en ai eu pour $60 €$ pour le captain (-) [http://www.marvelscustoms. net/t19079p90-premium-collectibles-hawkeye-14-scale-statue-comics-wip] (19.1.2015)

REMARQUES : Presque toujours modifié par tout, déclarer (tout) bas se dit du fait de formuler un jugement ou d'énoncer ses idées, ses pensées, ses opinions ou ses sentiments à voix basse, en cachette, ne voulant pas être entendu de tous, par timidité, pudeur, honte ou peur. Bas reste invariable. Notons dans le CW l'emploi de dire haut, l'antonyme de déclarer bas. Le dernier exemple met évidence la productivité de l'emploi adverbial : en emploi absolu, déclarer bas réfère à la déclaration d'un montant inférieur pour, en l'occurrence, économiser sur les frais de douane.

\section{Déclarer court}

Déclarer brièvement, sans rien ajouter, sans plus, sans différencier

Transitif

1858 Enfin, Pline déclare tout court que l'idée d'une existence après le trépas, est une chimère de la simplicité enfantine ou de l'insatiable désir de vivre qui tourmente les mortels (Johann Joseph Ignaz von Döllinger, Paganisme et judaïsme [trad.])

1901 Et je dis que lorsque les radicaux déclarent tout court qu'ils veulent maintenir la propriété individuelle, ou cela ne signifie rien, ou cela signifie qu'ils veulent maintenir la propriété capitaliste (Jean Jaurès, Études socialistes)

1937 Si faute de mots, vous appelez poésie la langue des trois écrivains ci-dessus (Chateaubriand, Bossuet, Claudel), vous tombez instantanément d'accord avec tous les Anglo-Saxo-Germains qui déclarent haut et court... que la poésie française n'existe pas (Goéland, 1 février 1937 / Grundt : 317)

\section{CORPUS Web :}

J'essaye de remplir le formulaire d'aide juridictionnelle, et je ne sais pas si déclarer les revenus de mon copain et voire même si je dois le déclarer tout court ? [http://droit-finances. commentcamarche.net/forum/affich-4016415aide-juridictionnelle] (19.1.2015)

Lors d'un dossier de surendettement de ma part, est-ce que ses ressources sont prises en compte lors du montage du dossier. dois-je déclarer son emploi récent dois-je la déclarer tout court sur le dossier de surendettement [http:// droit-finances.commentcamarche.net/forum/ affich-6281820-ressources-prises-en-comptedossier-de-surendettement] (19.1.2015)

« Vous n’avez pas déposé ces sommes dans le circuit ? On vous déclare court même si vous avez la taille requise, ou alors ils décident que votre tension est haute, donc ne venez pas mourir ici " avis recueilli auprès de quelques candidats au recrutement à Bafoussam [http:// www.cameroun24.net/?pg=actu\&ppg=1\&pp=1 \&id=6196] (19.1.2015)

REMARQues : Déclarer (tout) court se dit du fait de formuler un jugement ou d'énoncer ses idées, ses pensées, ses opinions ou ses sentiments de façon brève, en peu de mots, sans différenciation (ce qui serait cependant nécessaire selon l'auteur). Notons la collocation déclarer haut et court. Court reste invariable et est modifié par tout. La collocation usuelle tout court fonctionne comme adverbe de phrase au sens de 'sans plus' en français moderne. Dans le dernier exemple du CW, court est employé comme prédicat second orienté vers l'objet, en l'occurrence une recrue dont on estime que la taille est trop petite pour le service militaire, en français d'Afrique. 


\section{Déclarer haut}

I. Énoncer (un fait) de manière claire, évidente, avec conviction ; déclarer ouvertement

Transitif

1582 ce Pontife lors caloit ou appelloit le Peuple des champs au Capitole, pour declarer tout haut, combien de jours restoient des $\mathrm{Ca}$ lendes jusques au Nones (Henri LancelotVoisin de La Popelinière, L'Histoire des histoires)

1699 On couroit en foule le signer. Déjà même plusieurs prélats de l'assemblée déclaroient tout haut qu'ils n'avoient jamais prétendu exiger d'autre signature (Jean Racine, Abrégé de l'histoire de Port-Royal)

1713 Si tôt que nous y fûmes je me retirai avec elle dans la chambre qui nous avoit été préparée ; et là les habits qu'elle avoit sur le corps, ne m'empêchérent point d'en faire ma femme. Je le déclarai tout haut ensuite, afin que qui que ce fût n'en pût douter ; et je le fis, parce que j'aprehendois encore quelque accident (Robert Challe, Les Illustres Françoises)

1734 Chaque société forme un public à part : Mais il en est un autre, et c'est le véritable, Le moins nombreux de tous, et le plus redoutable,

Qui sçait ce qui lui plaît, qui sçait ce qu'il lui faut,

Qui, tous les jours ici, le déclare assez haut (Pierre Claude La Chaussée, La Fausse Antipathie)

1823 Aussi, quand la lutte fut finie, et que le directoire triomphant se plut à déclarer tout haut qu'il devait toute son existence à Napoléon, il conserva néanmoins dans le cœur quelques sentiments vagues que Napoléon n'avait embrassé son parti que dans l'espoir de le voir culbuté, et de se mettre à sa place (Emmanuel de Las Cases, Le Mémorial de Sainte-Hélène)

1881 Ce soir, Labiche, après avoir déclaré bien haut qu'il n'avait jamais lu une ligne de Manuel, pas plus que de Sully Prudhomme, a annoncé qu'il voterait pour Manuel (Edmond et Jules de Goncourt, Journal)
1883 Le bourgeois, en les parcourant d'un cerveau brouillé par les affaires, écarquille les yeux, vous traite, tout bas, de « poète », sourit in petto et se désabonne, - en déclarant, tout haut, que vous avez beaucoup de talent ! (Auguste de Villiers de L'Isle-Adam, Contes cruels)

1921 Vincent estimant nécessaire de couper court à cette illusion, déclara bien haut " que celui-là serait fou qui s'imaginerait que la compagnie était celle dont a prophétisé saint Vincent Ferrier » (Henri Bremond, Histoire littéraire du sentiment religieux en France)

1937 Si faute de mots, vous appelez poésie la langue des trois écrivains ci-dessus (Chateaubriand, Bossuet, Claudel), vous tombez instantanément d'accord avec tous les Anglo-Saxo-Germains qui déclarent haut et court... que la poésie française n'existe pas (Goéland, 1 février 1937 / Grundt : 317)

II. se déclarer tout haut contre quelque chose : faire savoir ouvertement qu'on prend parti contre quelque chose

Pronominal

1914 Dès les premières séances, il apparut avec évidence qu'un certain nombre des commissaires, n'osant se déclarer tout haut contre l'opinion générale, utiliseraient tous les moyens obliques pour faire échouer le projet (Maurice Barrès, Mes cahiers)

\section{CORPus Web :}

Après nous avoir récemment donné quelques bonnes infos sur l'histoire de ce Uncharted 4, les développeurs sont revenus sur des problématiques techniques, et déclarent tout haut que la priorité, c'est l'expérience de jeu [http://www. journaldugamer.com/2015/01/15/uncharted-4images-seconde-framerate] (19.1.2015)

Ce n'est pas rare de rencontrer des personnes qui disent : " Moi, j’aime tel musicien ou rien ». Certains en politique, le déclarent tout haut : " c'est lui ou personne " d'autres encore, sans gêne, crient en public : " c'est mon rappeur préféré, je l'adore » et les exemples sont légions [http://notrevoix.mondoblog. org/2014/06/30/119] (19.1.2015) 
Nous retrouvons les mêmes ingrédients, entre drogue et expériences à vivre. Ces jeunes filles déclarent tout haut leur rupture avec un monde qui semble privatiser les populations, une société chère et mensongère [http:// cinematoman.blogspot.co.at/2013_05_01_ archive.html] (19.1.2015)

REMARQUES : Déclarer (tout) haut se dit du fait de formuler un jugement ou d'énoncer ses idées, ses pensées, ses opinions ou ses sentiments à voix haute, ouvertement ou en public (I). Dans son emploi pronominal (II), il désigne le fait de donner son avis, s'expliquer, se prononcer contre quelque chose (ou quelqu'un). Notons la collocation déclarer haut et court. Haut reste invariable, étant presque toujours modifié par assez, bien, tout. Mentionnons également l'emploi de couper court.

\section{Déclarer net}

I. Annoncer clairement et franchement un fait Transitif

1667 ALCESTE. Mais après ce qu'en vous je viens de voir paroître, Je vous déclare net que je ne le suis plus, Et ne veux nulle place en des cœurs corrompus (Molière, Le Misanthrope)

1732 Je le déclarai tout net à ma mère, qui, se sentant elle-même très mortifiée de l'accueil dont le peuple m'avait régalé, ne s'opposa point à un si prompt départ (Alain-René Lesage, Histoire de Gil Blas de Santillane)

1768 Que ne restiez-vous où vous étiez ? Vous étiez si bien! Pourquoi vous charger de payer pour les sottises d'autrui ? Que ne déclariez-vous net à votre père que ce rôle ne vous convenait pas ?... Cet ange est tout à fait goguenard, et le Christ paraît assez convaincu de la justesse de sa remontrance (Denis Diderot, Salon de 1767)

1833 Un médecin lui conseilla l'usage du safran, qui n'eut aucun résultat; alors il la déclara tout net en grossesse. A cette nouvelle, Apolline tomba dans la consternation et le désespoir (Pétrus Borel, Champavert)
1839 Après s'être jeté à ses genoux en amant jaloux et passionné, il lui déclara fort net que son honneur était intéressé à ce qu'elle ne fût pas la dupe du jeune prince (Stendhal, La Chartreuse de Parme)

1882 J'aime mieux décidément avoir une explication avec cette jeune fille et lui déclarer net que son mariage n'est pas remis, mais qu'il est rompu (Henry Becque, Les Corbeaux)

1894 C'était accepté par Injalbert ; mais ce sculpteur, qui a de la conscience, dans ses études sur les faunes, ayant acquis la conviction qu'ils étaient une race poilue, barbue, déclara un jour tout net au glabre cabotin « qu'il n'était pas du tout son affaire comme faune » (Edmond et Jules de Goncourt, Journal)

1936 Eh bien, l'ukase du tsar a été signé avanthier jeudi, dans l'après-midi ; - et cela, malgré le terrible avertissement qu'avait donné l'Allemagne, en déclarant d'avance et tout net que la mobilisation russe signifierait la guerre (Roger Martin du Gard, Les Thibault. L'Été 1914)

1995 Afin que vous mesuriez l'injustice d'une telle accusation, voici quelques exemples de ce que ma femme considère chez moi comme des preuves irréfutables de ma méchanceté :

[...]

- avoir perdu ses illusions et le déclarer net (méchanceté entre toutes impardonnable) (Lydie Salvayre, La Puissance des mouches)

2009 C'est plus que n'en pouvaient supporter naguère ces catéchistes du Nord-Cameroun déclarant tout net que cette page de l'Évangile apportait avec elle la « mort du village » (René Luneau, Jésus, l'homme qui évangélisa Dieu)

2011 Je mentionne au téléphone à ma sœur que je viens de raconter le jour où elle est venue me chercher à Normale sup, après mon absorption excessive de barbituriques. Elle me déclare aussi net qu'elle 
n'est jamais venue me chercher à Normale (Serge Doubrovsky, Un homme de passage)

II. se déclarer tout net pour (ou contre) quelque chose/quelqu'un : faire savoir qu'on prend parti pour (ou contre) quelque chose/quelqu'un Pronominal

$1864 \mathrm{Au}$ reste, vous voyez que dans mon livre je me déclare tout net pour l'admiration en bloc (Victor Hugo, Correspondance)

\section{CoRpus Web :}

Je suis en ce moment, chez mes parents, sur les terres de Mgr d'Ornellas et l'on vient de me mettre sous les yeux le texte étonnant que le prélat a jugé bon de publier sur le site du Diocèse de Rennes, faisant l'apologie de la pièce de Castellucci Sur le concept de visage du Christ et déclarant tout net, sous l'inter-titre : Le débat est ouvert, « ceci n'est pas de la christianophobie » [http:// ab2t.blogspot.co.at/2011/11/leveque-le-ministrele-journaliste-et.html] (19.1.2015)

Qu'elle coure donc porter plainte contre ceux-là - seulement - et qu'elle nous dispense de la légende propagée par un film, déclarant tout net que toute la Creuse ou peu s'en faut a été, pour de jeunes Réunionnais, une sorte de territoire nazi sur lequel tout le monde a su fermer les yeux et que le premier des nazis... est Michel Debré, à l'origine de la prétendue déportation [http:// www.courriers-reunion.fr/Stele-Gillot.html] (19.1.2015)

Ainsi, le représentant des ouvriers comme celui de la paysannerie déclarent tout net leur opinion au nom de l'immense majorité du peuple, mais le gouvernement Kérensky fait le contraire, pour servir les capitalistes! [https://www.mar xists.org/francais/lenin/works/1917/09/ vil19170910i.htm] (19.1.2015)

REMARQues : Déclarer (tout) net (I) réfère au fait de faire connaître un sentiment, une volonté ou une vérité d'une façon manifeste. Dans son emploi pronominal (II), il désigne le fait de donner son avis, s'expliquer, se prononcer pour ou contre quelque chose ou quelqu'un. Net reste invariable et est modifié par aussi, d'avance, fort, tout, un jour.

\section{Décocher droit}

Lancer (un projectile) tout droit avec une arme de trait

Transitif

$\sim 1460$ ilz se mirent a une fenestre. Sy n'y eurent guieres esté, quant Patroclus le bon archier descocha sa saiette sus la dame si droit qu'il lui en percha la gorge et morte l'abaty au prez de Jason, et puis il s'en issy de son embuche moult joyeux. Trop fu troublé Jason quant il vey sa dame ainsy trebuchier morte. Il la cuida relever, mais l'ame lui party du cors (Raoul Lefèvre, L'Histoire de Jason, p. 238, 15)

1596 Mais c'est peu que d'un cœur pour offrir à vos yeux,

Rois de tous les esprits de ceux qui s'en approchent ;

J'en voudroy mille et mille, afin de pouvoir mieux

Recevoir tous les traits que si droit ils décochent (Philippe Desportes, Euvres)

\section{CORPuS WeB :}

quand je suis sur place à l'heure, ma procédure est la suivante :

greffe

buvette (sandwich du matin)

échauffement (court, juste parvenir à l'allonge et à décocher droit)

peloton

arbitre

GO !!! [http://www.webarcherie.com/index. $\mathrm{php} /$ topic/19396-vous-prenez-combien-detemps-le-midi-a-la-pause/page-4] (19.1.2015)

Un des loups s'attaqua alors à ses confrères et, après avoir repris ses esprits, l'archer encocha vite une nouvelle flèche qu'il s'empressa de décocher droit dans un des loups, qui dans sa chute emporta un autre loup à côté du lac gelé [http:// www.skyrim-universe.com/forum/index.php?/ topic/2338-presentez-votre-personnage/page_ st_580] (19.1.2015)

Soudain, sous le regard médusé des dizaines de personnes présentes dans le bar, il prend une flèche, la décoche droit sur moi et s'en va en courant [http://www.wattpad.com/41948739until-i-die-arrow-fan-fiction-arr\%C3\%AAt $\%$ C3\%A9-black-feather/page/2] (22.1.2015) 
REMARQues : Décocher droit désigne l'action de lancer un projectile, de tirer à l'arc en suivant une ligne droite. Droit reste invariable et est modifié par si. Droit tend à former un groupe syntaxique avec la préposition qui le suit : dans, sur. Notons l'emploi absolu dans les deux premiers exemples $\mathrm{du}$ CW. Mentionnons également l'emploi de abattre mort ; trébucher mort.

\section{Décoincer direct}

Décoincer immédiatement, sans hésiter

$\lambda$ redescendre doux

\section{Décoller court}

Décoller sur une courte distance

$\lambda$ atterrir court

\section{Décolleter profond}

Laisser le cou et une grande partie de la gorge ou du dos nu

Transitif

1958 Une robe décolletée profond (Exemple entendu, 18 février 1958 / Grundt : 292)

CORPuS WEB :

Très bien pensée, cette robe ultra sexy possède un lien entre la poitrine permettant de la sublimer et en même temps évitera que la robe s'ouvre malencontreusement. Très courte et décolletée profond, cette robe Dreamgirl présentée peut se fronçer... [http://www.loucaline.fr/Mode-Femi nine/Les-Robes/Robes-Courtes-Sexy/Robe-liber tine-decollete-profond,1,84999.html] (22.1.2015)

Vintage : Robe longue rouge. Décolletée profond dans le dos. Devant perlé et plissé [https:// fr.pinterest.com/urap/robes-longues] (22.1.2015)

Robe de mariée élégante décolletée profonde dos nu en satin et dentelle description détaillée [http://www.chouchourouge.com/robe-demariee-elegante-decolletee-profonde-dos-nu-ensatin-et-dentelle.html] (22.1.2015)

REMARQues : En parlant d'un vêtement, décolleté profond se dit d'une robe ou d'un corsage qui dégage le cou, parfois les épaules ou le dos, dont l'échancrure est plus ou moins profonde, large. Profond tend à l'emploi invariable, mais il s'accorde dans le dernier exemple du CW avec le nom féminin (la robe) sur lequel porte le participe passé du verbe.

\section{Décorer baroque}

Décorer dans le style baroque, parer de

décorations baroques

Transitif

1967 Un grenier décoré très baroque (Robert Siegfried, Sabine ou La Décision)

CORPus WeB :

Une jolie nappe baroque, associée à ces chaises modernes, mais aux formes rétro, voilà une jolie façon de décorer baroque sans l'esprit rococo [http://www.idee-deco-by-helline.fr/ decoration-baroque-conseils-deco-interieure] (22.1.2015)

Cadre en bois médium à décorer baroque avec de la mosaïque [http://www.choozen.fr/tsmosaiques-a-poser mosaiques,3090814.html] (22.1.2015)

Remarques : Décorer baroque désigne le fait d'orner, parer ou agrémenter une pièce d'ameublement, de décors, d'accessoires ou de meubles de style baroque de façon à les embellir. Notons l'emploi absolu dans le CW.

\section{Découper menu}

Découper en petits morceaux

Transitif

1557 La première [= espèce] a les fueilles [sic] fort menu decoupées, estendues sur la terre (Rembert Dodoens, Histoire des plantes)

1584 Racines en laict buré cuits, et peaux decoupé menus, estoit viande à plusieurs (Pedro Cornejo, Histoire des troubles et guerres civiles du Pays-Bas)

1603 Poussière de pièces de marbre ou de cailloux de rivière trés-blancs, et de verre blanc, le tout subtilement sassé, est destrempé dans huile de noix, où sont ad-joustées des fines estoupes de chanvre, découppées menu, et de la graisse crue de bouc ou de chèvre, hachée à petits morcillons (Olivier de Serres, Le Théâtre d'agriculture et mesnage des champs)

1624 Quant à sa preparation, il faut premierement decouper menu et concasser les racines de souchet, de sarrazine, de gentiane, et de cappres, puis les faire infuser dans l'huyle, les exposer au soleil 
(Jean de Renou, Le Grand Dispensaire medicinal)

1811 Elles se préparent en mêlant les substances qui les composent, dans des proportions déterminées. Il faut avoir soin de découper menu sur-tout celles qui sont les plus denses ou les plus actives, afin de les bien disséminer dans le mélange (Julien-Joseph Virey, Traité de pharmacie théorique et pratique)

1945 Quel effondrement quand, par exemple, le vendredi elle reçoit inopinément un contre-ordre de madame Bassinet, la veuve du marbrier, la privant du blanc fromage hebdomadaire, arrosé de crème presque rosée, saupoudré de gros sel, de poivre fin, de ciboulettes et d'échalotes découpées menu menu! (George Chepfer, Portraits, sketches, divers)

1952 Elle avait découpé menu des pages du Larousse, " pour faire des livres de lecture à ses animaux » (Béatrix Beck, Léon Morin, prêtre)

2011 Même si en cadeau, dans Monrovia en ruine, on a offert à ces gamins, des mitraillettes et des machettes pour découper menu ceux qui se présentaient à eux (Ahmed Kalouaz, Je préfère qu’ils me croient mort)

\section{CORPUS WEB :}

Bien élevés on répond alors que nous avons une seule envie que cela se finisse, trouver une excuse n'importe quoi une gastro fulgurante, notre hamster cardiaque qui doit prendre ses médocs sinon il va croiser la grande faucheuse et vu sa taille elle va le découper menu menu en quelques secondes [https://misspivoibulle. wordpress.com/2014/09/page/2] (22.1.2015)

Tout découper menu тепи (oignons, poivrons, œufs, olives...) [http://www.unomafu.fr/ article-argentinaaaaaa-80460117.html] (22.1.2015)

Tout ça pour dire... j’ai acheté un beau filet de saumon, des pétoncles, et des miliards de légumes (si si au moins !). Et surtout : j’aurai le courage de découper menu menu ces ptites bestioles crues! [http://missbonbon95.canalblog. com/archives/2007/10/26/6666170.html] (22.1.2015)

Père Dodudaboum sonne plus comme une marque de petits plats surgelés pour la famille qu'un projet électro skizophrene, et pourtant. Sa recette secrète, jouer nu sous son tablier derrière sa console, à découper menus des beats de violons et de jeux vidéos, puis mixant le tout au robot électrique [http://www.lesinrocks. com/lesinrockslab/news/2011/08/decouvrez-laselection-daout] (22.1.2015)

Remarques : Découper menu est souvent employé dans le contexte culinaire, se disant du fait de réduire, de couper en menus morceaux des ingrédients (aromates ou légumes) avec un instrument tranchant. L'objet peut aussi désigner un morceau de papier. Notons la réduplication mепи тепи qui suggère ou met l'accent sur une découpe particulièrement fine. Dans cet emploi, menu se rapproche sémantiquement de l'adjectif-adverbe fin. Il souligne plutôt le résultat de l'action de trancher ou couper l'aliment que la précision ou la minutie dans le geste. Menu tend à l'invariabilité, mais les exemples de 1582 (s.v. chiqueter) et 1584, extraits de deux éditions de la même œuvre, montrent qu'il ne s'agit pas d'une règle fixe. Ces exemples - avec deux verbes différents mais sémantiquement proches (découper et chiqueter) - semblent cependant confirmer que l'accord se produit plus facilement quand menu vient après le verbe, ce qui renforce la dynamique résultative du verbe. Dans le $\mathrm{CW}$, menu reste invariable dans la plupart des cas, s'accordant toutefois avec l'objet pluriel dans le dernier exemple, ce qui le rapproche des prédicats seconds orientés vers l'objet. VoIR AUSSI : couper fin / menu / petit ; hacher menu

\section{Décrire juste}

Représenter avec justesse et précision

Transitif

1707 Comme il est difficile de déterminer les differentes combinaisons de ces causes, il est pareillement difficile de décrire juste toutes les cataractes mixtes (Antoine Maître-Jan, Traité des maladies de l'œil)

1761 ainsi il faut corriger cet endroit dans la description, où ces derniers vaisseaux ne 
sont pas décrits justes (Joseph-Guichard Duverney, Euvres anatomiques de M. Duverney)

1834 En vous préparant tous les matins par la lecture de vingt pages de Marianne de Marivaux, vous comprendrez les avantages qu'il y a à décrire juste les mouvements du cœur humain (Stendhal, Correspondance)

1989 Tous ces messieurs de la finance que décrivent les romans de J.L.B. se posent la même question : qui est-il ? qui donc les connaît si bien pour les décrire si juste? Cette émulation par la curiosité se répercute jusqu'aux couches du tout petit commerce et n'est pas pour rien dans notre chiffre de vente, croyez-moi ! (Daniel Pennac, La Petite Marchande de prose)

Emploi absolu

1836 Que de choses à dire pour qui aurait la patience de décrire juste! (Stendhal, Vie de Henri Brulard)

1996 Par quel miracle leurs yeux étaient-ils tous bleus, délavés, reptiliens ? Maman décrivait juste : des yeux de fonctionnaires antisémites, faits pour le mépris et l'aplatissement (Boris Schreiber, Un silence d'environ une demi-heure)

\section{CORPuS WeB :}

Je ne mens pas, je décris, je parle en décrivant juste, ne vous inquiétez dans ma description la chose s'invite à avoir une part de chaleur [http://www.penrose.fr/m/article-122075160. html] (22.1.2015)

En disant que tu étais un Batard, je ne t'insultait pas, mais je te décrivait juste donc viens pas me saouler maintenant... [http://astrid-ethaming way.skyrock.com/3178940563-posted-on-201308-09.html] (22.1.2015)

Jésus accorde plus de place à ceux qui reconnaissent leurs erreurs et se tournent vers Dieu, qu'à ceux qui ont tout fait pour être dans les « petits souliers » de Dieu se décrivant justes et purs, par pur orgueil ! [https://fr.answers.yahoo. com/question/index?qid=20110316121022AAM ATG7] (22.1.2015)
REMARQues : Décrire juste désigne le fait de dépeindre, représenter en détails quelqu'un ou quelque chose par écrit ou oralement. Juste reste invariable, sauf dans l'exemple de 1761. Il est modifié par si. Dans le second exemple du CW, juste est pris au sens de 'seulement'. Le dernier exemple du CW représente une lecture orientée vers le complément d'objet : ils se décrivent comme étant justes et purs. Si juste peut être remplacé par justement dans les autres exemples, ou par avec justesse, pour éviter l'ambiguïté, cela n'est pas possible dans ce dernier exemple, où le verbe n'est pas la cible d'attribution.

\section{Déduire bel}

se déduire bel : s'amuser beaucoup

Pronominal

+1200 La pucele bel se deduist Et messire Gavains et tuit Rient et juent sor le table. Mais ço n'est pas de cuer estable Que messire Gavains s'envoise (Raoul de Houdenc, La Vengeance Raguidel [début XIII'], 2447)

1349 Mais la dame premierement Me vit, eins que nuls me veïst, Ne que nuls semblant en feïst, C'est assavoir d'icelle gent Qui conduisoient son corps gent. Lors un escuier appella Et li dist : Vois tu celui la Qui bel se deduit et deporte? (Guillaume de Machaut, Le Jugement dou roy de Navarre, 561

-1400 « Sy me deduiray volentiers avoecq ces dames que tu peus oïr que sy bel se deduisent, mes que tu ne t'en voelles chourouchier » (Ysaÿe le triste [fin XIV ${ }^{\mathrm{e}}$, p. 389)

REMARQUES : Dans l'ancienne langue, se déduire bel désigne le fait de se divertir, de se distraire, le sujet animé passant un moment fort agréable en compagnie d'une ou plusieurs personnes. Beau adopte toujours sa forme neutre bel et est modifié par si. VoIR AUSSI : déporter beau 


\section{Défendre bel}

Défendre bien, avec vigueur, énergie

$\lambda$ assaillir bel

\section{Défendre dur}

Défendre de toutes ses forces, âprement

Pronominal

1925 On l'attaquait ? On le volait ? Et bien, il allait se défendre! et raide, et dur, sans pitié pour le bandit (Maurice Genevoix, Raboliot)

\section{Corpus Web :}

La priorité était de défendre dur face à une équipe très offensive nous n'avons encaissé que 66 points donc c'est une bonne chose ! [http:// www.insidebasketeurope.com/actu/pascaldonnadieu-la-priorite-etait-de-defendre-dur. html] (26.1.2015)

Antoine Mendy défend dur, Tony Dobbins est partout en défense, Mykal Riley est malin. Toute l'équipe défend dur et c'est ce qui nous permet d'être là dans les matches [http://www.lnb.fr/fr/ Accueil/100003/Article/19639/Ferdinand-Pre nom-Dijon-On-ne-va-pas-commencer-a-se-voirtout-beaux] (27.1.2015)

C'est possible. On a d'abord un match à Bourg à gagner. Je crois que nous sommes prêts à défendre durs lors de cette rencontre décisive [http://www.pb86.fr/actualite/basket/2304/ gomez-le-maestro-donne-le-la] (26.1.2015)

Les deux équipes défendent dures : 5 à 4 pour Donetsk, il reste 6'38 dans le premier quart temps [https://www.facebook.com/BCMbasket/ posts/10150386149215787] (26.1.2015)

Pour moi, l'équipe qui nous a causé le plus de soucis est Neuville en Ferrain. Elles sont combattants et défendent dures [http://www. femina-wasquehal-basket.asso.fr/ope/menuprincipal-equipes/menu-seniors/menu-senior2/a-la-decouverte-de/443-a-la-decouverte-de-lanf3-lauriane-zwolinski] (26.1.2015)

REMARQues : Le sujet de défendre dur désigne un animé qui montre la volonté de résister à une attaque physique ou du moins tente de la repousser en y mettant toute son énergie. Notons la collocation se défendre raide et dur. Dans le cas de raide, le sujet fait preuve de vigueur et de rigidité face à son adversaire. Dans le CW, dur reste inva- riable dans le deuxième exemple malgré le sujet féminin, tandis que, dans le troisième, le quatrième et le cinquième exemple, il s'accorde avec le sujet au pluriel ou au féminin, sujets qui réfèrent aux joueurs d'une équipe. Dans ces cas-là, il garde son interprétation d'adverbe de manière, en se rapprochant par nuance stylistique des prédicats seconds orientés vers le sujet. Notons l'emploi absolu dans le CW.

\section{Défendre ferme}

Défendre en opposant une forte résistance $\lambda$ défendre fort

\section{Défendre fort}

I. Défendre violemment, énergiquement Pronominal

1160 La bretesche fist asaillir, Et cil dedenz fort se deffandent Et merveillos estor lor randent (Eneas, 5403)

+1227 Mais cil de toutes pars l'assalent, Mout durement si le travaillent, De grans haces fierent au bort ; Mais cil se desfendent si fort K'il ne pueent dedans entrer (Roman de Wistasce le Moine [ $2^{\mathrm{e}}$ tiers XIII ${ }^{\mathrm{e}}$, après 1227], 2290)

1372 Tantost monta sus son courcier Et s'en ala devers le roy, Et li dist : « Monsigneur, je voy Vostre gent qui se sont retrait Pour la deffense et pour le trait Des Sarrasins qui se deffendent Moult fort, et a bien traire entendent » (Guillaume de Machaut, La Prise d'Alexandrie [(1370-)1372], 2847)

1389 Ilz [= les blaireaux] font une foiz l'an leurs cheaus comme renarz et portent autant comme renarz, et les font dedanz les fosses comme renarz. Quant on les chasce, ilz se deffendent fort et ont leur morsure venimeuse comme renart. Encore se deffendent ilz plus fort que ne fet le renart [variante : encore plus fort se deffendent il] (Gaston Phébus, Livre de chasse, p. 102, 8 et 9) 
1403 Toute la terre conquesta; Grans batailles ot, et gasta La contree et puis s'en ala En Gaule, et tant fu par dela Qu'il l'ot aux Rommains toute acquise ; Et sur les Bretons, par tel guise, Ala, mais fort se deffendirent ; En bataille les desconfirent (Christine de Pisan, Le Livre de la mutacion de fortune, IV, 21979)

1580 Suivant donc cette délibération, l’Amiral avec son armée, ayant passé la Loire à Baugency le 30 décembre, arriva le 2 janvier 1563 devant la ville de Selles en Berry, où s'était retiré grand nombre de moines et de prêtres du pays qui commencèrent, avec les habitants à se défendre fort et ferme contre les soldats gascons et provençaux restés de la bataille, qui les environnèrent de toutes parts (Théodore de Bèze, Histoire ecclésiastique des Églises réformées au royaume de France)

1598 Puis apres il se presenta au Docteur Fauste, dans son poisle un lyon et un dragon qui combattoyent ensemble : et combien que le lyon se defendist fort et ferme, si fust-il toutesfois englouty par le dragon (Pierre-Victor Cayet, L'Histoire prodigieuse du Docteur Fauste)

1627 M. de Suilly nous l'avoit voulu retrancher, mais nous nous deffendismes fort et ferme (Nicolas de Peiresc, Lettres aux frères Dupuy)

Transitif

+1400 Requestes du Palaiz, fust oudit lieu de Marle, et combien que ledit monseigneur le Chancellier eust moult fort defendu la cause de la Court et dudit esleu, toutevoie le Roy lui avoit commendé qu'il sellast la lettre du don par lui fait, et combien que il eust fait tout son effort (Nicolas de Baye, Journal [1400-1417])

1612 Cependant Galathée lisoit les lettres de Celadon, car il estoit fort vray, qu'elle les avoit ostées à Meril, suivant la curiosité ordinaire de ceux qui aiment ; mais elle luy avoit fort deffendu de n'en rien dire, parce qu'elle avoit intention de les rendre, sans qu'il sceust qu'elle les eust veues (Honoré d'Urfé, L’Astrée)

II. se défendre de quelque chose : nier, refuser d'admettre

Pronominal

1824 Pendant que l'on m’interrogeait à la préfecture de police sur mes nom, prénoms, qualités, comme vous avez pu voir dans les gazettes du temps, un homme, se trouvant là sans fonctions apparentes, m’aborda familièrement, me demanda confidemment si je n'étais point l'auteur de certaines brochures ; je m'en défendis fort. Ah ! Monsieur, me dit-il, vous êtes un grand génie, vous êtes inimitable (Paul-Louis Courier, Pamphlets politiques)

\section{CORPUS WEB :}

SIG : il faudra défendre fort à Dijon [http:// www.lalsace.fr/sport/2013/04/20/sig-il-faudradefendre-fort-a-dijon] (27.1.2015)

Coach Todorov n'envisage pas autre chose que la victoire. "Si on arrive à défendre fort sur de longues séquences, on doit passer. On connaît cette équipe, ses points faibles et ses points forts » [http://www.lamontagne.fr/limousin/sports/ actualite/basket/2014/10/11/lus-tulle-correze-ale-couteau-sous-la-gorge_11177850.html] (27.1.2015)

Sérieux t'en a pas marre? Qu'est ce que tu viens me citer encore alors que je suis un des seuls ici à défendre forte ? [http://www.www.csplive. net/viewtopic.php?pid=337099] (27.1.2015)

Sitôt un tir ou une passe ratée, une balle perdue, ils sont déjà dans l'action suivante, prêts à défendre forts et à repartir à l'assaut intelligemment et en équipe, en partageant la balle, pendant que nous, on se lamente encore sur l'action d'avant, et on finit par sortir du match en usant d'actions individuelles trop rapides (une passe - un tir), et surtout en relâchant nos efforts défensifs [http://www.mondial-tour-basket.com/ actualites/bilan_du_sejour_a_porec.html] (27.1.2015)

REMARQues : Le sujet de défendre fort désigne un animé qui montre la volonté de résister à une attaque physique ou de la repousser en y mettant toute sa force, de façon énergique. Notons la col- 
location fort et ferme, qui renforce la fonction d'intensification de fort. Du point de vue sémantique, la motivation par l'idée de force (fort 'avec force') est souvent présente, mais la fonction d'intensification est exclusive dans les exemples de 1612 et 1824. Fort reste généralement invariable. Dans le CW, fort s'accorde avec le sujet dans le troisième et le quatrième exemple, introduisant ainsi une nuance de prédication seconde, mais tout en gardant son interprétation d'adverbe de manière. Notons aussi l'emploi de sérieux comme adverbe de phrase dans le troisième exemple du CW. Fort est modifié par encore plus, moult, si. Notons aussi l'emploi absolu dans les exemples du CW.

\section{Défendre net}

Défendre, interdire formellement, catégoriquement

Transitif

1669 ORGON. Taisez-vous, vous ; parlez à votre écot :

Je vous défends tout net d'oser dire un seul mot (Molière, Le Tartuffe)

1730 POLÉMON. C’est que jamais je ne puis y répondre,

Et que vous vous donnez les airs de me confondre.

Mais, lorsque nous aurons tous deux un entretien,

Je vous défens tout net de raisonner si bien.

Comme pere, je veux paroître le plus sage ;

Et vous l'étes toujours plus que moi, dont

j'enrage (Philippe Destouches, Les Philosophes amoureux)

1738 FRANCALEU. (à Lisette, qu'il ne voit que par derrière)

Lucile, redoublez de fierté pour Dorante, Vous n'êtes pas encore assez indifférente.

Vous souffrez qu'il vous parle; et je défends cela

Tout net ! entendez-vous, ma fille !

(Alexis Piron, La Métromanie)

1889 Lors donc que son frère lui parla de la nécessité du recours en cassation, il répondit en défendant tout net ce recours, suivant lui aussi inutile que fâcheux (Louis de Loménie, Les Mirabeau)
2005 Primitivement, l'aérostat devait être monté par le chevalier de Chevelu, qui était le moteur et le chef naturel de l'entreprise, et le public, dont il est fort aimé, aurait bien désiré le voir suivre son projet ; mais, la tendresse paternelle s'opposa au vœu général et l'amour de la physique n'empêcha point un père alarmé de défendre net à M. son fils de monter cette voiture d'un nouveau genre (Philippe Barthelet, Joseph de Maistre)

Pronominal

2005 Je me défendis tout net de le suivre du regard, bien qu'une atroce curiosité me brûlât le cœur : Qui donc voulait-il ainsi, à toutes forces rencontrer? (Isabelle et MarieHélène Morot-Sir, De lettres en lettres...)

CORPUS WEB :

Et croyez-moi, le Fouta peut décider son retrait et le défendre net. Comme en Ethiopie et au Soudan ou dans d'autres pays, il y aura des morts de tous les côtés et non plus du côté peul seulement mais on finira bien par consacrer le partage de la Guinée [http://www.guineepresse. info/index.php?id=10,12180,0,0,1,0] (26.1.2015)

Hâte de voir, peut être un jour, défiler notre fils sur les champs élysée ! Avec la Marine Nationale ! Hommage à nos militaires qui défendent net représentent notre pays et drapeau français [http://m2.facebook.com/127027683999474/ photos/a.270174389684802.57852.1270276839 $99474 / 701974769838093 /$ ?type=1\&_tn__=E] (26.1.2015)

REMARQues : Défendre net se dit du fait d'empêcher, d'interdire à quelqu'un de faire quelque chose. Net reste invariable et est modifié par tout.

\section{Défendre raide}

Défendre en résistant aux attaques

Pronominal

1925 On l'attaquait ? On le volait ? Et bien, il allait se défendre ! et raide, et dur, sans pitié pour le bandit (Maurice Genevoix, Raboliot)

CORPUS WEB :

Il se peut que j'en oublie ou que je me trompes, mais toujours est-il que, l'infrastructure 
se développe considérablement, on voit quand même les résultats, et Lulu ne laisse jamais attaquer sa guadeloupe gratuitement ni ses guadeloupéens et les défends raide [http://www. volcreole.com/forum/sujet-8387.html] (27.1.2015)

Remarques : Défendre raide désigne le fait de vouloir résister à une attaque physique (ou morale) ou de la repousser, le sujet faisant preuve de vigueur et de fermeté face à son adversaire.

\section{Déguster juste}

Déguster correctement, comme il faut

$\lambda$ boire fin

\section{Demander bas}

I. Demander à voix basse

Transitif

+1365 Mais Courtoisie m’appella,

Disant : «Ta chambre, où tu jerras,

Est là dessus, tu la verras ;

Demande ceens, bas et hault,

Tout plainement ce qu'il te fault »

(Jean Froissart, Poésies [3e tiers XIV']

1559 Et, à l'heure, le plus bas qu'il luy fut possible, luy demanda sy elle estoit aussy contante de luy que luy d'elle (Marguerite d’Angoulême, Heptaméron, p. 139, 118)

1594 Aprés que ledit sieur Archevesque eut fini son epiphoneme en grande emotion de corps et de voix, il demanda permission tout bas à Madame de Montpensier de se retirer pour changer de chemise, parce qu'il s'étoit eschauffé en son harnois (Satyre Ménippée)

1627 Aussi tost le dieu de riviere commença de ronfler comme un pourceau, et Lysis s'en estonnant tira Synope par la manche, et luy demanda tout bas en quel langage c'estoit que parloit ce dieu (Charles Sorel, Le Berger extravagant)

1631 Mais en fin pour ne se point méprendre, elle s'addressa à Thamire, et luy demanda assez bas, si ce berger qui parloit n'estoit pas Hylas, et luy ayant respondu qu'ouy, elle revint vers Daphnide, et s'approchant à son oreille, luy dit : " Madame, vous parlez à Hylas sans le cognoistre »
(Honoré d'Urfé, L’Astrée)

1761 Délia ne se fit point prier. Roxelane parut charmée. Elle demanda tout bas un mouchoir à Soliman : il lui en donna un, sans se douter de son dessein (Jean-François Marmontel, Contes moraux)

1832 Prenant pour fiancée un rêve, une ombre vaine, et fouillant dans le cœur d'une hécatombe humaine, prêtre désespéré, pour y chercher ton dieu. Et que voulais-tu donc? Voilà ce que le monde au bout de trois cents ans demande encor tout bas. Le sphinx aux yeux perçants attend qu'on lui réponde (Alfred de Musset, Namouna)

1869 Et, sans attendre sa réponse, il demanda bas à Hussonnet :

- Comment l'appelez-vous, votre ami ? (Gustave Flaubert, L'Éducation sentimentale)

1928 Comme je savais que M. d'Hennezel jouait du violon, je le tirai par sa jaquette, en lui demandant, très bas :

- Qu'est-ce qu'on joue, dites, monsieur ? (Gyp, Souvenirs d'une petite fille)

1960 Armand, il feinte :

- Vous êtes certaine qu'elle est morte ? il demande bas.

La mère Communal pose la pogne sur le mince avant-bras de la petite vieille.

- Elle est glacée... tenez, rendez-vous compte! (Albert Simonin, Du mouron pour les petits oiseaux)

2011 Mes deux compagnons sont en train de draguer les gonzesses. Elles semblent se prêter de bonne grâce au jeu. Je demande bas à Walter, qui sont-elles. Répond, des étudiantes de droit à la Faculté (Serge Doubrovsky, Un homme de passage)

II. Se demander en silence, en son for intérieur ; hésiter

Pronominal

+1532 GEORGE LE VEAU. Je vous prye, sans longue pose, Vous me conseillez sur ce cas. Tousjours me demande hault et bas Qui je suis et d'où suis venu 
(Farce de George le Veau / Ancien théatre françois [entre 1532 et 1550])

1719 Tandis que notre homme marchande, Hésite sur le choix et tout bas se demande, Lequel vaudra le mieux? (Antoine Houdar de La Motte, Fables)

1794 Sur la foi de mes vers mes amis transportés Cherchaient partout vos pas, vos attraits si vantés,

Vous voyaient, et soudain, dans leur surprise extrême,

Se demandaient tout bas si c'était bien vous-même,

Et, de mes yeux séduits plaignant la trahison,

M'indiquaient l'hellébore, ami de la raison (André Chénier, Élégies)

1851 Il y avait des instants où il voyait Gaspard blanc comme neige, et il voulait aller le chercher ; il y en avait d'autres où ses yeux se dessillaient à demi, et il osait se demander tout bas si sa fille n'avait pas raison (Jules Sandeau, Sacs et parchemins)

1867 Plus d'une fois, quand j'étais dans ma chambre, seul et les portes fermées à double verrou, je me suis demandé tout bas si la femme n'était pas naturellement supérieure à l'homme (René Lefebvre, Paris en Amérique)

1910 Et tandis qu'elles écrivaient, écrivaient, sans que leur regard curieux cessât de détailler furtivement la figure et les gestes de l'idole, Jacqueline et Simone se demandaient tout bas :

- Crois-tu qu'il serait bien, avec une cravate à pois bleus ? (Romain Rolland, Jean-Christophe. Les Amies)

\section{CORPUS WEB :}

Les parents de Juliette ne sont pas à la maison? Mais cet homme, il n'est pas le père de Juliette ? Alors, c'est qui ??? Luc demande bas à Juliette qui est l'homme. « C'est Serge, notre domestique. Tu as vraiment pensé qu'il est mon père? » [http://www.avwernsing.de/contes.html] (27.1.2015)
Je me demande s'ils sont à deux,

Où s’ils ont baissé les bras,

Même si quand on veut on peut,

Je me demande tout bas,

je me demande tout bas,

Comment garder l'amour,

comment faire que ce jour ne ressemble pas aux autres.

Comment tenir l'amour... [http://www. letrasmania.com/letras/letras_de_canciones_ john_mamann_64103_letras_fais_pas_la_ gueule_john_178386_letras_comment_garder_ lamour_1611552.html] (27.1.2015)

Ensuite je me suis demandé tout bas, quel est mon trait particulier? La reponse que je me donnai fut longue oreille...mais pour rien au monde je n'accepterai que cela soit mentionné dans mon passeport... [http://www.affection. org/trait-particulier_102271_HISTOIRE_poemetype] (27.1.2015)

Remarques : Demander bas (I) désigne le fait de faire connaître à quelqu'un, ce qu'on désire obtenir de lui, exprimer un désir, un souhait de manière à en provoquer la réalisation, sans toutefois l'exprimer à haute voix, le sujet ressentant de la pudeur, de la honte ou de la peur. (II) réfère au fait de se poser une question à soi-même, en la gardant pour soi, ou à d'autres personnes, mais en l'exprimant à voix très basse, généralement par manque de certitude ou par peur. Bas reste invariable et est modifié par assez, encore, plus, tout, très. Notons la collocation très usitée tout bas, ainsi que haut et bas / bas et haut.

\section{Demander bel}

Demander gentiment

Transitif

1365 AMIS. Diex vous gart de pesance, sire ! Vous estes, je croy, traveilliez. S'il vous plaist, dire me vueilliez Ou vous alez.

AMILLE. Sire, si bel le demandez Que je respons, ne vous ennuit, Que je pense ains demain la nuit A Paris estre (Miracle de Amis et Amille, 106) 
REMARQUES : En ancien français, demander bel désigne le fait de faire connaitre à quelqu'un ce qu'on désire obtenir de lui, le fait également d'exprimer un désir, un souhait de manière à en provoquer la réalisation, la requête étant formulée avec gentillesse, bonté, galanterie.

\section{Demander cher}

I. Demander, exiger un prix élevé (pour quelque chose)

Emploi absolu

1824 Tout le monde me dit que j'ai tort de chercher de ce côté. D’ailleurs je n'ai rien vu qui pût nous convenir qu'un seul appartement $\mathrm{n}^{\circ} 53$ avant la place Beauveau, dont on demande trop cher (George Sand, Correspondance)

1843 - Au fait, quand il bavarde, vous vous tenez tranquilles... Au moins on n'a pas besoin d'être sur votre dos.

- Oui, reprit le Squelette, mais PiqueVinaigre demande cher pour conter... il veut vingt sous.

- Oui, la bagatelle de vingt sous... et c'est pour rien, s'écria Pique-Vinaigre

(Eugène Sue, Les Mystères de Paris)

1890 et la voilà à me conter les canailleries de Derenbourg, qui avait voulu faire racheter à Porel un congé de Dumény, après lui avoir écrit une lettre, où il le poussait à demander très cher en lui insinuant qu'ils partageraient, - canaillerie qui lui avait valu d'être traité de filou par Porel et par Sardou (Edmond et Jules de Goncourt, Journal)

1932 Parions que le musicien avait demandé moins cher que notre confrère. Nous avons dit que les femmes avaient recours, pour la grande toilette, aux faux cheveux (Stéphane, L'Art de la coiffure féminine)

1955 Il fera ça pour vous rendre service.

- Oui, je vous remercie. Mais j'ai mon billet de retour qui est encore valable, ça m'ennuie de le perdre. - Ceux-ci ne vous demanderont pas bien cher, soyez tranquille, et peut-être que la compagnie vous remboursera (Alain Robbe-Grillet, Le Voyeur)
1995 au début de l'hiver, un pastelliste ambulant, qui allait avec sa boîte de château en château, s'était arrêté à La Commanderie pour offrir ses services. Il ne demandait pas cher : le quart d'un " toîton » de meule. Bien qu'à court d'argent, Madame de Breyves n’avait pu résister au plaisir d'immortaliser son fils avant qu'il grandît (Françoise Chandernagor, L'Enfant des Lumières)

2004 Ce qui me fait hésiter, pour le cheval de Fernand, c'est plutôt le prix. Gilles Chapeyroux risque d'en demander cher (Bernadette Puijalon, Un parfum de gentiane)

II. ne pas demander cher: se contenter de peu Emploi absolu

1975 Il était assis devant sa tasse de café, il avait posé sa main sur le livre de Victor Hugo et il paraissait heureux parce que c'était un homme qui ne demandait pas cher.

- Mon petit Mohammed, je ne pourrais pas épouser une Juive, même si j'étais encore capable de faire une chose pareille (Romain Gary, La Vie devant soi)

\section{CORPUS Web :}

Les hôpitaux sont inaccessibles, les médicaments coutent cher, les analyses médicales coutent cher, les radios et scanners coutent cher, les médecins et spécialistes demandent cher. Qu'est ce qui reste ? les plantes qui ne coutent pas cher, et on est trop nombreux à les utiliser [http://www.seneweb.com/news/commentaire/ de-nombreuses-plantes-medicinales-risquentde-disp_n_104607_c_2803845.html] (27.1.2015)

on parle de trou a la secu mais la sante bucco dentaire et sa prevention eviterais bien $d$ autres pathologies donc d autres soins qui a la base sont causer par ses problemes les dentistes sont de moins en moins competents demandent cher et il fournissent des matieres appareils dont on ne connait pas l origine DANGER [http://jesigne. fr/non-aux-soins-dentaires-trop-chers] (27.1.2015)

J'ai pas mal d'amis qui ont fait le trajet Bangkok - Siem Reap en mini van/bus, trajet arrangé et proposé par des logements à Bangkok, malheureusement ceux ci étaient des plus pénibles car ils ont changé plusieurs fois de véhi- 
cules, attendus que ceux ci se remplissent de touristes, entassés dans e mini van et pour terminer ces compagnies de mini vans vous déposent à Siem Reap dans un coin perdu près de l'aéroport de Siem Reap, où il n'y a rien du tout mis à part des chauffeurs de tuktuks qui vous demandent chers ! pour rejoindre le centre [http://www.routard. com/forum_message/3052873/2/aux_habitues_ du_passage_poipet_siem_reap.htm] (27.1.2015)

Moi j'habite Bailleul je sais pas si tu connais (à 10km d'Armentières) et je me marie le 26 août 2006. Le problème où j'habite c'est que la ville ne veut pas louer les salles communales aux particuliers avant le mois de décembre (les associations passent avant) et les particuliers demandent chers. Essayes les salles communales des petites villes autour sinon si tu veux je peux me renseigner aurpès de mon beau père, il habite marcq en baroeul ????? [http://forum.aufeminin. com/forum/mariage1/_f151118_mariage1-Lesfilles-du-nord.html] (27.1.2015)

Remarques : Demander cher (I) se dit du fait d'indiquer la somme que l'on veut obtenir contre un objet ou un service, celle-ci étant trop haute, démesurée pour le client. En (II), à la forme négative, il réfère à quelqu'un de modeste, se contentant de peu sur le plan financier. Cher tend à être invariable et est modifié par bien, moins, très, trop, mais il s'accorde dans les derniers exemples $\mathrm{du}$ CW, tout en gardant sa fonction de modifieur du verbe.

\section{Demander fort}

\section{Réclamer avec véhémence}

Transitif

+1389 a Item, confessa que, un an avoit ou environ, il mal print et embla, ès estables dudit evesque, trois paires d'esperons neufs qui estoient penduz en ycelle estable, et yceulx vendi aus esperonniers de Paris, ne scet à qui, vii s. par. ; et dit que lors on les demanderoit fort (Registre criminel du Châtelet de Paris [1389-1392])

+1400 Jacques fut quis en maint païs ; tant que messire Enguerran a Rodes arriva et fort le demanda, mais on ne savoit qui estoit Jacques de Voisines (Nouvelles françaises du $X V^{e}$ siècle, p. 7)

\section{Désirer, exiger fortement}

Transitif

+1389b Perrin Houssaut, prisonnier cy-dessus escript, juré et examiné l'an et jour dessus diz, par serement, de dire verité sur les accusacions dessus dites, dit et afferme par serement qu'il est demourant en icelle ville de Rungy, en l'ostel Jehan du Pressouir, et que au temps et heure du lundi de Penthecouste, que l'en dit que iceulx compaignons prisonniers dessus nommez furent en icelle ville de Rungy, il estoit present quant ilz vindrent en icelle ville de Rungy, environ heure de vespres, et vit et oy que iceulx compaignons demandoient moult fort à avoir icelle fillete (Registre criminel du Châtelet de Paris [1389-1392])

1559 Au demourant, Monseigneur, me semble qu'il eust esté bon que les Gentilshommes qui sont de la retenue de ceste ville, y fussent venus servir ; la Justice et les habitans le demandent fort (Hyacinthe Morice, Mémoires pour servir de preuves à l'histoire ecclésiastique et civile de Bretagne, [lettre de 1559])

1564 Ne demandent aussi grand solage : parquoy, sera bon les semer soubs les treilles : sur tout le persil demande fort estre arrousé, qu'ainsi ne soit quand il est semé ou planté pres de quelque fontaine ou ruisseau, il croist fort beau et en grande quantité (Charles Estienne, L’Agriculture et maison rustique)

1672 On dit qu'il demande fort à revenir à Paris, mais qu'il est si foible et si abattu, que l'on ne sait comment l'y ramener. Peu de gens le voient ; il n'y a guère que le roi, et peu de ses officiers ; le prince de Condé ne le voit point (Gui Patin, Lettres)

\section{Demander à voix haute}

Transitif

1393 Les mariez firent aprez leurs rapports, l'un aprez l'autre. Le premier dit qu'il fist avant couchier, secretement, le commandement a sa femme, qui lui demanda moult fort a quoy c'estoit bon et que ce vouldroit ( $L e$ Menagier de Paris, p. 85, 21) 
1961 Je me réveillai en entendant la maîtresse qui demandait, plus fort, en nous regardant d'un air sévère :

- Qu'est-ce que Dieu ? (Christiane Rochefort, Les Petits Enfants du siècle)

2005 En tout cas, j'ai pas dû le demander fort. Si j'avais su... (soupir) Les gens sont tellement ingrats avec nous. Dans le temps, on nous craignait un peu, on n'osait pas nous vexer. C'est fini ça. Ils n’ont plus foi en rien. Vous leur demandez s'ils croient en Dieu, bon bah, s'ils ont un peu de jugeote, ils vous répondront non, hein, comme tout le monde (Thomas C. Durand, Mont de Dieux)

IV. S'enquérir avec grand intérêt ou avec insistance

Transitif

1675 Monsieur le duc me demanda fort de vos nouvelles l'autre jour, et me pria de vous faire beaucoup d'amitiés, M. et Mme de Noailles, Mmes de Leuville et d'Effiat, les Ravay, les Beuvron, qui vous diraije encore ? (Mme de Sévigné, Correspondance)

1676 Pour cette cause, Monsieur, ce Roy et autres Seigneurs ses Ministres me demandent fort, s'il est vray que l'accord de l'Empereur soit fait avec le Turc (Lettres et memoires d'Estat)

V. Demander quelque chose de fort

Transitif

1746 Dose : maladies qui la demandent forte, celles qui la demandent plus foible

(François Alexandre Pierre de Garsault, Le Nouveau Parfait Maréchal)

CORpus Web :

Oui mais je fait plutot des fetes pour les jeunes, et ils demandent fort même si cela couvre déjà suffisament la piste de danse. $=\backslash[$ http://fr. audiofanzine.com/sono/forums/t.392425, changement-d-enceintes,p.2.html] (27.1.2015)

REMARQues : Demander fort (I) se dit du fait de prier quelqu'un de venir, de le faire chercher, le sujet éprouvant un grand besoin de voir la personne réclamée. En (II), suivi de la préposition à, il réfère à un fort désir, à un souhait impatient. En (III), il désigne le fait de poser une question en élevant fortement la voix ; moult, plus est intercalé entre le verbe et l'adjectif-adverbe, qualifiant le degré d'intensité de la voix. En (IV), il renvoie au fait de s'informer auprès de quelqu'un, de lui poser beaucoup de questions au sujet de quelque chose ou de quelqu'un. (V) est une prédication seconde où fort, fléchi, réfère au complément d'objet : requérir une forte ou faible dose de médicament. Fort reste invariable. Notons l'emploi de croître beau.

\section{Demander gros}

Demander une grosse somme

Emploi absolu

1709 On dit que le traité de M. de Savoie avec l'empereur est à renouveler, comme les gazettes l'ont imprimé, mais qu'il demande gros (Journal du marquis de Dangeau)

1865 En même temps, plus lui arrive des commandes plus il élève le prix de ses ouvrages ; et plus il demande gros plus on lui demande de tableaux (L’Artiste)

1913 C'est vraiment demander gros à une Compagnie qui, ainsi que ses congénères, a eu, pendant bien longtemps, les plus sérieuses difficultés à payer de médiocres dividendes (Revue politique et parlementaire)

1998 La vue des billets alignés dans le coffre attire l'appétit et on n'hésite pas à demander gros (Guédouma Samaké, Le Chemin de l'honneur)

\section{Demander haut}

I. Demander à haute voix

Transitif

+1365 Mais Courtoisie m’appella, Disant : « Ta chambre, où tu jerras, Est là dessus, tu la verras ; Demande ceens, bas et hault, Tout plainement ce qu'il te fault » (Jean Froissart, Poésies [3 $3^{\mathrm{e}}$ tiers XIV ${ }^{\mathrm{e}}$ )

+1532 GEORGE LE VEAU. Je vous prye, sans longue pose, Vous me conseillez sur ce cas. 
Tousjours me demande hault et bas

Qui je suis et d'où suis venu

(Farce de George le Veau / Ancien théatre françois [entre 1532 et 1550])

1610 L'AUTRE. Sur l'aprés-disnée, on le pria de fiancer une belle fille ; ainsi qu'il estoit aprés, et que desjà il tenoit sa main, il se souvint de son valet et de son advertissement ; parquoy, de peur de faillir, il demanda tout haut : " Luy en a-t-on rien fait ? » (Béroalde de Verville, Le Moyen de parvenir)

1627 Il se delibera de l'interroger pour se divertir, et luy demanda fort haut par trois ou quatre fois si elle estoit là, et comment elle se portoit, mais elle n'avoit garde de parler, car Anselme n'y estoit pas pour respondre au lieu d'elle (Charles Sorel, $L e$ Berger extravagant)

1713 Laprès-dînée il alla courre le cerf avec ses chiens. Au retour de la chasse, M. Voisin, qui étoit demeuré hier à Versailles, vint dans le temps qu'il se débottoit ; le roi lui demanda tout haut s'il n'avoit point de nouvelles de Landau, il dit au roi qu'il n'en avoit que du 20, qui étoient venues par l'ordinaire (Philippe de Dangeau, Journal)

1778 Il vit tous ses péchés lavés d'un petit mot de pénitence, et reçut ce que vous savez avec beaucoup de bienséance. Il fit même un très-beau sermon, qui satisfit tout l'auditoire. Tout haut il demanda pardon d'avoir eu trop de vaine gloire (Voltaire, Épîtres)

1832 Ces pauvres hommes! S'écrie au surplus en terminant la mère Susanne, qu'ils cessent donc de se montrer si récalcitrans, et se hâtent de nous octroyer notre affranchissement définitif ; autrement nous allons le leur demander si haut et d'une voix si étourdissante, nous allons tant crier, si nous ne faisons mieux, qu'ils seront bien contraints de nous l'accorder (Alfred de Musset / Revue des deux mondes)

1845 - Veux-tu être à Châteaubrun demain soir?
- Oui, Monsieur. Prenez des précautions pour ne pas vous faire suivre, et ne me demandez pas trop haut à la porte. Allons, grâce à vous, j'ai encore les étoiles sur la tête, et je n'en suis pas mécontent.

Il partit comme un trait (George Sand, Le Péché de Monsieur Antoine)

1862 C'était un bourdonnement confus de voix qui chuchotaient. Quelqu'un demanda assez haut :

- A-t-on fait chercher un médecin?

- Il vient.

- Et le prêtre?

- Il faudrait de la lumière!

On entendit courir dans la rue

(Paul Reider, Mademoiselle Vallantin)

1869 Et la nuit s'avançant, la douleur désespérée de ses supplications, le cri de cette grâce qu'elle demandait toujours plus haut, finissaient par réveiller Honorine qui crut un moment quelqu'un entré chez sa maîtresse (Edmond et Jules de Goncourt, Madame Gervaisais)

1886 Mais déjà l'entrepreneur s'était planté sur ses courtes jambes, écarquillant les yeux, lui demandant très haut, de sa grosse voix rauque :

- Dites donc, quel est le sabot qui a fichu ça ? (Émile Zola, L’Euvre)

1900 La rousse, décidément devenue son esclave, n'y tient plus et va la trouver en demandant très haut : "Mademoiselle Lanthenay, vous n'avez pas chez vous le registre des présences? » Ça y est, elle est partie ; elles jacassent tout bas (Colette, Claudine à l'école)

1929 - Que vous êtes drôle ! fit-elle avec un rire qu'elle étouffa. J'aurais cru que ça vous faisait plaisir de me voir.

Le bruit de l'eau couvrait presque ces paroles prononcées à mi-voix. Elle demanda plus haut :

- Vous n'avez rien à me dire?

(Julien Green, Léviathan)

1968 Monseigneur trouva cette vue excessive. Le visage apoplectique du docteur s'en- 
flamma, et il demanda fort haut pourquoi on l'avait dérangé pour donner son avis sur des erreurs en matière de mœurs et de doctrine qui n'eussent pas fait hésiter un instant un juge de village (Marguerite Yourcenar, L'Euvre au noir)

1986 On fit sortir les enfants, qui avaient tout compris. Du haut de ses dix ou douze ans, Jessica, les yeux brillants, demandait très haut si elle pouvait venir avec nous et me murmurait à l'oreille qu'elle savait des tas de choses (Jean d'Ormesson, Tous les hommes sont fous)

II. Se demander à voix haute, ouvertement Pronominal

1848 Bref, de détours en détours, pied à pied, pas à pas, il en arriva tout doucement à ses fins, c'est-à-dire à se demander tout haut, sous forme de réflexion, si, par ces mauvais jours, une alliance avec les Stamply n'offrirait pas aux La Seiglière plus d'avantage et de sécurité qu'une alliance avec les Vaubert (Jules Sandeau, Mademoiselle de la Seiglière)

1919 Le vieux ne répondait pas. Il avait une barbe blanche, et les copains qui le dévisageaient se demandaient tout haut ce qu'il venait faire là.

- Ce qu'il vient faire ? nous expliquait Lambert, il vient prendre ma place, tout bonnement

(Roland Dorgelès, Les Croix de bois)

1993 Et une bleue, le soir, quand il commence à pleurnicher, à se rencogner dans son fauteuil, à errer sans but, les bras ballants dans l'appartement, à se demander tout haut si la vie a un sens en oubliant de s'occuper des biberons. Une pilule rose, on atténue ! Une pilule bleue, on remonte ! Très bon dosage suédois : Homo reconciliatus... (Philippe Sollers, Le Secret)

2008 Yacine se demandait tout haut si l'on disait baleinon ou baleineau, Nedra contemplait la flamme d'une bougie et Charles contemplait Nedra (Anna Gavalda, La Consolante)

\section{CORPuS WeB :}

A nous de demander haut et fort ce changement, car il est à la fois réaliste (v. le site de negawatt.org), responsable et apaisant. C'est un changement profond à entreprendre vite et en protégeant les plus démunis [http://www. alternatives-economiques.fr/il-faut-changer-demodele-_fr_art_1083_53730.html] (27.1.2015)

Il est là, toujours prêt à convoquer la presse pour demander haut et fort que justice soit faite. Le tueur a l'air d'un notable de province [http:// forum.aufeminin.com/forum/enfants6/_f 3595 enfants6-Erreur-medicale-qui-a-eu-le-cas-etcomment-faire.html] (27.1.2015)

Pour maintenir l'intégrité des professions d'ingénieurs et par respect pour la Science ellemême, les ingénieurs et les scientifiques du monde entier doivent s'exprimer et demander haut et fort une nouvelle étude validée par un comité de lecture, qui soit transparente et ouverte, portant sur l'effondrement des Tours Jumelles du WTC, et qui utilise l'ensemble des éléments factuels à disposition [http://www.reopen911. info/News/2014/10/22/les-trucages-du-nist-danslaffaire-du-11-septembre-etales-publiquement] (27.1.2015)

REMARQues : Demander haut (I) réfère au fait d'exprimer un désir, un souhait à voix haute et forte de manière à en provoquer la réalisation. (II) exprime le fait de se poser une question à soimême, d'exprimer un doute à haute voix, ouvertement. Notons les collocations haut et bas, haut et fort. Dans le CW, demander est employé au sens de 'exiger'. On constate donc un contraste assez fort avec l'emploi comme verbum dicendi dans les textes littéraires. Haut reste invariable et est modifié par assez, fort, plus, tout, très, trop, si. Notons l'emploi de jacasser tout bas.

\section{Demander long}

en demander long (à quelqu'un)

\section{Exiger, réclamer beaucoup \\ Intransitif}

1849 Mais ceux qui n'ont rien à eux n'en demandent pas si long au bon Dieu, et ils s'accommodent de la première pierre venue pour poser leur tête (George Sand, La Petite Fadette) 
II. Poser une question qui demande une longue explication ou à laquelle on ne peut pas répondre

Intransitif

1850 - C'est la faute aux riches.

- La faute aux riches ! comment donc ça ?

- Tu m'en demandes bien long aujourd'hui ; je te dirai ça plus tard (George Sand, François le Champi)

1874 - Alors... vous m'aimez ?

- Vous m'en demandez trop long, répondit-elle avec un air de tête qui me rendit fou

(Arthur de Gobineau, Les Pléiades)

1934 - Une chose m'étonne, monsieur Beausoleil, dans votre récit. Comment se fait-il que les soldats aient eu des cartouches? - Vous m'en demandez trop long, mon bon monsieur (Gabriel Chevallier, Clochemerle)

\section{Demander net}

Demander quelque chose sans détours, sans ambages, sans gêne

Transitif

1641 L'amour qu'il portoit à la saincte Vierge le poussa à de grands desirs de la voir durant cét exil : il fut bien si assidu et pressant en ce sien desir, demandant tout net a la saincte Vierge cette faveur de la voir en sa beauté (Paul de Barry, L’Année saincte)

1828 L'une des douairières alla jusqu'à demander tout net à la moderne Cléopâtre, dans quelle ville de France ou d'Italie avait été conclu son mariage avec le général Moreau, leur compatriote (Charles Louis de Sevelinges, La Contemporaine en miniature)

1882 Les bras de la marquise se tendirent vers le ciel, la baronne se laissa tomber avec abattement dans un fauteuil, et resta dix minutes sans parler. Octave demanda tout net à sa sœur si elle devenait folle Philippe ne fit pas connaître sa manière de voir (Georges Ohnet, Le Maître de forges)

1906 Puis sur une réponse favorable, se tournant vers la Cordouane, il lui demanda tout net qu'ils mourussent ensemble, car il ne pouvait vivre sans elle (Maurice Barrès, Mes cahiers)

1938 Il a dit aussi : « Vous savez, Sartre n'est pas un type à vous prendre les mains et à vous embrasser : il vous demandera tout net de coucher avec lui. Est-il amoureux de vous ? " (Jean-Paul Sartre, Lettres au Castor et à quelques autres)

CORPUS WeB :

Yop, j'ai 15 ans, et y'a 2 mois, j'avais jamais eu de copine (comme 99\% du 15-18) et une fille m'a demander net mon num en septembre (j'avais fais un topic sur elle) là après avoir fais mes premieres baisés sur elle (elle en à 14 ans) elle veut $\mathrm{Z}+<\mathrm{V}$ [= zizi et vagin] elle me la clairement dit et demain elle vient chez moi ;) je fais comment pour aborder ça ? [http://www.jeuxvideo.com/ forums/1-50-151794568-1-0-1-0-j-ai-changer-net. $\mathrm{htm}](28.1 .2015)$

Je vais garder un bébé au domicile des parents, 40h semaine ! lundi, mardi, jeudi, vendredi de $8 \mathrm{~h}$ a $18 \mathrm{~h}$ combien puis-je demander net par mois ? [http://droit-finances.comment camarche.net/forum/affich-5721402-combiendemander-pour-garder-un-bebe] (28.1.2015)

J'aimerais savoir combien je pourrais $d e$ mander net de l'heure pour un contrat de 40 à 45 heures par semaine sur 37 semaines ? [http:// www.forums.assistante-maternelle.org/topic/ 74438-tarif] (28.1.2015)

REMARques : Demander net désigne le fait de faire connaître à quelqu'un ce qu'on désire obtenir de lui ; il renvoie au fait d'exprimer un désir, un souhait de manière à en provoquer la réalisation, la requête étant formulée d'une manière claire, sans ambiguïté, ni équivoque. Net reste invariable et est généralement modifié par l'adverbe d'intensité tout qui vient en renforcer le sémantisme. Les deux derniers exemples du CW y ajoutent l'emploi au sens de net d'impôts et de charges où net s'oppose à brut.

\section{Demander sec}

Demander sèchement, froidement

Transitif

1958 Ce jour-là le dénommé Maurice Schumann se pointe au Quai d'Orsay, tenant L'Express sous le bras et avisant l'huissier, lui demande aussi sec : 
- Est-ce que le roi des cons est là ? (Canard enchaîné, 7 mai 1958 / Grundt : 359)

2008 Cette fois j'étais allé demander aussi sec à tout mon voisinage s'il n'y avait pas un problème de connection [sic] aujourd'hui (Jean Pierre Ceton, Le Pont d'Algeciras)

Corpus Web :

En couenne, sortir une voie signifie partir du bas, et clipper le relais sans demander sec. Ca veut dire quoi sortir une grande voie ? Est ce qu'il faut sortir chaque segment sans demander sec ? (ca me parait impossible) [http://www.camptocamp. org/forums/viewtopic.php?id=245363] (28.1.2015)

bf42 > C'est le moment de te jeter à l'eau et de lui demander sec. (-) [http://www.jeuxvideo. com/forums/1-50-71984907-4-0-1-0-all-je-reglevos-problemes-d-amour.htm] (28.1.2015)

Inhabitués à faire fonctionner leur raison, ils préfèrent esquiver toute joute ruinant leurs folles superstitions. Et évidemment, ils demandent aussi sec le recours à la censure! [http:// www.forumfr.com/sujet77391-post490-peut-onencore-critiquer-l-islam.html] (28.1.2015)

$\mathrm{Si}$ je prends ta question au pied de la lettre, ce que tu veux capter c'est comment on fait pour se pointer fine fleur avec sa teub et sa cravate devant son boss et lui demander sec une augment' [http://econsultantpointcom.com/ index.php?2006/07/19/146-salaire] (28.1.2015)

REMARques : Demander sec désigne le fait de faire connaître à quelqu'un ce qu'on désire obtenir de lui, sans ambages ; il renvoie au fait d'exprimer un désir, un souhait de manière à en provoquer la réalisation, le sujet s'exprimant rapidement, froidement, avec dureté, sans amabilité. Dans le premier exemple du CW, sec est une interjection employée, dans le langage de l'alpinisme par un grimpeur, demandant à celui qui l'assure, de réduire la longueur de la corde (s'oppose à mou). Dans les deux derniers exemples du CW, demander actualise le sens de 'exiger'. Sec reste invariable et est modifié par aussi.

\section{Demander soef (suave)}

Demander d'une manière douce, tranquillement

Transitif

1100 A icel colp l'ad Rollant reguardet,
Si li demandet dulcement e suef : «Sire cumpain, faites le vos de gred? Ja est ço Rollant, ki tant vos soelt amer ! Par nule guise ne m'avez desfiet ! » (Chanson de Roland, 1999)

1988 Le président R..., connu au Palais pour les tours sadiques qu'il se plaisait à jouer aux avocats, se cale dans son fauteuil : « Vous avez terminé, Maître B... ? » demande-t-il, suave. L'avocat se rassoit, satisfait : " J'ai terminé, monsieur le Président » (Gisèle Halimi, Le Lait de l'oranger)

2011 Les blonds ne doivent pas rougir : on croit qu'ils ont attrapé un coup de soleil. Elle avança de quelques pas puis demanda, suave :

- Pourquoi entreprends-tu ça ? (EricEmmanuel Schmitt, La Femme au miroir)

\section{CORPuS WeB :}

La même garce demandait suave à une autre des nouvelles de son mari alors qu'elle savait que le mari en question s'était fait la malle avec une autre... [http://forum.orange.fr/messages/indexpage-2/100207/ecrivez-en-ligne-l-homme-quivoulait-se-faire-hair.html] (28.1.2015)

J'y mis pourtant fin, demandant, suave :«Quelle surprise? Tu fais bien des mystères pour attiser la curiosité, c'est mal de me faire languir ainsi ! » [http://miradelphia.forumpro.fr/t14069quelques-mots-echanges-avant-de-partir-roxane] (28.1.2015)

REMARQues : Dans l'ancienne langue, demander soef désignait le fait de faire connaître à quelqu'un ce qu'on désire obtenir de lui calmement, doucement, voire avec précaution et renvoie au fait d'exprimer un désir, un souhait de manière à en provoquer la réalisation. L'adjectif-adverbe réapparaît dans cette même interprétation au $\mathrm{xx}^{\mathrm{e}}$ siècle, mais avec une connotation plutôt ironique, permettant également une analyse de prédicat second orienté vers le sujet, éventuellement détaché par une virgule. 


\section{Démarrer sec}

Démarrer, mettre brusquement en mouvement Intransitif

1963 Démarrant sec, dans un tintamarre d'aluminium, le camion attaqua les lacets, vira onze fois au plus court et ne fit qu'une bouchée du dernier raidillon (Hervé Bazin, Bouc émissaire)

1983 Il mit la main sur son cœur. La bande recula. Il éclata de rire, mit le contact et la bagnole démarra sec, crissant de tous ses pneus (Mehdi Charef, Le Thé au harem d'Archi Ahmed)

1984 - Gabin est drôlement plus baraqué, dit-il. Celui-là a l'air d'un sale youpin, comme dit Polo.

- D’un quoi ? dit Victoire.

- Au plaisir quand même ! dit Raymond en démarrant sec, debout sur les pédales, le mollet déjà noueux, comme un livreur chevronné (Bertrand Poirot-Delpech, L'Été 36)

2008 La baleinière est une embarcation longue et fine qui ressemble à une pirogue. «On y voyait des choses extraordinaires. Les bœufs étaient débarqués attachés par une patte. Si une voiture était livrée, on couplait deux baleinières. À l'approche de la plage, le conducteur devait enclencher la première et attendre un creux de vague pour démarrer sec... » (Eddy Przybylski, Brel, la valse à mille rêves)

Transitif

1984 C'est plein de monde qui veulent lyncher le brigadier Poilala, biscotte cézigue, en voyant débouler l'ancien échineur de bidets coursé par Lurette, a eu la belle géniale idée de démarrer sec son fourgon et de catapulter le fuyard (San-Antonio, Les Deux Oreilles et la queue)

\section{CORPus WeB :}

En fait, le mazout, c'est bien en côte en 5 ème, et à la caisse de la station service, mais si tu veux démarrer sec et pousser tes rapports, laisse tombé.... ça vaut pas une essence [http://www. yaronet.com/posts.php?s=78561\&p=3] (28.1.2015)
Accrochez vos ceintures car ça va démarrer sec avec Fast \& Furious : Showdown ! Pilotez de bons gros bolides ou mettez vous du côté passager pour tirer sur vos ennemis, en solo ou en coopération ! [http://www.gamoniac.fr/jeu-fastfurious-showdown-ps3-gid-1646.html] (28.1.2015)

Perso je vais tenter Trintignant sur arte et ça a intérêt à démarrer sec je vous le dis ! [http:// forum.psychologies.com/psychologiescom/ rencontres-et-seduction/demande-olivesujet_4094_4134.htm] (28.1.2015)

REMARques : Démarrer sec réfère au fait de démarrer une mécanique (moteur d'un véhicule, pédale d'un vélo) ou une action directement, sans préliminaire, de manière brusque (deux derniers exemples du CW). Sec reste invariable. VoIR AUSSI : filer / relayer sec

\section{Demeurer coi}

I. Rester silencieux sans bouger, rester tranquille

Intransitif

+1200 D’Abevile vint a Paris ; Ilueques demora tout qoi, Et si fist hommage le roi Et fu ses hom et ses borgois (La Housse partie [XIII $]$, 35)

+1313 Or me couuient demourer coi En cest lieu, si ne sai de quoi Ie puisse .ij. mois entiers viure, Ensi sui menes pour la wiure, Et le sierpent qui m'a trahi, Bien croi qu'elle ait .j. autre ami, Qu'elle a le cuer felon et fier (Jean de Condé, Poèmes [1313-1337], 805)

-1334 Mes maintenant, quant il sara

Que tués est li emperere, Du tournoy se retrest arrere Et s'en va con tous adolés. Le tournoy est quois demorés (Le Romans de la dame a la lycorne [1 ${ }^{\mathrm{er}}$ tiers XIV $]$, 3605)

1580 Quoy voyans et n'ayant lors pas un seul de nous harquebuzes ni pistoles, ains seulement nos espées, et à la maniere des sauvages chacun l'arc et les flesches en la main (armes qui ne nous pouvoyent pas beaucoup servir contre ce furieux animal 
si bien armé), craignans neantmoins si nous nous enfuiyons qu'il ne courust plus fort que nous, et que nous ayant attrappez il ne nous engloutist et devorast : fort estonnez que nous fusmes en nous regardans l'un l'autre, nous demeurasmes ainsi tous cois en une place (Jean de Léry, Histoire d'un voyage faict en la terre du Brésil)

1841 Je demeurai aussi coi et penaud qu'un président à qui son greffier aurait pris une puce chevauchant sur le nez (Aloysius Bertrand, Gaspard de la nuit)

1879 Quand Céline eut terminé une série d'exclamations qui ne voulaient rien dire, ils demeurèrent cois, les uns devant les autres (Joris-Karl Huysmans, Les Soeurs Vatard)

1904 ACHILLE. Achille, disent-ils, est-ce Eurus ou Borée

Qui s'apprête à souffler par le détroit d'Eubée?

Attendrons-nous toujours ces butins, ces lauriers,

Qui nous ont fait te suivre et quitter nos foyers?

De nous tirer d'Aulis en vain tu t'évertues : Puisqu'il te faut encore ici demeurer coi, Que ne retournons-nous plutôt à nos charrues,

En laissant ceux d'Argos aux lenteurs de leur roi ? (Jean Moréas, Iphigénie)

1914 La comtesse s'obstinant à demeurer coite, le chanoine lâcha son bras, reprit sur un ton plus posé :

- Je ne chercherai pas, madame, à vous apitoyer sur les souffrances d'un captif (André Gide, Les Caves du Vatican)

1924 Mais M. Vedel était bon : il répéta sa définition avec la patience des vrais maîtres, proposa de nouveau le même exemple ; mais quand il me demanda de nouveau de redire après lui le mot synonyme de « coudrier », de nouveau je demeurai coi (André Gide, Si le grain ne meurt)

1933 Un moment, il demeura immobile et coi, comme se dérobant à un péril, puis l'obscurité lui rendit l'inspiration ; j'entendis le souffle rauque du vieillard et le halètement complaisant de la servante (Marcel Aymé, La Jument verte)

2000 Mais je trahissais la Marquise. "Court» est un mot féroce et drôle. Moi je disais : « coi » (et son dada demeura coi, à Lérida), ce qui était charmant, mais un doute, quand même, me venait, je tâtonnais (François Nourissier, À défaut de génie)

2009 Bref, filles de la laïque nous sommes, et devons le rester. Et c'est pourquoi nous nous gardons bien de poser des questions et demeurons immobiles et coites sur les bancs du fond avec notre lot de perplexités (Mona Ozouf, Composition française : retour sur une enfance bretonne)

II. Rester muet, être stupéfait

Intransitif

1610 Nous demeurasmes tous cois, et plus estonnez qu'un evesque sans mitre. Elle nous ferma la bouche, puis nous dit : il luy faudroit dire : C... sans cul, que fais-tu là ? (Béroalde de Verville, Le Moyen de parvenir)

1899 Les autres demeuraient cois, le pape, trop politique, n'ayant point bougé (Georges Clemenceau, Vers la réparation)

1918 J’y demeurai coi, et j'entendis ma mère accabler de reproches l'inerte Gomboust (Anatole France, Le Petit Pierre)

1956 Et ça, ça m'épate plus que si je voyais JésusChrist se radiner drapé dans ses rideaux pour me commander un Byrrh-cassis. Milou et Pinel demeurèrent cois. Juju n'avait pas même fini son verre (René Fallet, $L a$ Grande Ceinture)

CORpus Web :

Ce restaurant a fait de la pasta, de la pâte fraîche, sa spécialité. Et avec quelle maestria ; à demeurer coi devant la nouille [http://www. tripadvisor.fr/Restaurant_Review-g580326d3361086-Reviews-Celeste-Cadaques_Costa Brava_Province_of_Girona_Catalonia.html] (28.1.2015)

Entendre M. Prudhomme tenir des propos à la Danton : «De l'audace, encore de l'audace, 
toujours de l'audace! » et demeurer coi devant les agences de notation, l'hyper-libéralisme en cours à Bruxelles driblé depuis Washington et Berlin, on hésite comme Jean Ferrat [http://blogs. mediapart.fr/blog/max-angel/050115/hollandeou-la-grande-consternation] (28.1.2015)

Dans La littérature à l'estomac, Julien Gracq se moque d'un certain esprit français qui adore parler de littérature, quitte à répéter les propos des autres plutôt que de demeurer coi [http:// www.troisiemebureau.com/regards-croises-14e/ edito-cest-quoi-le-probleme] (28.1.2015)

A ce moment-là, j'ai eu droit à un énorme foutage de deux ados illares postées juste derrière moi à la caisse. Etrangement, moi qui suis de nature à l'ouvrir, ce jour-là je suis demeurée coi [http://maboiteallumette.canalblog.com/ archives/2013/04/18/26953358.html] (28.1.2015)

A juste titre, il a souligné que la communauté internationale n'eût su demeurer coite, tandis que la violence faisait plus que jamais rage entre les deux parties [http://www.ism-france. org/analyses/Quels-naifs-ces-Europeens--article5820] (28.1.2015)

REMARQues : Demeurer coi (I) réfère au fait de ne pas se mouvoir et se taire ou simplement se tenir tranquille et silencieux, les circonstances le prescrivant. Le sujet étant normalement animé, on trouve néanmoins un exemple de sujet inanimé : «Le tournoy est quois demorés ». Dans l'acception (II), il désigne le fait d'arrêter de se mouvoir, le sujet étant stupéfait, bouche bée. $\mathrm{Coi}$ peut s'accorder avec le sujet, et dans ce cas-là il se prête également à une analyse de prédicat second orienté vers le sujet. Coi reste invariable dans le quatrième exemple du $\mathrm{CW}$, malgré le sujet féminin, tandis qu'il s'accorde avec le sujet féminin dans le dernier exemple, adoptant une fonction de prédicat second orienté vers le sujet. Il est modifié par aussi, ainsi, tout. On peut se demander si dans l'exemple de 1580 " tous" est pronom ou - plus probable - l'équivalent de la forme adverbiale moderne tout. En français moderne, l'emploi de coi est pratiquement limité à des collocations du type demeurer / se tenir coi, en langage soutenu. Notons l'emploi de courir fort.

\section{Demeurer court}

Manquer d'idées, d'à-propos, être à court de

mots

Intransitif

1592 Mais, comme il leur a esté bien aisé de representer leurs rithmes, ils demeurent bien aussi court à imiter les riches descriptions de l'un et les delicates inventions de l'autre (Michel de Montaigne, Essais)

1596 Mais bien souvent encor, au milieu de ma plainte,

Je demeuroy tout court, palle et tremblant de crainte,

Et reprenoy mon cœur qui de vous se plaignoit,

Quand vostre cruauté plus fort le contraignoit (Philippe Desportes, Euvres)

1655 « Il en va des langues tout de mesme; qui rencontre cette vérité de lettres, de mots et de suite, ne peut jamais, en s'exprimant, tomber au dessous de sa conception : il parle toûjours égal à sa pensée ; et c'est pour n'avoir pas la connoissance de ce parfait idiome que vous demeurez court, ne connoissant pas l'ordre ny les paroles qui puissent expliquer ce que vous imaginez » (Savinien Cyrano de Bergerac, Les Estats et empires du soleil)

1675 Je ne saurais plus écrire depuis que mes lettres ne vont point à vous ; me voilà $d e$ meurée tout court. Je songe quelquefois que, pendant que je me creuse la tête, on tire peut-être le canon, on est aise, on se réjouit pour votre accouchement (Mme de Sévigné, Correspondance)

1696 Je suis en peine de la santé de monsieur le chevalier, et de l'effet du quinquina, redonné dans sa dose ordinaire ; sa chaleur contre celle du sang du chevalier me fait souvenir de ce qu'on dit quelquefois : quand brave rencontre brave, brave demeure. Nous espérons aussi que ce brave quinquina fera demeurer tout court ce brave sang. Dieu le veuille ! Il est bien difficile à dompter. Dites-moi donc ce que vous avez fait de Mme Reinié. Parle-t-elle encore ? (Mme de Sévigné, Correspondance) 
1732 Je ne demeurai pas court à des paroles si propres à m'obliger de rompre le silence : je lui découvris le fond de mon âme, et lui dis qu'il pouvait me rendre le plus heureux des hommes en m'accordant Eugénie (Alain-René Lesage, Histoire de Guzman d'Alfarache)

1821 Ayez le plaisir de voir que vous n'êtes arrêté dans la lecture que par les difficultés qui sont invincibles, où les commentateurs et les scholiastiques eux-mêmes demeurent courts, si fertiles d'ailleurs, si abondants (John Locke, De l'éducation des enfants / Euvres philosophiques de Locke [trad.])

1836 - Est-ce que je le savais ? m'écriai-je ; est-ce que je savais que cette misérable?... Desgenais pinça les lèvres comme pour signifier : vous en saviez assez.

Je demeurais court, balbutiant à tout moment une phrase ridicule (Alfred de Musset, Confessions d'un enfant du siècle)

1950 Chez lui, dans sa petite ville natale, on le trouvait plus instruit que la moyenne des garçons parce qu'il connaissait l'écriture et qu'il retrouvait sans peine les passages qu'on en citait devant lui ; de plus, il s'exprimait presque aussi bien que le pasteur, mais à l'université on entrait dans un monde très différent et il semblait à Joseph que tous les élèves étaient mieux équipés que lui : à les entendre parler entre eux, il les trouvait plus rapides de pensée, plus prompts à répondre, alors qu'il lui fallait toujours du temps pour réfléchir et que, sans cesse, il demeurait court (Julien Green, Moïra)

1981 Je le regardai bien en face en souriant et dis seulement entre haut et bas : « SaintLegier, tient-on bien les hommes par l'esprit ? » Mon Saintongeais en demeura tout court (Françoise Chandernagor, L’Allée du roi)

2000 «Et son dada demeura court, à Lérida. » " Lérida? " La citation traînait depuis si longtemps dans ma mémoire qu'elle s'y était usée (François Nourissier, $A$ défaut de génie)
2003 Marcel, qui n'a pas ces préventions, s'alarme comme tant d'autres Français de la menace croissante de guerre, de la faiblesse des alliés français et britanniques demeurés court face aux provocations hitlériennes (Michel Winock, Jeanne et les siens)

CORPUS WEB :

L'URL est très important pour le référencement. Il devrait demeurer court, contenir des mots-clés pertinents et ne pas inclure de caractères spéciaux ( ?, \%, \$, = ) [http://www.abacusreferencement.com/lexique/url.htm] (28.1.2015)

Ce temps de préparation par le massage doit demeurer court et rapide dans son exécution et généralement ne pas dépasser 20 minutes pour l'ensemble du corps [http://www.luimagazine.fr/ sports/quel-massage-pour-quel-sport] (28.1.2015)

D'une manière générale, la sieste doit demeurer courte et circonstanciée [http://www. sommeil-mg.net/spip/Sieste-Fiche-detaillee] (28.1.2015)

REMARQUES : Demeurer court désigne le fait de se retrouver dans une situation où le sujet manque subitement d'idées, d'arguments, de repartie, est à court de mots. Court tend à l'invariabilité, mais l'exemple de 1821 fait exception, ce qui montre l'incertitude du XIX ${ }^{\mathrm{e}}$ siècle à cet égard ; celle-ci est bien reflétée dans le discours normatif (v. Introduction §4.2). Court est modifié par bien aussi, tout. Dans les exemples du CW, demeurer est un verbe copule au sens de 'rester'. Court est alors pris au sens de 'bref' et est accordé.

\section{Dénoncer fort}

Dénoncer quelque chose avec une grande intensité

$\lambda$ dénoncer haut

\section{Dénoncer haut}

Dénoncer (quelque chose/quelqu'un) à voix haute, publiquement

Transitif

1560 L'Escriture dénonce par tout haut et clair que Dieu ne trouve rien en l'homme dont il soit incité à luy bien-faire, mais qu'il le prévient de sa bénignité gratuite (Jean Calvin, Institution de la religion chrestienne) 
1922 Ces deux Américains, nos voisins (je te les dénonce tout haut, car ils ne savent pas le français ; et d'ailleurs, entre membres d'une association secrète, ce qui est le plus inutile, c'est de se comprendre quand on parle), récoltent de l'or par tous les moyens défendus (Jean Giraudoux, Siegfried et le Limousin)

1951 Je lui fis faire à Rome des funérailles triomphales, réservées d'ordinaire aux seuls empereurs ; cet hommage à un bon serviteur obscurément sacrifié fut ma dernière et discrète protestation contre la politique de conquêtes : je n'avais plus à la dénoncer tout haut depuis que j'étais maître d'y couper court (Marguerite Yourcenar, Mémoires d'Hadrien)

2002 Que la torture, en ce temps-là, était une doctrine militaire et la négation de l'autre une doctrine politique. " Amère victoire », a écrit Pierre Vidal-Naquet, pour ceux qui, comme lui, ont dénoncé cela haut et fort au temps où il fallait le faire (François Maspero, Les Abeilles et la guêpe)

\section{CORPUS WEB :}

Dénoncer haut et fort ce sujet tabou peut choquer, mais le taire serait également un leurre [https://www.facebook.com/POSEMAG/posts/ 130069163836627] (28.1.2015)

Les habitants de Gaza : les langues se délient pour dénoncer haut et fort les crimes de guerre du Hamas [http://www.europe-israel.org/2014/09/ les-habitants-de-gaza-les-langues-se-delientpour-denoncer-haut-et-fort-les-crimes-de-guerredu-hamas] (28.1.2015)

Je viens dénoncer haut et fort les conditions de vie de la MA de Fleury [http://prison. eu.org/spip.php?page=imprimer_article\&id article $=4494](28.1 .2015)$

REMARques : Le sujet de dénoncer haut peut désigner un animé (plus rarement un inanimé) dont le but est de faire connaître à haute voix ou publiquement une chose de manière à la faire condamner par l'opinion. Notons les collocations dénoncer haut et clair et haut et fort. Haut reste invariable et est modifié par partout, tout. Mentionnons également l'emploi de couper court.

\section{Départir dru}

Départager, séparer, diviser

Intransitif

-1334 En eux se fiert si radement,

Que par force les faut partir.

Lors leur conmenche a despartir

De ces grans cops dru et souvent

(Le Romans de la dame a la lycorne [ $1^{\mathrm{er}}$ tiers $\mathrm{XIV}^{\mathrm{e}}$, 2564)

Remarques : Départir dru se disait du fait de porter des coups vigoureux et fréquents pour départager. La locution dru et souvent signifiant 'à plusieurs reprises' suit le modèle de menu et souvent.

\section{Dépenser malin}

Dépenser sans tomber dans les pièges, sans se

faire avoir

$\pi$ bronzer idiot

\section{Déplier grand}

Déplier complètement

Transitif

1927 Et là, insouciant, tranquille malgré le tintamarre de la vaisselle, caché de la tête aux genoux derrière La Presse toute grande dépliée, il se mit à fumer sa vingtième pipe (Robert Choquette, La Pension Leblanc)

$1945 \mathrm{Nu}$; le poète : homme nu ; le poème est nu mais avec cette rondeur antique, signe de fertilité ; les beaux fruits ne sont jamais ratatinés, les grandes idées sont toutes grandes dépliées (Jean Bouhier, La Bataille du poète)

1955 Cette garce de fille $H$. derrière un journal grand déplié (Exemple entendu, 15 août 1955 / Grundt : 392)

1976 D'un seul coup de couteau, l'Auguste avait fendu le pigeon de bas en haut, puis il avait tiré sur les ailes pour bien l'écarteler. L'oiseau tout grand déplié sur sa poitrine, l'Auguste s'était mis à insulter la maladie (Jacques Lanzmann, Le Têtard)

2017 Je me suis avancé vers lui, les bras tendus et les mains grandes dépliées (Adrien Gygax, Aux noces de nos petites vertus) 
CORPuS WeB :

Je sautai donc du haut de mon échafaudage les bras croisés, les jambes pliées et mes sabres pointant vers le bas, en direction de cette troupe de marine. Puis, à environ deux mètres du sol, je dépliai grand mes bras et tournai sur moimême dans les airs, créant une jolie tornade de coup [http://www.onepiece-requiem.net/t6710une-apres-midi-quelque-peu-mouvementee] (29.1.2015)

Le pokémon oiseau déplia grand ses ailes et se secoua rapidement [http://www.allsoluces. com/gba/forums/fans-fics/a_10-387-1-330-quandles-pokemons-revinrent-sur-terre.html?s=1] (29.1.2015)

REMARQUES : Déplier grand se dit du fait de défaire, d'étendre, d'ouvrir ce qui est plié, fermé ou intact, l'adjectif-adverbe grand soulignant la forme ou le format de l'objet complètement ouvert. Grand tend à l'emploi accordé. Dans les exemples de 1927 et 1945, l'accord est réalisé, probablement favorisé par le féminin toute, mais on trouve l'accord aussi dans l'exemple de 2017. Grand est modifié par tout. VOIR AUSSI : déployer / ouvrir grand

\section{Déployer grand}

Étendre largement, complètement une chose qui était pliée

Transitif

1834 Oh ! reviens, céleste religion, reviens planer sur nous, tes ailes blanches toutes grandes déployées! (Journal des femmes)

1843 Les conjurés avaient caché dans les plis d'un drapeau, qu'ils espéraient déployer grand, leurs arrhes d'avenir (Jérôme Delandine de Saint-Esprit, Histoire de l'Empire, 1804-1814)

1893 Des bouteilles, heurtées, croulèrent ; des journaux, sortis on ne sait d'où, s'abattirent, grand déployés, sur l'éparpillement des quintes et des quatorze (Georges Courteline, Messieurs les ronds-de cuir)

1972 et je ne m'en plains pas, m'en étant accommodé tout jeune, d'autant que les vacances étaient là pour déployer grandes les ailes de la liberté (Pierre de Brissac, En d'autres temps, 1900-1939)
$2006 \mathrm{Au}$ fond de lui-même, il ne voulait pas d'une existence sans envergure et se sentait appelé à déployer grand ses ailes pour une vie plus extraordinaire (Xavier de Brabois, L'Éclat du pendentif)

\section{Corpus Web :}

mais quand elle passa à leur niveau, leurs ailes se déployèrent grand toutes seules et ils écarquillèrent les yeux tout en étant bouche bée, laissant tomber leurs lances... [https://mlpfic tions.com/chapter/354] (29.1.2015)

Il s'agit de se libérer des limites imposées pour déployer grand ses ailes et découvrir le vaste horizon ! [http://aikidotenjinkai.centerblog. net/91-le-sabre-de-aiki-v-devoir-de-vacances] (29.1.2015)

L'absence de quatre exposants de renom aura permis à plusieurs distributeurs de prestige de déployer grandes leurs ailes de telle sorte que le Salon de janvier prochain regorgera de nouveautés [http://m2.facebook.com/notes/ association-maritime-du-qu $\% \mathrm{C} 3 \% \mathrm{~A} 9 \mathrm{bec} / \mathrm{un}$ salon-haut-en-couleur-le-salon-2011-plus-actifet-plus-diversifi\%C3\%A9-que-jamais-/488520 199490] (29.1.2015)

REMARQues : Déployer grand (ses ailes) est une expression figée, parfois pris au sens figuré. Grand reste invarié ou s'accorde avec l'objet, ce qui peut le rapprocher d'un prédicat second référant à la taille de l'objet (journal, drapeau). Dans l'exemple de 1834, la présence du féminin au pluriel toutes favorise l'accord de grand. Notons l'usage pronominal dans le premier exemple du CW. VOIR AUSSI : déplier grand

\section{Déporter beau}

Se divertir, bien s'amuser

Pronominal

$\sim 1180$ " Cist doit bien en cheval seoir Et la lance et l'escu porter, Qui si bel s'en set deporter.» Et sa suer, qui lez li seoit, Li dist que plus bel i avoit (Chrestien de Troyes, Perceval ou Le conte du Graal, 5008)

1200 Puis que la dame ot esté morte, Le bourgeis, qui bel se deporte, Par le conseil de ses amis $\mathrm{A}$ a reson le pere mis (Auberee, 64) 
1349 Mais la dame premierement

Me vit, eins que nuls me veïst,

Ne que nuls semblant en feïst,

C'est assavoir d'icelle gent

Qui conduisoient son corps gent.

Lors un escuier appella

Et li dist : Vois tu celui la

Qui bel se deduit et deporte?

(Guillaume de Machaut, Le Jugement dou

roy de Navarre, 561)

+1350 Et la dame entra ens qui moult bel se deporte,

Sur son cheval emblant qui moult souef la porte (Brun de la Montaigne [ $2^{\mathrm{e}}$ moitié XIV $], 1892)$

1560 Toutesfois il ne peut tant faire par ses crieries, que le Décret du Concile n'eust sa vigueur. Parquoy ses successeurs, voyans qu'ils n'y gagnoyent rien, se déportèrent bien et beau de ceste obstination ; car ils ordonnèrent qu'il deust estre le second Patriarche (Jean Calvin, Institution de la religion chrestienne)

REMARQues : Déporter bel est une expression aujourd'hui hors d'usage, référant au fait de s'amuser, se divertir, se réjouir ou jouer, l'adjectif-adverbe bel ayant une fonction emphatique. Calvin remplace le neutre de l'ancien français par le masculin-neutre beau, coordonné avec bien. Beau (bel) reste invariable et est modifié par moult. Notons l'emploi de porter soef.

\section{Dépouiller nu}

Dépouiller de tout, totalement, dénuder

entièrement

Transitif

1230 Puis, faites les enfans trestous nus despoiller,

C'ancor nos pueent bien lor dras avoir mestier (Gui de Bourgogne, p. 34)

+1389 Lequel prisonnier, sur ce juré et affermé par serement de dire verité, après ce qu'il ot fait et dist qu'il n'en estoit ne n'en savoit aucune chose, et qu'il eust esté despouilliez tout nu, et lié et ataché par les mains à ladite question, afin qu'il deist de ce la verité, et aussi fait plusieurs variacions en ce, requist que il feust desliez, et qu'il diroit verité de ce que dit est, et autres chosses qu'il avoit faites et commises (Registre criminel du Châtelet de Paris [1389-1392])

1559 Et, quant elle fut hors de ce villain lieu, la faillut despoiller toute nue et changer de tous habillemens avant qu'elle partist du couvent (Marguerite d'Angoulême, Heptaméron, p. 109, 42)

1782 Je devins furieux ; on sauta sur moi, on me lia les pieds et les mains ; un monstre en ma présence, apporta un grand bain d'eau chaude ; ma Julie se fit dépouiller toute nue. Hélas! (Robert-Martin Lesuire, L'Aventurier françois ou Mémoires de Grégoire Merveil)

1859 Plus de paroles, plus de repos (brebis qui bêle perd sa dentée d'herbe) ; le mûrier qui les porte est à l'instant dépouillé tout nu ! (Alphonse de Lamartine, Cours familier de littérature)

1863 Son amant est massacré par vingt drôles qui l'attachent sanglant sous ses yeux ; elle est dépouillée nue et violée. Elle survit, sa raison lui est conservée (Alfred de Vigny, Le Journal d'un poète)

Pronominal

1275 S'en ont si grant pitié les nues

Qu'eus s'en despueillent toutes nues,

Ne ne prisent lors un festu

Le neir mantel qu'eus ont vestu ;

Car a tel deul faire s'atirent

Que tout par pieces le descirent (Jehan de Meun, Roman de la rose [1269-1278], 17922)

1558 L'abbesse leur feit sa remonstrance et leur dit pourquoy elle les avoit assemblées, et leur commanda qu'elles eussent à se despouiller toutes nues (Bonaventure des Périers, Les Nouvelles Récréations et joyeux devis)

1592 Cela faict, elle descent, et, prenant par la main le plus proche des parents de son mary, ils vont ensamble à la riviere voisine, où elle se despouille toute nue et distribue ses joyaux et vestements à ses amis et se va 
plongeant dans l'eau, comme pour y laver ses pechez (Michel de Montaigne, Essais)

1673 PIERROT. O ! donc, tanquia qu'à la parfin, pour le faire court, je l'ai tant sarmonné, que je nous sommes boutés dans une barque, et pis j'avons tant fait cahin caha, que je les avons tirés de gliau, et pis je les avons menés cheux nous auprès du feu, et pis ils se sant dépouillés tous nus pour se sécher (Molière, Dom Juan)

1691 Cette petite chrétienne avait été si bien accoutumée, lorsqu'on la voulait vendre, de quitter son manteau blanc et de se dépouiller toute nue, que j'ai eu beaucoup de peine à l'empêcher de le faire (MarieCatherine d'Aulnoy, Relation du voyage d'Espagne)

1766 En finissant ces mots, le compère se dépouilla tout nu comme la main, et jeta ses habillemens dans le feu (Henri-Joseph Dulaurens, Le Compère Mathieu)

\section{CORPuS WeB :}

Ce qui fit soupçonner qu'il était muni de quelque enchantement et, pour en être éclairci, on le fit dépouiller nu comme la main et, après une exacte recherche, on ne trouva autre chose sur lui qu'un petit papier où était la figure des trois Rois, avec ces paroles sur le revers [http:// univers-paranormal.over-blog.com/2014/06/sortd-invulnerabilite-a-la-torture-selon-albert.html] (29.1.2015)

Ces manuels recommandent l'arrestation de suspects tôt le matin par surprise, leur bander les yeux, et les dépouiller nu [http://mon independancefinanciere.com/lenciclopedie/ seccion-c/cia-actions-humaines-transnationalede-lhomme.php] (29.1.2015)

Les gardiens ont ordonné à un groupe de huit détenus de la dépouiller nue à l'extérieur d'une toilette d'hommes au premier étage [http:// fr.clearharmony.net/articles/a22769-printSeptembre-2005-Encore-quarante-quatre-44autres-deces-de-pratiquants-de-Falun-Gongconfirmes-Photo.html] (29.1.2015)

REMARQues : Dépouiller nu est résultatif, l'adjectif désignant l'état de ce qui est dénudé ou de celui qui est dénudé. En parlant d'une personne, il se dit pour 'ôter tout ce que l'on porte sur soi, enlever ses vêtements ou ses bijoux'. Le sujet peut aussi désigner un végétal (ici : le mûrier) qui ne possède plus de fruits. $\mathrm{Nu}$ s'accorde normalement avec le sujet. Notons que nu reste invariable dans le deuxième exemple du CW, malgré l'objet au pluriel. Il est modifié par tout. Mentionnons l'emploi de l'incise discursive pour le faire court.

\section{Dérouler impeccable}

Se passer sans problèmes

Pronominal

1933 Avec son clair génie, l’auteur du Traité de l'Amour de Dieu, dont la logique se déroule impeccable à travers les méandres des images et des comparaisons, avait bien vu que [...] (Ernestine Lecouturier, Françoise-Madeleine de Chaugy et la tradition salésienne au XVII siècle)

1938 À ce principe mes camarades ne voulaient pas faillir ; ils m’avaient désigné comme leur délégué et, dans leur esprit, leur chef. De sorte que le travail se déroulait impeccable, sans incident, sans faute (Gaston Guiraud, P'tite gueule)

1987 Tout se déroule impeccable (Victoria Thérame, Bastienne)

REMARQUES : Se dérouler impeccable signifie que quelque chose se passe sans problème. La combinaison « verbe + impec $($ cable $)$ » constitue une série ouverte dont nous ne citons que quelques variantes.

\section{Désafeutrer dur}

Désarçonner avec force, vigueur

Transitif

1275 Cil qui a lui jousta est plains de seürté, Celui doit on tenir pour vassal esmeré : Or demandés Corsolt se je di verité, De lui le vi je ore si dur desafeutré Que ce est grans merveille se il l'a oublié (Adenet le Roi, Buevon de Conmarchis, 2964)

REMARQUES : Désafreutrer dur est une expression hors d'usage référant au fait de faire tomber vivement un adversaire de sa monture (en général, un cheval), dérivée du verbe afeutrer signifiant 'harnacher'. 


\section{Désarêter complet}

Enlever toutes les arêtes d'un poisson

Transitif

2010 Je les [= les poissons] ai désarêtés complet (Exemple entendu [par un cuisinier], février 2010)

\section{Désarmer soef}

Ôter doucement, délicatement une armure Transitif

1100 Li reis ad pris Tierri entre sa brace, Tert lui le vis od ses granz pels de martre, Celes met jus, puis li afublent altres ; Mult suavet le chevaler desarment. Munter l'unt fait en une mule d'Arabe (Chanson de Roland, 3942)

REMARQues : Désarmer soef désigne le fait d'enlever doucement, avec précaution et calme les armes ou l'armure, l'objet désignant une personne. Il est modifié par moult.

\section{Descendre aise}

Descendre facilement

Intransitif

1372 Sire, je m'en vueil entremettre,

Car de ce fait assez suiz duiz,

Et si voy assez de lieux vuiz

Pour y descendre aise et monter

Fuiez vous : je m'y vueil bouter

(Miracle de saint Jehan le Paulu, 1500)

REMARQUES : Dans l'ancienne langue, descendre aise réfère au fait de descendre avec facilité d'un cheval.

\section{Descendre bas}

I. S’avilir, devenir indigne

Intransitif

1235 S’en tele honneur estoie entree, Griés me seroit la consiurree.

Pour chou me vaut mix a bas tendre Que haut baer pour bas descendre

(Philippe de Remi, sire de Beaumanoir, $L a$ Manekine, 1974)

1639 Quand le ciel pour nos fronts a marqué des couronnes,

Ses soins dès le berceau veillent sur nos personnes,

Gouvernent notre vie, et ne permettent pas
Que, destinés si haut, nous descendions si bas (Jean de Rotrou, Laure persécutée)

1652 Quiconque me choisit pour maître, Et ne cherche qu'à me gagner, M'approche d'autant plus qu'il sait mieux s'éloigner

Des consolations que les hommes font naître :

Plus dans leur folle estime il se trouve compris,

Plus il ravale de son prix,

Et va d'autant plus haut vers ma grandeur suprême,

Qu'il descend plus bas en lui-même,

Et se tient abîmé dans le propre mépris (Pierre Corneille, L'Imitation de Jésus-Christ)

1767 ATHAMARE. Je m'abaisse, il est vrai ; mais je veux tout tenter.

Je descendrais plus bas pour la mieux mériter.

Ma honte est de la perdre ; et ma gloire éternelle

Serait de m’avilir pour m'élever vers elle (Voltaire, Les Scythes)

1812 Un peuple qui s'était élevé si haut pouvait-il descendre si bas ? (François de Chateaubriand, Itinéraire de Paris à Jérusalem)

II. Descendre jusqu'à une certaine limite Intransitif

+1354 Bien est voir car aussi comme nule foiz il ne descendoient si bas que il venissent a la multitude derreyne, (43.12) ne ne se doit nus mervillier se le nombre et l'ordre des trente et sinc ligniez doublés qui est horesendroit en la cité ne se proporcionnent pas au nombre des centuriez dessus dictes (Pierre Bersuire, Les Décades de Titus Livius [trad.] [probablement 13541358])

1377 Et la cause est pour la difference de l'aer a l'eaue en pesanteur et en legiereté, lequel aer est dedens le vaissel et resiste a ce que il ne descende plus bas (Nicole Oresme, Le Livre du ciel et du monde, p. 400, 113)

-1465 Conduy tes sens

En telle forme que Raison ne soyes sans 
Et a Folie jamais ne te consens,

Ne monte hault ne trop bas ne descends, Le moyen garde,

De toutes pars mect en toy seure garde :

L'on oyt tes dicts, tes gestes on regarde,

Bien seras dyct sy aulcun ne te larde

(Jean Meschinot, Lunettes des princes, p. $84,1813)$

1560 ROYNE CATHOLIQUE. Comme un beau Lys, est en fleur la jeunesse D’Elizabeth, et si en corps mortel Vouloit çà bas descendre une Déesse, Pour estre belle elle en prendroit un tel (Pierre de Ronsard, Mascarades, p. 196)

1776 Alors les salaires se proportionneroient toujours au prix permanent des bleds : ils ne monteroient jamais trop haut, ils ne descendroient jamais trop bas (Étienne de Condillac, Le Commerce et le gouvernement)

1911 On pourrait descendre plus bas, à 1900 et même 1800 calories (A. Gautier), soit 30 calories par kilogramme de poids corporel, dans le repos absolu et dans un but thérapeutique (arthritisme, dyspepsies) (Maxime Macaigne, Précis d'hygiène)

1919 Ceci posé, il faut savoir qu'en hiver, soit du mois d'octobre jusqu'en avril, il y a souvent des gelées nocturnes, donc la température descend souvent très bas (Hubert Tscheuschner, La Prévision du temps sans instrument)

1927 Il faut descendre bas dans la mine du rêve pour trouver les plus belles pépites (Pierre Reverdy, Le Gant de crin)

1942 La température nocturne y descendait assez bas pour transformer en glace l'eau de mon pot à eau (Antoine de SaintExupéry, Pilote de guerre)

2004 Quarante-huit kilos, ça ne fait pas bien lourd...

- Oui, acquiesça-t-elle vaincue, oui... Je suis d'accord... Il y a longtemps que je n'étais pas descendue aussi bas... Je..

- Vous?

- Non. Rien

(Anna Gavalda, Ensemble, c'est tout)
III. S’éloigner vers le bas

Intransitif

1465 Et aprés que tous deux furent rassis, Fyrebras trait Plourance, qui luy pendoit au cousté ; Olivier prinst Haulte Clere, reluysant a merveilles, et vint sur Fyrebras, et en hault de son heaulme luy donna sy grant coup que les fleurs et pierres precieuses, dont il estoit moult anobli, fist voller a terre ; et de ce coup, en descendant bas, luy entame l'espaule, mais le cuyr de Capadouce le saulva (Jehan Bagnyon, L'Histoire de Charlemagne, p. 48)

1515 Et nostre amoureux, voiant les choses mieulx aller qu'il ne pensoit, descendit bas et tout doulcement à pas de larron s'en alla en son hostel (Philippe de Vigneulles, Les Cent Nouvelles nouvelles, p. 188, 70)

1932 Il descendit encore plus bas et atteignit les salles à manger (Édouard Peisson, Parti de Liverpool)

2004 Longtemps tes yeux myopes ont cru que les étoiles descendaient très bas le soir pour aider les lucioles à éclairer les bruits de la nuit (Daniel Maximin, Tu, c'est l'enfance)

IV. Descendre jusqu'à une couche sociale moins élevée

Intransitif

1844 Plus elle a oublié la haute position où elle était placée, plus elle est bas descendue (Alexandre Dumas père, Les Trois Mousquetaires)

1845 - Plus bas on descend dans la société, dit amèrement Marie, plus on y trouve de sentiments généreux sans ostentation (Honoré de Balzac, Les Chouans ou La Bretagne en 1799)

1849 Le sentiment de la liberté politique, cette aspiration des hommes de loisir, ne descend pas si bas dans le peuple (Alphonse de Lamartine, Les Confidences)

CORPUS WEB :

La profondeur du squat est très importante et fait une grande différence dans le développement. Le fait de descendre bas est plus difficile mais il offre un entraînement plus efficace car il 
nécessite un plus grand recrutement des fibres musculaires [http://www.all-musculation.com/ exercices-entrainement/conseils-pour-squat. html] (30.1.2015)

La difficulté n'est pas de descendre bas en fréquence, mais d'avoir du niveau, de la puissance acoustique, dans le grave. Quand le contrebassiste de Georges BRASSENS par exemple tire sur les cordes de son instrument, il en sort un son qui n'est pas rikiki [http://www.petoindominique.fr/ php/caisson.php] (30.1.2015)

respire autant de fois que tu en ressens le besoin. et pour pas étouffer, visualise qq chose que tu aimes, moi c est un arbre. dans ta tete pour te sentir mieux, et imagine ton angoisse qui t étouffe, là sur la poitrine, visualise la, et fais-la descendre bas, très bas, tout en bas.. pour libérer ta poitrine [http://www.regime-jean-michelcohen.fr/forum/questions-medicales/112758/ maladie-bipolaire-ou-maniacodepressive. asp?topic_id=112758\&p=5] (30.1.2015)

La Bourse est bradée en ce moment. Je vous l'aurais dit...

Attends un peu quand même, ils vont la tuer et la faire descendre basse pour mieux repartir [http://www.bulle-immobiliere.org/forum/ viewtopic.php? $\mathrm{f}=204 \& \mathrm{t}=43596 \&$ start $=22650$ ] (30.1.2015)

REMARQUES : Descendre bas apparaît au sens propre et au sens figuré. En (I), souvent dans un sens abstrait, il se dit du fait de déchoir de son rang, de sa dignité, de s'abaisser sur le plan moral. En (II), il se dit de quelqu'un qui descend, au sens propre comme au figuré, ou de quelque chose (température, salaire, poids) qui décroît, diminue jusqu'à une certaine limite. En (III), il désigne le fait de s'éloigner en descendant les étages d'une maison, par exemple. En (IV), il réfère au fait de déchoir, de passer à un rang inférieur. Bas est modifié par assez, aussi, encore, jamais, plus, si, souvent, très, trop. Il reste invariable ; très exceptionnellement, dans le quatrième exemple du CW, bas s'accorde avec l'objet au féminin, en l'occurrence, la bourse ; il y suit un schéma répandu dans le registre informel (v. Introduction § 4.6). Notons l'emploi de tendre bas, baer 'aspirer' haut, aller haut, élever haut, monter haut.

\section{Descendre chaud}

tout chaud descendu : juste descendu,

descendu à l'instant

Intransitif

1891 Et il n'est certes pas leur parent ce Richepin, non plus que nul des siens, son père, son cousin, - un ancien médecin de marine, aujourd'hui retraité, rabattu au pays, - qui, avec ses moustaches à la chinoise, semble quelque Hun tout chaud descendu de cheval (Hugues Le Roux, Jean Richepin)

\section{Descendre doux}

Se diriger en un lieu situé plus bas avec douceur $\pi$ descendre soef

\section{Descendre droit}

I. Descendre, aller directement ou immédiatement Intransitif

$\sim 1235$ Es les vous a la court venus, Droit au perron sont descendus (Philippe de Remi, sire de Beaumanoir, $L a$ Manekine, 1246)

1371 LE SENATEUR. Dame, vous estes descendue

A Rome droit

(Miracle de la fille du roy de Hongrie, 1877)

1579 La sepmaine passée, une femme de la vallée d'Andelle lavoit sur le bord de la rivière un oreiller sur lequel un sien petit enfant avoit chié (ne vous vueille desplaire), et pour mieux le laver et nettoyer (après l'avoir longuement froté entre ses mains) ruoit et dauboit dessus à grands coups de batoir, comme dessus un linge qui vient de la buée, et si bien le coigna, frapa et dauba qu'elle le creva, et par ce moyen toute la plume en sortit, qui s'en alla, nageant aval la riviere, droit descendre à quelques moulins (Philippe d'Alcripe, La Nouvelle fabrique des excellents traicts de vérité)

1629 que de deux choses l'une, nous irions servir un de ces deux Roys pour faire parler de nous, ou que nous descendrions tout droit dans un des ports de Narsingue, 
dont le Roy est voisin, amy et allié du Roy de Zeilan (François de Boisrobert, Histoire indienne d'Alexandre et d'Orazie)

$1668 \mathrm{Au}$ partir de ce lieu, qu'elle remplit de crainte

La perfide descend tout droit

À l'endroit

Où la Laie était en gésine (Jean de La Fontaine, L'Aigle, la laie et la chatte / Fables)

1732 Je ne connoissois personne à Ganderon, ni dans le pays, qui m'y pût introduire ; je craignois de leur faire de la peine, et de passer pour un aventurier si j'osois descendre tout droit chez elles (AlainRené Lesage, Aventures du chevalier de Beauchêne)

1839 Ainsi pendant qu'à travers les ténèbres, je vais descendre aisément par votre chemin chez mes puissances associées, pour leur apprendre ces succès et me réjouir avec elles, vous deux, le long de cette route, parmi ces orbes nombreux (tous à vous), descendez droit au paradis (François de Chateaubriand, Le Paradis perdu)

1876 MISTRESS CLARKSON. Ça passera. Quand j’ai reçu votre dépêche m’annonçant votre arrivée pour ce matin, j’ai été vraiment heureuse. Je vous avais fait préparer votre appartement, comptant que vous descendriez tout droit ici (Alexandre Dumas fils, L'Étrangère)

1911 Il se leva, prit son chapeau : il descendit tout droit au cimetière (Charles-Ferdinand Ramuz, Aimé Pache, peintre vaudois)

1935 Et je me perdais en conjectures mais je «suivais » la tige qui de cette pauvre plaque rouillée devait descendre droit jusqu'au cœur de la dépouille, homme ou femme (Pierre-Jean Jouve, La Scène capitale)

1985 - C'est normal, j'ai dit, c'est un ange qui descend tout droit $d u$ ciel, vous voyez pas... ? (Philippe Djian, $37^{\circ} 2$ le matin)
II. Descendre de manière rectiligne

Intransitif

1377 Et appert par ce que dit est que tout mouvement n'est pas simple qui est selonc droite ligne mais seullement celui qui est en montant droit ou en descendant droit (Nicole Oresme, Le Livre du ciel et du monde, p. 60, 53)

2006 Il me faut donc traverser le coude du canal et descendre tout droit par la broussaille, où des oiseaux se disputent une petite charogne (Pierre Guyotat, Coma)

2008 Elle était prête à sortir, en robe du soir de Lucien Lelong, une coupe raffinée, d'extrême sophistication dans sa géométrie. Le long fourreau bleu d'eau moulait sa taille et descendait droit, fluide sur les hanches, ouvert d'un fin plissé sur le devant, une fente pleine de promesses qu'écartait le moindre mouvement du genou (AnneMarie Garat, L'Enfant des ténèbres)

\section{CORPUS Web :}

De même, pour une pente légère, vaut mieux la descendre droit avec les deux roues avants qui touchent le bas en même temps ou descendre en biais, une roue après l'autre en bas de la pente ? [http://www.patrol-gr.net/lapratique-du-4x4/26955-qts-sur-devers-et-pente. $\mathrm{html}$ (30.1.2015)

Vous pouvez aussi descendre droit vers le Grand Bornand par une super piste nouvelle et enneigée tout l'hiver [http://lapetitemya.com/ lapetitemya/Les_pistes_de_la_Floria.html] (30.1.2015)

Le plus difficile, fut de déposer la cuve droite dans le trou, car il faut la lever haut et la descendre droite [https://sites.google.com/site/ voyagegastronomieetculture/bricolage/cuve] (30.1.2015)

Impossible de descendre droit, je suis obligé quand je descends de continuer a cambre, je n'arrive pas (même sans poids) a descendre sans cambrer [http://www.jeuxvideo.com/forums/178-399233-1-0-1-0-squat-impossible-morphologie. $\mathrm{htm}]$ (30.1.2015)

REMARQues : Descendre droit (I) désigne le fait de descendre ou simplement de se rendre de 
manière directe en un lieu (ou vers une personne). (II) se dit de quelqu'un ou de quelque chose (ici : une flèche) qui, « selonc droite ligne » (ex. de 1377), se déplace de manière verticale vers le bas, sans osciller. Il reste invariable et est modifié par tout qui vient en renforcer le sémantisme. Notons que dans les exemples 1 et $3 \mathrm{du}$ CW, descendre apparaît dans son emploi transitif ; droit reste invariable dans le premier exemple malgré l'objet au féminin, tandis qu'il s'accorde avec l'objet dans le troisième exemple où il sert de prédicat second indiquant la position, comme dans le dernier exemple. Notons que dans l'avant-dernier exemple, descendre droite est syntaxiquement coordonnée avec lever haut, mais seul le premier est accordé, ce qui permet de l'interpréter comme modifieur du complément d'objet (prédicat second). Dans les deux derniers exemples du CW, droit ne réfère pas à la direction du mouvement mais à la position verticale du sujet (prédication seconde). Droit est généralement précédé ou suivi d'une préposition (à, chez, contre, dans, par, sur, vers, au-dessus). Droit a tendance à s'associer avec ces prépositions au point de faire partie du groupe prépositionnel comme modifieur de la préposition. Notons l'emploi de monter droit ; lever haut. VoIR AUSSI : aller droit

\section{Descendre dru}

I. Descendre, tomber vigoureusement, énergiquement

Intransitif

1393 Et lors senty descendre sur lui, aussi dru que pluie chiet du ciel, coups et horions d'un costé et d'autre et fu moult defroissiéz de coupz orbes, et puis fu tiréz moult vilainement hors de la forteresse et traynéz tout hors de la barriere et la fu laissiéz (Jean d’Arras, Mélusine, p. 806 [manuscrit Ars])

1934 La pluie descendait aussi drue et le vent la jetait par gerbes au visage (Roger Vercel, Capitaine Conan)

2006a Elle étouffait, alors elle entrouvrit la fenêtre, se pencha, aussitôt fascinée par la neige silencieuse, qui descendait dru, en rideau serré, ensevelissant les formes, au point que la lanterne n'était plus qu'un vague halo jaune dans toute cette blancheur (Anne-Marie Garat, Dans la main du diable)

2006b Le lendemain il neigeait encore, le vent était tombé et la neige descendait épaisse et drue, recouvrant les arbres et la terre (Jonathan Littell, Les Bienveillantes)

II. Parvenir à une destination avec vigueur, force

Intransitif

1572 - C'est le vaillant et juste Merovée, Aspre ennemy des Huns, qui descendront Plus dru que gresle, et par force prendront, Pillant, bruslant, à flames allumée

(Mars tout sanglant conduira leurs armées)

(Pierre de Ronsard, La Franciade, p. 225)

CORPUS Web :

Hier soir a partir de $22 \mathrm{~h} .30$ feu d'artifice du nord-est au sud-est qui a dure trois heures. Tres peu d'eau on etait dans une zone neutre. ça a du descendre dru vers Nantes et Rennes [http://www2.mgcontact.eu/phpBB2/viewtopic. php?p=289790] (30.1.2015)

$\mathrm{Au}$ début c'est plus ou moins plat, mais très vite ça va descendre dru, le GR est encombré des pierres comme toujours dans ces pentes, je dois veiller aux endroits où poser les pieds, rares sont ceux où le pied est à plat [http://doische-quarante.blogs.midilibre.com/ archive/2011/06/29/mercredi-29-juin-2011.html] (30.1.2015)

Le chemin descendait dru à certain endroits pour aller dans les Woods indiqués sur la carte... [http://soomfz.blogspot.co.at/2011_10_01_ archive.html] (30.1.2015)

REMARQues : Descendre dru (I) se dit de quelque chose (pluie, coups, neige) tombant avec force, pouvant même blesser sur son passage. (II) désigne quelqu'un se déplaçant, arrivant rapidement et énergiquement, en donnant une impression de force. Notons les expressions associées à des éléments météorologiques : " aussi dru que pluie » ou « plus dru que gresle ». Dru peut s'accorder avec le sujet (ex. de 1934 et de 2006b) et être modifié par aussi, plus. Le premier exemple du CW contient l'emploi quotidien du tour impersonnel ça descend dru 'il pleut très fort'. Les 
deux derniers exemples du CW montrent un glissement de sens de l'idée de concentration ou d'apparence compacte vers la signification de 'beaucoup'.

\section{Descendre isnel}

Descendre rapidement

Intransitif

1275 Lors descendi Geras moult tost et moult isnel, Car se Limbanors noie, ne li sera pas bel. Ferrant a atachié a un rain d'un aubel, A s'espee a coupé le plançon d'un saucel, Tant fist que Limbanors refu sor le prael (Adenet le Roi, Buevon de Conmarchis, 2634)

REMARQUES : L'adjectif-adverbe isnel, usité jusqu'au moyen français, signifie 'rapidement'. Il désigne le fait de descendre rapidement, avec hâte. Cette idée est renforcée par moult tost 'sans tarder, rapidement'.

\section{Descendre profond}

I. Pénétrer loin à l'intérieur de quelque chose Intransitif

1936 car le sourire descend aussi profond que le bâillement, et, de proche en proche, délie la gorge, les poumons et le cœur (Alain, Propos)

1945 Il descendait toujours plus profond dans le regard, jusqu'aux cailloux de mica et jusqu'aux sables

(Jean-Louis Bory, Mon village à l'heure allemande)

1995 Et comme chaque nuit je descendais plus profond dans la faiblesse, l'esprit avait de plus en plus de mal à redresser le corps que je voulais noble, pas dolent, portant bien haut la tête, afin de me faire respecter malgré ma saleté, me donnant une importance qui seule m'aidait encore à ne pas me sentir dépossédé de moi-même (Hector Bianciotti, Le Pas si lent de l'amour)

2010 au lieu de se briser, le miroir m'avale comme le ferait une bouche : c'est celle de ma mère, et je vais descendre profond dans son gros corps tout fiévreux : ((((il y a des milles et des milles d'intestins ; muni d'une petite pelle, je débarrasse les intestins des excréments durs comme la pierre qui les bloquent (Victor-Lévy Beaulieu, Bibi)

II. Aller chercher loin, descendre profondément Intransitif

1937 Les degrés du sépulcre, où les graves tenues des cordes qui, par le la bémol, descendent plus profond encore, jusqu'au sol, semblent prolonger sous les voûtes l'écho des plaintes, qui s'éteignent dans le silence (Romain Rolland, Beethoven)

1945 Toutefois certains docteurs vont plus loin et estiment que la musique ne descend pas encore assez profond dans l'ineffable (Julien Benda, La France byzantine)

1979 Sous les vagues du devenir qui agitent la surface de ce qui est, la courbe thermodynamique du temps s'efface et elle disparaît peu à peu au fur et à mesure qu'on descend plus profond (Claude Roy, La Traversée du Pont des Arts)

2013 Nous sommes capables d'aller dans l'espace, mais pour l'instant les vastes profondeurs océaniques nous sont interdites. Nous y envoyons des robots, nous les sondons avec des radars, mais pour descendre profond, il faudra inventer une combinaison spéciale (Yannick Bernabé, Demain sera pour aujourd'hui)

\section{CORpus Web :}

la largable, ascenseur ,hippopotame, bouteille de périer et tout le tointoin ne sont pas la pour aller plus profond... mais pour descendre profond avec plus de sécurité..... [http://www. chasse-sous-marine.com/forums/topic/51338recherche-chasseur-ou-apneiste-pour-allezprofond] (30.1.2015)

Entre ca et un vieux chisel à la con, jpense que le rapid fait un meilleur boulot, non ? pour descendre profond, c'est pas de ma faute si le chef veux descendre profond... pourquoi ca coute plus cher ? [http://www.agricool.net/forum/index.ph $\mathrm{p} ? \mathrm{~s}=\mathrm{dd} 21 \mathrm{ee} 0318058 \mathrm{fod} 2 \mathrm{~d} 91 \mathrm{ae} 6752 \mathrm{e} 5 \mathrm{e} 63 \mathrm{f} \&$ showt opic $=15586 \& \mathrm{st}=0 \&]$ (30.1.2015) 
Vous avez du temps à perdre et vous voulez découvrir les dessous d'une source géogienne, celle de Borjomi ? Et bien soyez heureux, un site promotionnel a été mit en place, et sur celui-ci, vous pouvez descendre profond, très très profond sous la terre, jusqu'à l'eau ! [http://jeromecold. fr/wordpress/2012/05/30/le-site-le-plus-profonddu-monde] (30.1.2015)

REMARQUeS : En (I), qui est un emploi souvent métaphorique, descendre profond se dit du fait de pénétrer dans quelque chose, le sujet désignant une personne ou, par métonymie, les yeux. Il peut aussi souligner le mouvement intérieur provoqué par un sourire chez une personne. Dans descendre profond (II), le sujet réfère généralement à une musique dont le ton baisse ou se définit par ses sonorités graves. Profond reste invariable et est modifié par aussi, pas encore assez, plus, toujours plus. L'emploi en prédication seconde en change le sens : dans la nuit descend profonde et silencieuse, c'est la nuit ellemême qui est profonde. Notons l'emploi de aller profond ; coûter cher.

\section{Descendre seul}

descendre tout seul : descendre facilement, par le propre mouvement, sans intervention externe Intransitif

1377 Et toutesvoies nous voions sensiblement que le bacin noera et le fonz tout seul descendroit, et pour ce il convient en ce cas et en samblables assigner et mettre autre resistence que celle par quoy l'eaue resiste a ce que elle ne soit divisee ne distraite (Nicole Oresme, Le Livre du ciel et $d u$ monde, p. 716, 87)

1864 - Allons, montez vous autres. Est-ce qu'on ne peut pas rabattre le manteau?

- Pardon, Monsieur Kobus, vous n'avez qu'à tourner le bouton, cela descend tout seul.

Ils montèrent donc, heureux comme des princes. Fritz s'assit et rabattit la capote. Il était à droite, Hâan à gauche, Schoultz au milieu (Émile Erckmann et Alexandre Chatrian, L’Ami Fritz)

1921 Heurté par une sentinelle maladroite, un boulet de l'arsenal descendait tout seul la rue à pic, ralenti aux passages à escaliers, poursuivi par la trompette. Puis la sirène de l'Amélie siffla, le dernier reflet de l'Europe me sourit (Jean Giraudoux, Suzanne et le Pacifique)

1972 On attaque. On se jette sur les douze douzaines sans perdre une seconde. On mange en silence, concentrés. Finalement 48 huîtres c'est rien du tout à liquider. Ça descend tout seul. Et c'est très bon. C'est plus que bon. C'est fascinant de la voir manger comme ça. Du coup je m'arrête pour la regarder (Bertrand Blier, Les Valseuses)

\section{CORPUS WEB :}

Volet roulant électrique descend tout seul [http://forums.futura-sciences.com/depannage/ 515300-volet-roulant-electrique-descend-seul. html] (30.1.2015)

Parfois, sur une période de quelque jours, le volume du son monte et descend tout seul, et la télécommande n'est plus opérante. Dans le pire des cas, le téléviseur s'éteint tout seul [http://www. teleservice-depannage.com/t8633-volume-LCDqui-monte-et-descend-tout-seul.htm] (30.1.2015)

le moteur de la vitre tourne toujours car je l'entent mais elle ne répond pas ! et aujourd'hui cet vitre ses mit à descendre tout seul ! [http:// www.auto-evasion.com/forum-auto/panneauto-mecanique-et-entretien/peugeot/306/ jeune-conducteur-qui-ne-connait-rien-la-vitredescend-tout-seul/228732-1050.html] (30.1.2015)

Pour testé ton système de frein, tu appuis fort sur la pédale sans laché et si elle descend tout seul çà peut etre un problème [http://www. forum-auto.com/les-clubs/peugeot-206-207/ sujet386880.htm] (30.1.2015)

J'ai un TV samsung serie 6000 UE46B6000 VWXXC, depuis peu le son monte et descend seul en ce moment [https://forums.futura-sciences. com/depannage/697580-tv-samsung-serie-6000monte-descend-seul.html] (28.1.2019)

salut, depuis quelques sorties, dans les montées bien pentues (donc quand je suis sur le pignon 1 ou 2), j'ai la chaîne qui descend tout seule du moyen au petit plateau [http://forum.velovert. com/topic/153168-chaine-qui-descend-sur-lepetit-plateau] (30.1.2015) 
Bonjour j'ai ma vitre passager qui descend seule et ne referme pas avec la télécommande skoda octavia 2010 merci de m'aider [http://forumauto.caradisiac.com/pole-technique/meca nique-electronique/sujet671300.htm] (28.1.2019)

Remarques : Descendre tout seul se dit d'un élément qui se déplace, se dirige vers le bas, sans obstacle, sans difficulté matérielle, sans être contraint à le faire. Le sujet peut aussi désigner un objet qui roule vers le bas, le mouvement s'exerçant sans problèmes. Dans son emploi familier, se dit du fait d'avaler, d'ingurgiter une boisson ou un aliment facilement, sans peine. La grande majorité des exemples contient la collocation tout seul. Les exemples 5 et $7 \mathrm{du}$ CW montrent cependant que l'emploi sans tout existe. Seul reste invariable et est généralement modifié par l'adverbe d'intensité (tout) qui vient en renforcer le sémantisme. Notons que seul reste invariable dans le troisième et dans le quatrième exemple du CW, tandis qu'il s'accorde avec le sujet féminin dans les deux derniers exemples sans se conformer au schéma usuel elle descend toute seule. Mentionnons également l'emploi de monter seul, éteindre seul.

\section{Descendre soef}

I. Déposer doucement, délicatement Transitif

+1150 Il dessendi a tere del destrier auferrant, Puis uint a la pucele al gent cors auenant, Entre ses bras le prent, tout soef le dessent, Tres enmi le maison l'asist desor .i. banc, Puis uint a ses cheuaus, si les ua atachant, As keuestres de quir les ua bient arenant (Aiol et Mirabel [ $2^{\mathrm{e}}$ moitié XII $]$ ], 5800)

+1225a Tantost le vait par les flans prendre. Si l'a mout souef descendue. Et quant il l'espee a veüe K'ele avoit chainte, si l'esgarde (Le Chevalier as deus espees [ $2^{\mathrm{e}}$ quart $\left.\mathrm{XIII}^{\mathrm{e}}\right]$, 1285)

+1225 bt li rois maintenant le prist Entre ses bras. Si le descent Mout souavet, et puis le prent Il meïsmes et l'a menee Es cambres, $\mathrm{u}$ estoit alee La roïne. Et jut en un lit (Le Chevalier as deus espees [ $2^{\mathrm{e}}$ quart $\mathrm{XIII}$ ] $]$, 5228)

\section{Descendre doucement}

Intransitif

1285 Quant ou chastel furent entré, Clarmondine, mout tres soué Jus dou palefroi descendirent (Adenet le Roi, Cleomadés, 6888)

1524 Et au fin beau mylieu, sur un tertre plaisant,

Duquel souef descend, maint ruissel arrosant

La racine fertile à tout fructueux arbre, Est un Palais, construit de dur et riche marbre,

De jaspe, de crystal, de porphyre poli, Dont l'ouvrage est tant cher, tant noble, et tant joli,

Qu'au monde ne se treuve un si bel habitacle

(Jean Lemaire de Belges, Description $d u$ rocher)

\section{CORPUS WEB :}

Cette parole, elle passa sur les lèvres des Prophètes, dans le cœur des Patriarches, sur la plume des Évangélistes ; elle retentit dans les plaines de la Palestine, tantôt faible et discrète dans la maison de Nazareth, tantôt éclatante et solennelle sur la montagne des béatitudes ; elle tomba terrible sur l'âme des Pharisiens, elle descendit suave et douce dans le cœur des malheureux ; elle promit le pardon à Madeleine, elle offrit la miséricorde à tous [http://lepaternoster. com/cariboost_files/Rayons_20Eucharistiques. pdf] (31.1.2015; texte de 1908)

REMARQueS : Descendre soef (I) réfère au fait de déposer quelqu'un/quelque chose à terre avec précaution. (II) désigne le fait de descendre, de se diriger en un lieu plus bas que le point de départ, en se déplaçant avec douceur, tranquillité, paisiblement. Soef reste invariable et est modifié par moult très, tout. L'exemple du CW montre que l'emploi de suave comme prédicat second orienté vers le sujet est possible dans l'usage moderne. VOIR AUSSI : baiser soef 


\section{Déshydrater sévère}

Perdre en grande quantité l'eau nécessaire à

l'organisme

Pronominal

1997 «Je suis en train de me déshydrater sévère » (publicité Coca-Cola, TF1 / StephanGabinel 2001)

REMARQues : Déshydrater sévère s'emploie par rapport au fait de ne pas boire assez d'eau. La combinaison "verbe + sévère " constitue une série ouverte dont nous ne citons que quelques variantes.

\section{Désirer ferme}

Désirer, convoiter quelqu'un, quelque chose intensément

Transitif

1576 Quoy advenant, encor qu'elle [= la reine Marie] fust grandement deplaisante de voir la paix rompue, come elle la desire ferme en toute la Chrestienté, elle esperoit tant au Dieu tout puissant qu'il luy donneroit force de resister à tels dangers (Louis Régnier de La Planche, Histoire de l'Estat de France, tant de la république que de la religion)

1607 Si vous peux-je assurer que nous sommes fort retenus, et qu'à la réponse qu'il a fallu faire à la proposition des États, j'en avais dressé par écrit une beaucoup plus modérée que celle que je vous envoie, que je fis après l'autre ; et que ne pouvions assez contenter les députés d'Angleterre qui la desiraient ferme, et tendant plutôt à approuver la guerre que la paix ; encore que leur but soit pour certain la paix, par ce qu'en avons pu découvrir jusqu'à présent (Pierre Jeannin, Négociations diplomatiques et politiques du président Jeannin)

1961 elle portait assez beaux le visage et le buste, ma future mère, pour qu'on la désirât ferme (René Étiemble, Blason d'un corps)
CORPUS Web :

Le nouvel affrontement entre Aliens et Predator laisse vraiment à désirer ferme [http://www. allocine.fr/membre-Z20060228114214647364117/ critiques/?sort=5] (31.1.2015)

Jean-Paul Belmondo pestait contre les 25 copies France de son dernier film, Désiré, et désirait ferme une salle sur les Champs-Elysées [http://www.lexpress.fr/informations/49emefestival-de-cannes-profession-acteur_613926. html] (31.1.2015)

D'une voix qu'elle désirait ferme et autoritaire, Elora héla le gamin tout en s'approchant, décidée [http://m.jeuxvideo.com/forums/1-27833176603-42-0-1-0-la-compagnie-de-mugill-acte-ii. $\mathrm{htm}]$ (31.1.2015)

REMARques : Désirer ferme désigne le fait de convoiter la possession de quelque chose, voire charnellement celle d'une personne, de montrer un attrait très fort envers l'autre. L'accord n'est pas visible dans le dernier exemple du CW, mais la signification est bien celle d'un prédicat second orienté vers le complément d'objet. Le premier exemple du CW contient laisser à désirer 'ne pas être parfaitement satisfaisant'.

\section{Désirer vif}

Désirer vivement

$\lambda$ aimer profond

\section{Dessiner ample}

Dessiner à grands traits, pleins d'ampleur

$\lambda$ dessiner large

\section{Dessiner confortable}

Dessiner à grands traits, larges et souples

$\lambda$ dessiner large

\section{Dessiner correct}

Dessiner scrupuleusement

$\lambda$ dessiner large

\section{Dessiner énorme}

Dessiner à très gros et grands traits

$\lambda$ dessiner fort

\section{Dessiner faible}

Dessiner avec des traits fins

$\lambda$ dessiner fort 


\section{Dessiner fort}

Dessiner des figures aux contours très marqués Emploi absolu

1943 en matière d'impressions, c'est ce qui est fort qui compte. Leçon d'esthétique : il faut écrire fort pour écrire bien et dessiner fort pour donner des impressions que le lecteur retrouve avec plaisir (Max Jacob [Lettre à François Sentein du 6 mai 1943])

Transitif

1977 Une fillette de seize ans, dont j'ai oublié le prénom, mais que grand-mère n'appelle que la « diablesse », lui paraît éminemment suspecte, pour sa passion du bain de rivière, qu'elle pratique en maillot noir une pièce, moulant ses formes déjà fort dessinées (Albert Simonin, Confessions d'un enfant de La Chapelle)

CORPUS WEB :

$\rightarrow$ Dessiner minuscule ou énormes, ou en agrandissant et diminuant.

$\rightarrow$ Dessiner fort ou léger, rapide ou lent [http://www.ac-orleans] tours.fr/fileadmin/ user_upload/eps37/conscience_corporelle/ APD_2009_2010_Fichier_Rituels.pdf (31.1.2015)

on applique une forme cercle ou carré et un angle et une taille en dessinant fort la traîne sera épaisse, et faible la trace sera fine [http:// forum.jenesaispasdessineretjemenfous.com/vostutoriels-f42/topic176.html] (31.1.2015)

Ça dessine fort à Boucherville... [http:// www.ravent.net/blog/index.php?post/2012/ 06/\%C3\%87a-dessine-fort-\%C3\%A0-Boucher ville...] (31.1.2015)

Sûrement cette flegme naturelle chez Hikari (après l'autre dessin j'ai eu envie de la dessiner forte, ronchon comme d'habitude, je n'aime pas la voir "faible »), la gentillesse naïve de Docky et... Marty toujours calme [http://goku-chan. deviantart.com/art/I-WANT-U-109883866] (19.5.2016)

REMARques : Dessiner fort désigne le fait de représenter quelque chose par le dessin en insistant fortement sur les contours, ou, par analogie, celui de rendre apparents, de faire ressortir fortement les contours, le dessin de quelque chose ou de quelqu'un (ici : les formes d'une femme). Notons la série d'adjectifs-adverbes qui se com- binent avec dessiner : minuscule, énorme, léger, rapide, lent et faible. Fort reste invariable. Le dernier exemple illustre les adjectifs fort et faible en fonction de prédicat second accordé orienté vers le sujet. Dans l'exemple de 1977 et dans l'avant-dernier exemple du CW (probablement un québécisme au sens de 'beaucoup'), fort peut signifier respectivement 'beaucoup' et 'très bien'. Le développement de toute une série d'adjectifs-adverbes s'alliant au verbe dessiner est caractéristique d'un langage de spécialité. Par contre, les adverbes en -ment ont tendance à transposer la signification sur un autre plan, plus abstrait, qui comprend l'intensification ou l'atténuation. On ne saurait remplacer large par largement, fort par fortement ou léger par légèrement sans changer le sens de l'énoncé. Notons l'emploi de écrire fort.

\section{Dessiner gros}

Dessiner de grosses formes, à gros traits

Emploi absolu

1768 Cela est savant de détails, contours bien sûrs, dessiné large, à ce que croit l'artiste ; c'est plutôt dessiné gros. Grosses formes (Denis Diderot, Le Salon de 1767).

1992 À trop faire joli, écrit-il, on oublie en route ce que l'on veut signifier. Par conséquent, il faut dessiner gros, ce qui ne veut pas dire grossièrement (Raymond Savignac, L’Affiche de A à Z)

\section{CORPuS WeB :}

Comment vous faites pour dessiner des croquis petit, jaitendancea dessinergros.... [http:// www.hyjoo.com/sujet-54281.html] (31.1.2015)

Seulement ça tombe en grande partie dans l'acte 3 avec Bart au courant, et puis surtout, le final de l'épisode commence à se dessiner gros comme une maison [http://www.simpsonspark. com/episodes/million_dollar_ma_biche.php] (31.1.2015)

Faut pas la dessiner grosse parce qu'en réalité, elle l'était pas [http://www.bulledair.com/ index.php?rubrique=album\&album $=$ commeriv $]$ (31.1.2015)

REMARques : Dessiner gros désigne le fait de représenter ou suggérer par le dessin des objets dont les formes sont grosses, voire grossières ; la 
grosseur du trait ou l'absence de contours précis souligne ainsi un manque de minutie ou de souci du détail. Gros reste invariable, sauf dans le dernier exemple du CW où il fonctionne comme prédicat second orienté vers le complément d'objet. L'emploi pronominal avec l'expression gros comme une maison désigne, au figuré, le fait de se manifester de manière évidente.

\section{Dessiner large}

I. Tracer des traits larges, souples Emploi absolu

1758 De l'étude du dessein, suivie par le maniement du pinceau, avec le secours de la couleur il résulte une maniere de dessiner large, mais incertaine, et telle que l'on la tâte dans l'empâtement des couleurs où l'on évite les contours trop décidés (Charles-Nicolas Cochin, Voyage d'Italie)

1768 Homme nu à demi-couché sur une espèce de sopha, dont le dossier est relevé. On le voit de face. Sa jambe droite est croisée sur la gauche ; et sa main droite posée sur sa jambe, il est appuyé du coude sur le sopha ; sa main embrasse son menton et soutient sa tête. Cela est savant de détails ; contours bien sûrs, dessiné large, à ce que croit l'artiste, c'est plutôt dessiné gros, grosses formes. Cela me rappelle un fait qu'on lit dans Macrobe et qui revient trèsbien ici (Denis Diderot, Salon de 1767)

1812 On remarque dans ses tableaux [= de Claude Charles], outre la fraîcheur du coloris, une grande facilité dans la composition, et une manière de dessiner large et correcte (Louis-Mayeul Chaudon, Dictionnaire universel)

II. Tracer (un chemin) large (opposé à étroit) Transitif

2006 En attendant, pour le commun des visiteurs qui s'y aventurent sur quatre roues (si possible, toutes motrices), le beltway est un parkway comme un autre, qu'on a dessiné assez large pour voguer encore à travers l'une des plus belles campagnes d'un continent qui n'en manque pas. Je n'en dirai pas autant de notre périphérique, définitivement aussi pénible à par- courir qu'à prononcer (Gérard Genette, Bardadrac)

\section{CORPUS WEB :}

Amusez-vous ! N'hésitez pas à dessiner large, ample, confortable. Ne vous inquiétez pas pour les marges, nous les supprimerons ensuite [http://www.forum-dessine.fr/index. php?id=06007] (31.1.2015)

Godet de 12 Dessinalo, couleurs assorties. Pointe ogive pour dessiner large ou fin [http://www. rueducommerce.fr/m/ps/mpid:MP-78654M8 9466\#moid:MO-78654M170262] (31.1.2015)

Les épaules architecturées. Elles se dessinent larges et rondes sur le haut des bras ou forment des plastrons, protection pour guerrières [http:// www.elle.fr/Mode/Les-defiles-de-mode/Print emps-Ete-2010/Femme/Londres/Defile-JulienMacDonald/Defile-Julien-MacDonald-968218] (31.1.2015)

REMARQUES : Dessiner large réfère soit au fait de représenter ou suggérer par le dessin des objets dont les contours sont larges, bien dessinés (I), soit aux dimensions effectives d'un objet, d'un espace (II). Dans les exemples de 1758 et 1812, la coordination avec un adjectif fléchi implique que large est également pris au féminin. En fait, il s'accorde dans les deux cas avec manière et fonctionne donc comme adjectif adnominal, mais dans un contexte toujours adverbial. Il est possible que l'auteur de la citation de 1812 ait choisi cette construction apparemment plus correcte pour éviter d'employer dessiner correct tout court. Le CW ajoute les adjectifs ample, confortable, fin et rond. Dans le deuxième exemple du CW, large pourrait avoir le sens de 'épais' (opposé à fin). L'emploi pronominal dans le dernier exemple réfère au fait de faire ressortir des formes généreuses (prédication seconde).

\section{Dessiner léger}

Dessiner avec des traits délicats

$\pi$ dessiner fort

\section{Dessiner lent}

Dessiner avec lenteur

$\lambda$ dessiner fort 


\section{Dessiner maigre}

Dessiner à traits fins, à peine visibles

Intransitif

1795 N'en déplaise à la prédiction, ces gravures seront de mauvais modeles, et n'apprendront qu'à dessiner maigre et sec (Mercure de France)

\section{Dessiner minuscule}

Tracer de tout petits dessins

$\lambda$ dessiner fort

\section{Dessiner rapide}

Dessiner avec rapidité

$\lambda$ dessiner fort

\section{Dessiner sec}

Dessiner sobrement

$\pi$ dessiner maigre

\section{Destiner haut}

I. Être destiné à un rang élevé

Transitif

1639a LE ROY. Quand le Ciel pour nos fronts a marqué des couronnes,

Ses soings dès le berceau veillent sur nos personnes,

Gouvernent nostre vie, et ne permettent pas

Que destinés si haut nous descendions si bas (Jean de Rotrou, Laure persécutée)

1648 LE ROY. Toute obscure qu'elle est, la nuit a beaucoup d'yeux,

Et n'a pas pû cacher vostre forfait aux Cieux,

(L'embrassant)

Adieu, sur l'eschaffaut portez le cœur d'un Prince,

Et faites-y douter à toute la Province, Si né pour commander, et destiné si haut, Vous mourez sur un throsne, ou sur un eschaffaut (Jean de Rotrou, Venceslas)

II. Prédestiner à quelque chose de noble Transitif

1639b LAURE. Ce jour si desiré, si cher aux yeux de tous,

Avec la mesme torche éclaireroit pour nous,
Si ma condition, à la sienne inégale,

N'armoit une puissance à nos désirs fatale, Qui destine plus haut la foy que j'ay de luy, Et nous comble tous deux de misere et d'ennuy (Jean de Rotrou, Laure persécutée)

\section{CORPUS WEB :}

Avant la création des quais, les navires mouillaient aussi à partir du Pont de Pierre et débarquaient par allèges pour ce qui était stocké à Bordeaux ou sur des bateaux de Garonne et des canaux du Midi pour ce qui était destiné «plus haut » vers Agen, Toulouse, voire Méditerranée.. [http://bordabord.org/news/variations-photosde-fluvial] (31.1.2015)

REMARQUES : Destiner haut s'emploie au figuré. Souvent dans un emploi passif, (I) réfère à quelqu'un ayant été destiné à un rang élevé, dont le destin, la destinée tend vers le haut. (II) désigne le fait de prédestiner quelque chose, de réserver à un destin noble, élevé. Haut reste invariable et est modifié par plus, si. L'exemple du CW reflète l'emploi par économie linguistique des adjectifs-adverbes dans un argot de métier, ici au sens de 'plus en amont'. Notons l'emploi de descendre bas.

\section{Détester ferme}

Détester quelqu'un, quelque chose

intensément, résolument

Pronominal (réciproque)

1874 Pour ça, ils se détestent ferme ! (Émile Zola, La Conquête de Plassans)

Transitif

1974 Elle se mit à le détester ferme (Jean Vautrin, Billy-Ze-Kick)

1975 S’agissant de toi, Polka, il n'est pas question d'exécution capitale ; je ne parle de guillotine que pour faire image. Encore qu'on nous déteste ferme, toi et moi, à l'occasion! (François Nourissier, Lettre à mon chien)

\section{Corpus WeB :}

- Ah... De toute façon il doit me détester ferme maintenant ! [http://tomber-danssesyeux. skyrock.com/3152439352-En-fuyant-la-pluie-onrencontre-la-grele.html] (31.1.2015) 
j'aime déjà pas la politique faite sous le règne de Sarko mais avec en plus cette ministre là : je la déteste ferme cette personne [http:// suppermamy76.skyrock.com/1695270626-raz-lebol.html] (31.1.2015)

Mais... il y a déjà ma Nini qui DÉTESTE ferme les autres chats... et qui a le privilège du grand âge... [http://www.beaute-test.com/forums/ index.php?topic $=154168 \&$ start $=15]$ (31.1.2015)

Moi sa me fait rire j'ai l'impression que la tecktonik c'est un peu comme dans les années 70-80 le disco qui était adoré par certains et que d'autres détestaient fermes cette mode [http:// www.xbox-gamer.net/forum/viewtopic.php?p= 174961] (31.1.2015)

Remarques : Détester ferme se dit du fait d'avoir en horreur, de condamner résolument quelque chose, d'éprouver une aversion forte pour quelque chose (un vice), d'exprimer une antipathie déclarée pour quelqu'un. Ferme reste invariable, mais dans le dernier exemple du CW l'accord est fait, peut-être par hypercorrection.

\section{Détester fort}

Abhorrer profondément ; condamner résolument Transitif

1546 Pour à la quelle chose obvier, luy faisoit tout plein de beaux contes touchant les desolations advenues par adultere ; luy lisoit souvent la legende des preudes femmes, la preschoit de pudicité, luy fit un livre des louanges de fidelité conjugale, detestant fort et ferme la meschanceté des ribauldes mariées ; et luy donna un beau carcan tout couvert de saphyrs orientaulx (François Rabelais, Tiers Livre)

1562 Bref un Peroceli aparoist entre vous Plus sage, et continent, plus modeste, et plus doux,

Qui reprend asprement les violeurs d'images,

Les larrons, les meurtriers : qui de fardés langages

N'entretient point la guerre, ains deteste bien fort

Ceux qui plains de fureur nourrissent le discord.
Il est vrai que sa faulte est chose abominable,

Toutesfois en ce fait elle est bien excusable (Pierre de Ronsard, Discours des misères de ce temps)

1657 Parlons maintenant des gens d'affaires. Vous savez que la plus grande peine qu'on ait avec eux est de les détourner de l'usure ; et c'est aussi à quoi nos pères ont pris un soin particulier ; car ils détestent si fort ce vice, qu'Escobar dit [...] que de dire que l'usure n'est pas péché ce seroit une heresie (Blaise Pascal, Les Provinciales)

1792 LE GRAND COUSIN. Par le cousin il est fort détesté,

Et vraisemblablement sera déshérité

(Collin d'Harleville, Le Vieux Célibataire)

1846 Si elle déteste si fort le mariage, pourquoi s'est-elle mariée elle-même?

(Alexandre Dumas père, Le Comte de Monte-Christo)

1874 Et comme je ne pouvais pas me délivrer de ses regards, je répétais machinalement en moi-même : Je t'aime ! Je t’aime ! Au moment où je me blâmais de la détester si fort ! (Arthur de Gobineau, Les Pléiades)

1924 Ce qui restait de ces droits était naturellement fort détesté (Jacques Bainville, Histoire de France)

1928 Car j’ai oublié de dire qu'à la suite d'une conversation avec le docteur De Schacken, on a supprimé la gymnastique que je détestais si fort, et on l'a remplacée par l'escrime et la danse (Gyp, Souvenirs d'une petite fille)

1975 - Je vois, monsieur Surin, que vous n'êtes pas encore parti et que vous apprivoisez ces miroirs que vous détestiez si fort (Michel Tournier, Les Météores)

1988 J'approchai mon visage du sien et lui murmurai à l'oreille :

- Je te déteste, maman. Je te déteste si fort! (Christine Aventin, Le Coeur en poche) 
CORPUS WEB :

On s'aimait bien, on détestait fort, mais on protégeait l'outil de production et le copain blessé sans que ce dernier puisse obtenir quoi que ce soit de l'État sinon l'avantage facilement acquis de quelques jours de taule [http://a-l-i. org/freud/Champs_specialises/Presentation/ Il_fut_un_temps] (31.1.2015)

On disait d'elle qu'elle était gentille, elle se détestait fort mais ne faisait pas de bruit qui s'entende, et sa porte était toujours fermée aux colères et aux revendications, mais derrière le bois brut [http://hazel04.skyrock.com/262279561une-vie-dans-les-tissus.html] (31.1.2015)

Mélanie ne devait rien connaître de plus sur moi, elle ne devait pas savoir que j'étais sortit avec Claire, car elles se détestaient fort à l'époque, mais je croyais que si je lui disais que Claire était morte dans une explosion, Mélanie serait peutêtre contente de joie! [http://fic-laytonxmelanie. skyrock.com/tags/gCuJFBNhYc0-Chapitre-4. html] (31.1.2015)

REMARQues : Détester fort se dit du fait d'avoir en horreur, de condamner résolument quelque chose, d'éprouver une forte aversion pour quelque chose (un vice, une activité, un sport), d'exprimer une antipathie déclarée pour quelqu'un. Notons la collocation fort et ferme, où ferme vient renforcer le sémantisme de fort. Fort reste invariable et est modifié par bien, si. Sa sémantique oscille entre l'emploi concret 'avec force' et celui de simple quantifieur, surtout en antéposition (fort détesté). Notons aussi l'emploi absolu dans le premier exemple du CW, et l'emploi pronominal dans les autres exemples du CW.

\section{Détourner court}

(Se) détourner brusquement, rapidement ; changer brusquement de direction

Pronominal

1538 «Si tu vas, amy, tu n’es pas sage;

Car tu pourrois avoir maulvais visage

De ton seigneur. » Lors, comme le nocher

Qui pour fuyr le peril d'un rocher

En pleine mer se destourne tout court, Ainsi, pour vray, m'escartey de la Court, Craignant trouver le peril le durté

Où je n'euz onc fors doulceur et seurté (Clément Marot, Épitres)
1681 Cette grande necessité lui fit perdre cœur, et ce qui mit le comble à ses ennuis, fut qu'un grand Hiroquois s'en vint'un jour droit à elle la hache sur l'épaule, alors croïant qu'il n'y avoit plus de vie pour elle, elle se disposa à la mort par la priere, mais Dieu permit que cet homme étant proche d'elle, se détourna tout court pour entrer dans le bois (Lettres de la vénérable mère Marie de l'Incarnation, première supérieure des Ursulines de la Nouvelle France)

\section{CORPus Web :}

Graham détourna les yeux, se détourna tout court [http://unseen-handled.skyrock.com/ tags/3nqJnzdC1VZ-Milice.html] (31.1.2015)

Vrai, beaucoup se détournent tout court de la location avec les impayés notamment [http:// www.forumconstruire.com/construire/topic250214.php] (31.1.2015)

Les images mentent souvent, qu'on les détourne de leur propos, de leur sens ou même aujourd'huiqu'onles détournetoutcourt[http://www. rtbf.be/info/emissions/article_la-chronique-depaul-hermant?id=5023753] (31.1.2015)

REMARQUeS : Détourner tout court désigne le fait de changer subitement de direction, de dévier brusquement dans le but de s'éloigner ou de s'écarter d'un danger. Dans le CW, la collocation usuelle tout court tend à développer le sens de 'sans plus', mais sans toujours perdre la connotation de changement ou de rupture brusques. Court reste toujours invariable. Notons l'emploi transitif du verbe, au sens de 'dénaturer', dans le troisième exemple du CW. Notons l'emploi de s'en venir droit à elle.

\section{Dévaler bas}

Descendre rapidement vers le bas

$\lambda$ tomber bas

\section{Deviner juste}

Deviner avec justesse, exactitude

Transitif

1678 Mme de Clèves rougit de ce que Mme la Dauphine devinoit si juste et de ce qu'elle disoit devant M. de Nemours ce qu'elle avoit deviné (Madame de La Fayette, $L a$ Princesse de Clèves) 
1760 Fort bien, reprit-il avec un sourire encore plus malin ; j’avois deviné assez juste, que l'amour avoit beaucoup de part à votre voyage (abbé Prévost, Le Monde moral)

1768 L'Homme Aux QuARANTE Écus. J'entends. Mais vous m'avez dit que nous sommes vingt millions d'habitants, hommes et femmes, vieillards et enfans, combien par chacun, s'il vous plaît?

LE GÉomètre. Cent vingt livres ou quarante écus.

L'Homme Aux QuARANTE Écus. Vous avez deviné tout juste mon revenu (Voltaire, L'Homme aux quarante écus)

1805 Ignorez-vous, madame, continua-t-il, poussé par cet instinct qui fait toujours deviner si juste le mot qui doit réussir, ignorez-vous tout ce que vous pouvez obtenir par l'intercession de la princesse? (Sophie Cottin, Mathilde)

1887 Si j'ai deviné juste à travers les conversations trop courtes, trop rapides qu'il m'a été donné d'avoir avec vous, votre vie, sous son apparence comblée, est déshéritée de bien des choses (Paul Bourget, Mensonges)

2008 Méfiez-vous de l'as de cœur, du valet de cœur, le cœur n'est pas pour vous. Ça, elle devinait juste. Une affaire d'argent, beaucoup d'argent voyage, le roi de carreau est éliminé, une bonne chose pour vous (Anne-Marie Garat, L'Enfant des ténèbres)

Emploi absolu

1740 MAÎTRE BLAISE. Stependant, je me baillerai bian du tourment pour avoir Angélique, et il en pourra venir que je l'aurons, ou bian que je ne l'aurons pas, faut mettre les deux pour deviner juste (Pierre de Marivaux, L'Épreuve)

1830 Ce mot tomba directement sur le cœur de Mathilde. Il est vrai, se dit-elle, ma mère a deviné juste, tel est le sentiment qui l'anime. Alors seulement cessa la joie de la scène qu'elle lui avait faite la veille. Eh bien, tout est fini, se dit-elle avec un calme apparent (Stendhal, Le Rouge et le noir)
1843 Tout cela est infâme, et convenez que j'ai eu raison d'éloigner de mes états ce $\mathrm{Ca}$ gliostro qui devine si juste, et qui donne de si bonnes nouvelles des gens morts et enterrés (George Sand, La Comtesse de Rudolstadt)

1885 «En voulez-vous une goutte ? ça vous rappellera l'pays. » Avec son instinct d'être de même race, loin de chez elle aussi peut-être, elle avait deviné et touché juste. Ils furent émus tous les deux (Guy de Maupassant, Contes et nouvelles)

1923 Et comme le jeune homme ne répondait pas, consterné d'avoir deviné trop juste, elle continua :

- Michelle est en âge de se marier (Paul Bourget, Le Geste du fils)

1963 Je comprends, je comprends, mais vous savez, quelquefois également, on croit deviner juste et on se trompe (Bernard Clavel, Celui qui voulait voir la mer)

2011 là, cette tumeur cancéreuse sous le rein droit, j’ai failli tourner de l'œil, mon cardiologue avait donc raison, il avait deviné juste, qu'est-ce qu'on va faire, opérer, bien sûr, mais où, quand, je cours chez le Dr J., il fronce les sourcils en regardant les clichés (Serge Doubrovsky, Un homme de passage)

\section{CORPUS WEB :}

Dans les grands classiques de la PB, il faut deviner le sexe de son enfant avant l'écho des 12 SA grâce à de nombreux conseils et astuces, j'ai décidé d'explorer toutes les théories que j’ai pu trouver sur plusieurs sites pour être certaine de deviner juste [https://lareinedelapma.wordpress. com/2015/01/16/pb-en-folie-deviner-le-sexe] (31.1.2015)

Si vous arrivez à deviner juste, le Cerveau vous offrira de quoi assouvir votre soif ou vous couvrir en cas d'intempéries. A gagner deux bouteilles de Tru Blood le vendredi 27 Septembre et un hoodie spécial Tru Blood le 5 Octobre prochain [http://braindamaged.fr/2012/09/27/trueblood-devinez-la-meteo-de-nt1-et-repartez-avecdes-lots] (31.1.2015) 
au passage je ne connais pas l'expression « pince sans rire » ben oui si personne ne vous explique un jour le sens des expression il est difficile de les deviner juste [http://forum.judgehype. com/judgehype/LaTaverneHardcore/vous-arriveaussi-sujet_181910_2.htm] (31.1.2015)

L'ennui avec les ordres de ce dieu-éprouvette, c'etait qu'il fallait les deviner, mais surtout qu'il valait mieux pour sa peau de les deviner justes [http://fevlia-v3.forumactif.com/t104-lapremiere-bataille] (31.1.2015)

REMARques : Deviner juste désigne le fait de parvenir à connaître quelque chose, un fait, par conjecture, supposition, intuition, avec succès, exactitude, sans se tromper. Juste reste invariable et est modifié par assez, si, tout, trop. Dans le CW, juste reste invariable dans le troisième exemple malgré l'objet au pluriel, tandis qu'il s'accorde avec l'objet pluriel dans le quatrième, tout en gardant son interprétation d'adverbe de manière. Notons l'emploi de toucher juste.

\section{Deviser bas}

Parler, discuter à voix basse

Intransitif

+1400 Si esveillay les autres, et le pas

Nous alames en devisant tout bas

Jusques au lices

De la grant court de hors, ou edifices

(Christine de Pisan, Le Livre du dit de Poissy / Euvres poétiques [début $\mathrm{XV}^{\mathrm{e}}$ ], II, p. 178, 635)

1558 Apres avoir salué toute ceste compagnie, nous commençames en troupe à deviser tout bas ; puis ce malade tira un de ses rideaux, à quoy la contesse Marguerite s’avança, me tenant par la main (Théodose Valentinian, L’Amant resuscité de la mort d'amour)

1642 (Angelique et Florestan devisent bas) CARRILLE. Je ne fus en ma vie

Surpris comme je suis, que mon ame est ravie,

Est-ce une illusion, ou quelque enchantement ? (Antoine d'Ouville, L'Esprit folet)

1749 Ravies de leur liberté, elles s’approchèrent en un tas, tout le long d'un lit de veille à pavillon et le joignant ; et comme elles étaient toutes affectées de même à l'égard de l'événement qui rassemblait là tout le monde, elles se mirent à en deviser tout bas ensemble dans ce groupe avec liberté (Saint-Simon, Mémoires complets et authentiques du duc de Saint-Simon sur le siècle de Louis XIV et la Régence [1739-1749])

1941 Sans même comprendre les raisons de ce changement de régime, les jeunes gens s'étaient mis à deviser tout bas et jetaient à l'entour des regards inquiets (Georges Duhamel, Suzanne et les jeunes hommes)

2007 Avisant deux dames de noblesse qui devisaient tout bas, il pensa que ces deux-là devaient se confier des secrets d'alcôves, certainement croustillants (Bernard Grousset, En ton nom, Révolution)

\section{CORPUS WEB :}

Distraite, nous sommes la même personne, biologiquement parlant du moins. Je sais que tu ne dors pas. » Distraite continue obstinément à deviser tout bas avec elle-même [http://plumedegivre.skyrock.com/3241801529-Distraite-etObstinee.html] (31.1.2015)

Sylphide et MKA devisaient tout bas de l'étroitesse d'esprit de Mme B., l'espionne intraitable et aveugle qui nourrissait Ursula [http:// www.weightwatchers.fr/community/mbd/ post.aspx?page_size $=25 \&$ rownum $=1$ \&page noHidden $=3 \&$ threadpage_no $=1 \&$ sincedate $=$ 25\%2F09\%2F2009+<00\%3A00\%3A00\&thr ead_id=9053008\&thread_name $=$ pause $+<$ caf $\% 26 \% 23233 \% 3 \mathrm{~B}+<$ dans $+<$ le $+<$ Nord\&forum id=1\&board_id=480\&setview=TRUE\&dateran] ge $=$ \&viewchange $=$ POSTSDESC (31.1.2015)

En gros, j'me dis qu'il est tout à fait possible que la réalisation de tout ceci pour 3000 euros soit rentable, à condition de faire simple et de bosser vite... en conséquence de quoi tu ne chercheras pas à construire une vrai putain d'identité visuelle pour le dit évènement, mais tu te contenteras de faire du propre et pas cher. On peut très bien bosser comme ça (et du coup deviser bas) mais il faut en avoir conscience... [http://forum. kob-one.com/graphistes-f7/le-juste-devis-votreavis-sur-un-devis-t29270.html] (31.1.2015) 
REMARQUES : Au figuré, deviser bas désigne le fait de s'entretenir familièrement sans trop élever la voix, afin de ne pas être entendu de tous. Bas reste invariable et est modifié par tout. Le dernier exemple du CW contient le néologisme deviser bas 'faire un devis pas cher' usuel dans le vocabulaire des artisans et architectes, tout comme faire simple et bosser vite.

\section{Deviser dru}

deviser dru et menu : parler, discuter beaucoup et souvent (de quelque chose)

Intransitif

1568 Mais la nouvelle mariée n'eut cognoissance par quelque temps de ce deffaut, sinon par communication d'autres bonnes commères qu'elle frequentoit, et lesquelles elle ouyt deviser du passe-temps dru et menu qu'elles recevoient de leurs jeunes marys (Bonaventure des Périers, Les Nouvelles Récréations et joyeux devis)

REMARQUES : Deviser dru et menu désignait le fait de s'entretenir familièrement au sujet de quelque chose avec fréquence et profusion, les adjectifs-adverbes dru et menu, en collocation, insistant sur la quantité et la répétition de paroles. Ils restent invariables.

\section{Deviser menu}

Parler beaucoup

入 deviser $d r u$

\section{Devoir gros}

Devoir beaucoup d'argent ; avoir une dette morale importante

Emploi absolu

1782 Figeac doit gros, mais pourtant par mégarde ;

Figeac s'obstine à ne jamais payer ;

Il a de plus mainte dette criarde,

Mais en revanche, il les laisse crier (Étrennes lyriques, anacréontiques, pour l'année 1782)

1862 Le Thénardier se replia en bon ordre.

- Cette signature est assez bien imitée, grommela-t-il entre ses dents. Enfin, soit ! Puis il essaya un effort désespéré.
- Monsieur, dit-il, c'est bon. Puisque vous êtes la personne. Mais il faut me payer « toutes les petites choses». On me doit gros (Victor Hugo, Les Misérables)

1884 Il n'osa pas refuser, car il devait gros dans la maison (Alphonse Daudet, Sapho)

1942 - Tu n'es pas libre ? Tu es son engagé ? - Ou tout comme, je lui dois gros d'argent. Mais c'est pas ça, pantoute, tu ne pourrais pas comprendre (Maurice Genevoix, Laframboise et Bellehumeur)

1987 Hélène ne décolérait pas. Il lui devait gros, ce trouchamand, toujours à voir le mal, à lasser le personnel, à rouméguer pour un oui pour un non! (Evelyne Sullerot, L'Enveloppe)

2004 Je ne sais pas s'ils lui seront reconnaissants. Mais ils lui doivent gros !...

Je peux le dire aujourd'hui. Il était obligé de compter sur tous. Il aidait. Il était payé en nature (Philippe Roucarie, Un passé pas si simple)

2007 Benoît était sûr à présent que Bogue n'était pas son père, mais il avait conscience de lui devoir gros. Sa lyre, déjà. Et depuis toujours cette précieuse présence masculine amicale, la seule (Georges-Olivier Châteaureynaud, L'Autre Rive)

\section{CORPUS WEB :}

Je lui souhaite un excellent courage à travers cette expérience, de garder la tête haute, car même si il a eu des erreurs de parcourt, il à jusqu'à maintenant apporter beaucoup au niveau de la justice québécoise. Je suis certain que beaucoup de gens lui doivent gros [http:// www.exruefrontenac.com/nouvelles-generales/ justice/27027-proces-lambert] (1.2.2015)

Non seulement il les accompagnait mais en plus il lui sauvait la vie. Visiblement, elle lui devait gros [http://www.gothicat-world.com/ forum/viewtopic.php?f=43\&t=11548\&start=50] (1.2.2015)

REMARQUeS : Devoir gros réfère au fait d'avoir à payer une grosse somme d'argent ou de devoir fournir à quelqu'un quelque chose de valeur, d'avoir beaucoup de dettes envers quelqu'un. Gros 
reste invariable. Dans l'exemple de 1942, l'adjectif-adverbe forme un groupe avec gros d'argent, explicitant ainsi ce qui reste implicite dans devoir gros. Dans les exemples de 2004, 2007 et dans le CW, le sens passe au figuré. Certains auteurs analysent devoir gros comme construction transitive (à complément « léger »; v. Introduction § 6.3), gros jouant le rôle du complément direct. En effet, devoir gros n'admet pas d'autre complément : on ne peut pas dire *devoir gros 3000 euros alors que devoir 3000 euros est usuel.

\section{Diagnostiquer juste}

Diagnostiquer avec justesse, poser le bon

diagnostic

Emploi absolu

1842 L'élève traitant interrogeait le malade en présence du professeur et de tous les élèves ; des questions de la part du premier, des discussions de la part des derniers, s'en suivirent toujours, et le traitant reçut des marques de bienveillance de la part de notre excellent professeur, s'il parvenait à diagnostiquer juste et à prescrire convenablement

(Constant Crommelinck, Rapport sur les hospices d'aliénés)

1893 Le coup d'œil du chirurgien avait diagnostiqué juste. La balle de Dorsenne avait frappé Gorka au-dessous du poignet. Deux centimètres de plus à droite ou à gauche, et sans doute Boleslas était tué du coup (Paul Bourget, Cosmopolis)

1952 Et s'il leur arrive de s'en apercevoir à la suite d'une consultation avec un confrère plus clairvoyant, il est généralement trop tard pour faire machine arrière : le mal irrémédiable est fait, le malade est perdu. Le confrère, qui a diagnostiqué juste, se tait : il préfère se retrancher derrière l'admirable invention du secret professionnel plutôt que de révéler au grand jour la faute impardonnable d'un collègue (Guy des Cars, La Corruptrice)

2008 À eux deux ils retournent la bicyclette, la mettent en équilibre sur sa selle et son guidon, puis entreprennent de démonter la roue arrière. Ils ont visiblement diagnos- tiqué juste, rapidement la roue est extraite, le moyeu démonté. Le réparateur m'en tend l'axe (Christophe Tanguy, Carnets d'un expatrié au cour de la Chine)

\section{CORPUS Web :}

«Diagnostiquer juste est à moitié guérir. » La France d'aujourd'hui se cherche et ne se retrouve pas, au lieu de chercher plus profondément les vrais raisons qui pourraient s'avérer complexes et compromettantes, on a préféré la facilité [http:// www.alterinfo.net/Une-crise-a-la-francaise a8567.html] (1.2.2015)

S'en tenir à cette vue négative serait pourtant négliger que l'hôpital reste le lieu de l'excellence médicale, que les urgences doivent une part de leurs problèmes à l'afflux de sollicitations que leur vaut la confiance dans leur capacité à agir vite, diagnostiquer juste ou soigner bien [http:// www.liberation.fr/evenement/2002/07/13/ myopie_410119] (1.2.2015)

Cela fait 10 ans que je vis le parcours du combattant et encore je ne suis pas arrivée à connaître des noms de médecins ou de pédopsychiatres formés en autisme pour diagnostiquer juste mon enfant, qui a aujourd'hui déjà 12 ans ! [http://forum.autisme.ch/viewtopic.php?id=432] (1.2.2015)

REMARQUES : Diagnostiquer juste désigne le fait d'identifier, de déterminer avec exactitude une maladie par ses symptômes, en faisant un diagnostic correct. Notons que diagnostiquer juste est transitif dans le dernier exemple du CW. Si l'on peut dire que juste réfère à l'objet interne du verbe diagnostiquer (son résultat, le diagnostic, est juste), cet objet interne ne correspond pas au complément d'objet direct 'mon enfant', qui est explicité dans cet exemple. Juste reste invariable.

\section{Dîner bel}

dîner bien et bel : bien dîner

Intransitif

+1365 Et cils, qui au parler s'arine, Les fist venir en un tropel Et dist : Dimence, à bonne estrine, Quant on ot disné bien et bel, De Saint Denis, ce bon hamel, Parti la dame à qui nous sons (Jean Froissart, Poésies [3 $3^{\mathrm{e}}$ tiers XIV ] $]$ ) 


\section{CORPus WeB :}

Jack : " très drôle !.... » Néanmoins, il confirme qu'il dînait bel et bien avec M Kim hier soir quand il a eu son malaise [http://www.lesfeu xdelamour.org/article-4227429.html] (1.2.2015)

Non non ne te frotte pas les yeux, tu n'es pas en train de rêver, on dîne bel et bien dans des bureaux ! [http://www.goutdfood.com/2013/10/ jpeux-pas-ce-soir-jcooknmeet.html] (1.2.2015)

Ils rentrèrent, et finalement, ils dînèrent bel et bien en amoureux [http://tamashii.skyrock. com/3.html] (1.2.2015)

REMARQUES : En ancien français, dîner bel souligne le fait de prendre un repas composé d'aliments délicieux, savoureux et de qualité, régalant et satisfaisant pleinement celui ou celle qui les mange. Notons la collocation dîner bien et bel qui confirme la fonction adverbiale du neutre bel. Le français moderne du CW ne retient plus que la collocation bel et bien au sens de 'effectivement, contre toute expectative', avec possible remotivation dans le dernier exemple. La collocation bel et bien sert donc d'adverbe de phrase à fonction évidentielle.

\section{Dire bas}

I. Dire à voix basse, en murmurant Transitif

1170 Mout par li fait Jason grant joie ; Soëf, basset, que l'om ne l'oie, [variante : bassez]

Li dist : Vassaus, ne tenez mie

A mauvaistié n’a legerie,

Se a vos me vieng acointier (Benoit de Sainte Maure, Le Roman de Troie, 1312)

1177 « Ja, ce croi, ne me leississiez

Sanz chalonge mener un pas !»

Mout le cuida avoir dit bas,

Mes li cuens Guinables l'öi, Qui au monter fu pres de li

(Chrestien de Troyes, Lancelot ou Le Chevalier de la charrete, 214)

+1250 La roïne l'anel li tent,

Et Renart volenters le prent.

Entre ses denz basset a dit

Certes qui unques ne le vit

L'anel, por voir le comparra (Le Roman de

Renart [2e moitié XIII ${ }^{\mathrm{e}}$, I, 1455)
1285 Pour ce en verité retint

Que il Cleomadés estoit,

Sa prouece li tesmoignoit.

Basset a dit : Mout sui joians,

Quant Cleomadés sui servans

(Adenet le Roi, Cleomadés, 13301)

1340 Suer Ysabel. Chiére dame, nous trois ensamble

La dirons, s'il vous plaît, tout bas.

Seez vous hault et nous en bas

Entre vos piez

(Miracle de l'abbeesse grosse, 675)

1357 L'ABBESSE. Pour estre a nous mains ennuiant,

Tout bas disons (Miracle de Theodore, 207)

+1415 Raison s'en rit, disant tout bas :

Escoutez moy ces malleureux !

(Charles d'Orléans, Poésies [ 1415-1440],

II, Rondel LXXIII, p. 331)

1515 Et encor ce qui leurs faisoit pis, c'estoit le tabourin, qui nullement ne se vouloit contenir et disoit tout bas que, par la chair bieu, il sortiroit (Philippe de Vigneulles, Les Cent Nouvelles nouvelles, p. 382, 99)

1596 Ma bouche à haute voix chante assez liberté,

Et dit que je suis franc d'Amour, mon adversaire ;

Mais mon cœur languissant tout bas dit le contraire,

Soupirant sous le joug d'une fiere beauté (Philippe Desportes, Euvres)

1627 Mais elles, feignants de ne recognoistre point son artifice, proferoient entr'elles assez haut des paroles pleines d'admiration qu'elles faisoient toutesfois semblant de vouloir dire bas (Honoré d'Urfé, L'Astrée)

1629 car quoy que je sceusse bien qu'il se devoit faire des jeux d'escrime les jours suivants, et qu'elle vouloit peut-estre parler des prix qui s'y donneroient, lesquels je me devois promettre de mon adresse, si est-ce qu'oyant une si grande Princesse, me dire bas en l'oreille une chose que le pur et simple effect de la courtoisie luy pouvoit 
faire dire tout haut, je fus contraint de prendre une civilité si grande et si extraordinaire, pour tesmoignage de sa bonne volonté, qu'elle me fit depuis assez parestre (François de Boisrobert, Histoire indienne d'Alexandre et d'Orazie)

1667 CÉLIMÈNE. C’est de la tête aux pieds un homme tout mystère,

Qui vous jette en passant un coup d'œil égaré,

Et, sans aucune affaire, est toujours affairé. Tout ce qu'il vous débite en grimaces abonde ;

À force de façons, il assomme le monde ;

Sans cesse il a, tout bas, pour rompre l'entretien,

Un secret à vous dire, et ce secret n'est rien ;

De la moindre vétille il fait une merveille,

Et jusques au bonjour, il dit tout à l'oreille (Molière, Le Misanthrope)

1833 Toujours gardée à vue, comme une criminelle d'État, je ne puis seulement te presser la main, te dire un mot bas à l'oreille (Pétrus Borel, Champavert)

1845 Avant que Gabriel se fût retourné, Rodin eut le temps de dire tout bas au révérend père :

- Il ne sait rien, et l'Indien n'est plus à craindre (Eugène Sue, Le Juif errant)

1866 Cela fut dit si bas que Gilliatt seul entendit (Victor Hugo, Les Travailleurs de la mer)

1886 Et Gaud s'excusait, comme étant chargée de sa tenue :

- C'est qu'elle sera tombée, pour être si sale, disait-elle tout bas ; sa robe n'est plus bien neuve, c'est vrai, car nous ne sommes pas riches, Monsieur Yann ; mais je l'avais encore racommodée hier, et ce matin quand je suis partie, je suis sûr qu'elle était propre et en ordre (Pierre Loti, Pêcheur d'Islande)

1907 Il dit, tout bas :

- Je ne partirai pas (Romain Rolland, Jean-Christophe. La Révolte)
1913 Cette fois, le jeune homme salua, en disant très bas :

- Voulez-vous me pardonner?

(Alain-Fournier, Le Grand Meaulnes)

1932 Une vraie scène de famille... Elle a comme réfléchi un bon coup et puis elle l'a dit plus bas, mais tu sais alors elle l'a dit et puis de tout son cœur «Assassin! Assassin! » qu'elle m’a appelé. Ça ma refroidi un peu (Louis-Ferdinand Céline, Voyage au bout de la nuit)

1979 Ce qui nous est dérobé de la nature et des hommes est incommensurable ; ce que nous en recueillons est minime tant les deux disent bas leurs secrets (René Char, Fenêtres dormantes et porte sur le toit)

1996 Même au moment où ma réputation fut telle qu'il était devenu à peu près inutile d'essayer de me faire passer pour « bonne à marier ", je ne pouvais entrer nulle part sans que ma mère me dise tout bas : "Souris, une jeune fille doit sourire », et elle-même arborait une espèce de pauvre grimace (Marguerite Duras, Cahiers de la guerre et autres textes)

1997 Le général, il était blême, il a dit tout bas : «Son apparition annonce ma mort prochaine », et il est allé dormir ailleurs (Patrick Rambaud, La Bataille)

2000 Alors Marie demande à nouveau combien et le gérant dit tout bas un prix bien plus bas que celui qu'il donnait tout à l'heure, si bien qu'il nous a mises dans sa poche, comme prévu, pour une bouchée de pain quotidien (Anne-Marie Garat, Les Mal Famées)

Pronominal

1698 ne voyant point paroître leur cadet, ils s'applaudissoient de sa négligence, et se disoient tout bas l'un à l'autre : voilà qui est bien heureux, il est mort ou malade, il ne sera point notre rival dans l'affaire importante qui va se traiter (Marie-Catherine d'Aulnoy, La Chatte blanche)

1755 Au fier aspect de cet animal pie le cordelier riant d'un ris malin se dit tout bas, cet 
homme est Jacobin (Voltaire, La Pucelle d'Orléans)

1833 Quand le flot me maudissait dans ma barque, l'orage dans mon sentier, l'épée dans son fourreau, la foudre sur ma tête, ils se disaient tout bas : prenons garde de le toucher, puisque les doigts du Christ l'ont touché avant nous (Edgar Quinet, Ahasvérus)

1886 De temps en temps, il lui montrait d'un signe sa petite sœur Marie et Sylvestre, les deux fiancés, qui dansaient ensemble. Il riait, d'un air très bon, en les voyant tous deux si jeunes, si réservés l'un près de l'autre, se faisant des révérences, prenant des figures timides pour se dire bien bas des choses sans doute très aimables (Pierre Loti, Pêcheur d'Islande)

1979 Mais dès qu'on le laissait seul, il regardait seulement couler le temps qui l'éloignait un peu plus chaque jour. Qui l'éloignait de quoi ? Il se disait tout bas : d'avant. Ce n'était pas un bonheur disparu qu'il regrettait, mais le plus jamais de l'autrefois (Claude Roy, La Traversée du Pont des Arts)

Emploi absolu

$1701 \mathrm{Du}$ soin d'aider le pauvre on dispensa l'avare ;

Et même chez les Rois le superflu fut rare.

C'est alors qu'on trouva pour sortir d'embarras,

L'art de mentir tout haut en disant vrai tout bas.

C'est alors qu'on aprit qu'avec un peu d'adresse,

Sans crime un Prêtre peut vendre trois fois sa Messe

(Nicolas Boileau, Satires [1664-1701])

II. Dire quelque chose secrètement

Pronominal

1694 Si tout votre discours n'est obscur, emphatique,

On se dira tout bas : " C'est là ce bel esprit?»

Tout comme une autre elle s'explique,

On entend tout ce qu'elle dit

(Antoinette Des Houlières, Épîtres)
1747 VALÈRE. Lise a quitté le rouge, et l'on se dit tout bas

Qu'elle ferait bien mieux de quitter Licidas (Jean-Baptiste Gresset, Le Méchant)

1830 Qu'elle m'aime huit jours, huit jours seulement, se disait tout bas Julien, et j'en mourrai de bonheur (Stendhal, Le Rouge et le noir)

1900 ces femmes me sont odieuses; je les déteste, et je me dis tout bas que je n'ai rien de commun avec elles... l'éducation, le frottement avec les gens chics, l'habitude des belles choses, la lecture des romans de Paul Bourget m'ont sauvée de ces turpitudes... ah! (Octave Mirbeau, Le Journal d'une femme de chambre)

Transitif

1898 LE BRET (après un silence, passant son bras sous le sein)

Fais tout haut l'orgueilleux et l'amer, mais, tout bas, dis-moi tout simplement qu'elle ne t'aime pas!

(Edmond Rostand, Cyrano de Bergerac)

CORPUS WEB :

je viens d'entendre la journaliste de BFM dire tout bas "putin " [http://www.jeuxvideo. com/forums/42-51-38099496-1-0-1-0-je-viens-dentendre-la-journaliste-de-bfm-dire-tout-basputin.htm] (1.2.2015)

Ce n'est pas de le dire tout bas, car crois moi j'aimerais bien avoir une discussion d'homme à homme avec Flamby ! [https://fr.answers.yahoo. $\mathrm{com} /$ question $/$ index?qid $=20141123003020 \mathrm{AAg}$ piM5] (1.2.2015)

vous savez il y a ceux qui clament tout haut que la thèse officielle ne peut tenir la ligne et ceux qui la disent tout bas entre 2 lignes comme je me suis laissée entendre par un attaché (intelligence ?) militaire Français que ce n'est pas Ben Laden et que ca se sait tres bien [http://archives. plumedepresse.net/spip.php?article1334] (1.2.2015)

REMARQUES : Dire bas (I) réfère au fait de communiquer quelque chose à quelqu'un en baissant la voix afin de ne pas être entendu de personnes non concernées. (II) désigne le fait d'exprimer par la parole un propos que l'on tient à garder 
secret. Il est souvent employé sous sa forme pronominale, le sujet voulant garder l'information exprimée pour lui-seul. Bas reste invariable et est modifié par bien, plus, presque, si, tout, très. L'exemple de 1701 combine deux adjectifs-adverbes dans dire vrai tout bas. Notons l'emploi de mentir tout haut (mentir haut), faire tout haut (faire haut 'faire semblant d'être') ; clamer haut. VoIR AUSSI : parler bas

\section{Dire beau (bel)}

Dire de façon éloquente, avec de belles paroles Transitif

-1200 Et Floovanz li dit bel et cortoisemant : «Sire, ce ne pout estre, sachez certenemant » (Floovant [fin XII ${ }^{\mathrm{e}}$, 2221)

+1250 Tybert a dit apres le vers, Renart li respont a envers. Puis dit Tybert en sa reison Moult bel Dominus vobiscum (Le Roman de Renart [2e moitié XIII ${ }^{\mathrm{e}}$, 874, XII)

1275 Quant furent pres des tentes, Malaquins s'arresta, Bel et courtoisement lor dist et devisa C'un petit l'atendissent car il revenroit ja. Hastés vous, dist Gerars, car ja ajournera (Adenet le Roi, Buevon de Conmarchis, 3643)

+1350a Tant chevaucha de jor et de nuit ensement Qu'il trouva des barons du seigneur jusqu'a cent,

Et les assembla touz a .i. avesprement, Puis leur dit en oiant bel et courtoissement : «Seigneur, entendez moy, oiez le mandement

Que mes sire vous mande a tous communaument» (Brun de la Montaigne [2 moitié XIV $]$ ], 71)

+1350b A genous se mist moult grascïeussement, Sa dame salua bien et honnestement Et li dit bien et bel : Chiere dame au cors gent,

Me [s]ire vous requiert a cel

commancement

Ceste premiere lance ; or vos veigne a talent (Brun de la Montaigne [ $2^{\mathrm{e}}$ moitié XIV ${ }^{\mathrm{e}}$, 2092)
1663 GROS-RENÉ. M’oses-tu bien encor parler, femelle inique, Crocodile trompeur, de qui le cœur félon Est pire qu'un satrape ou bien qu'un Lestrygon?

Va, va rendre réponse à ta bonne maîtresse, Et lui dis bien et beau que, malgré sa souplesse,

Nous ne sommes plus sots, ni mon maître, ni moi,

Et désormais qu'elle aille au diable avecque toi (Molière, Dépit amoureux)

Emploi absolu

+1200 Por seulement de biau parler

Puet l'en mout grant los acueillir.

Quar qui biau dit, biau veut oür,

Et qui mal dit et qui mal fait, Il ne puet estre qu'il ne l'ait (La Housse partie, 50)

REMARQUES : Dire bel réfère au fait d'énoncer un propos en choisissant bien ses mots, de façon à impressionner ou persuader son interlocuteur. La coordination de bel avec bien et courtoisement souligne sa fonction adverbiale. Le masculin-neutre beau tend à remplacer le neutre bel à partir du moyen français. Dans l'exemple de 1663, l'emploi en coordination syntaxique avec l'adverbe bien confirme que beau succède diachroniquement au neutre dans la fonction adverbiale; dans cet exemple, bien et beau a le sens moderne de 'bel et bien'. En ancien français, bel 'bien' s'opposait à beau 'joli', en ce qui concerne leur emploi au sein du groupe verbal. Ceci est mis en évidence par l'exemple de +1200 , en l'occurrence dans le dicton : qui biau dit, biau veut oïr. Biau parler dans l'exemple de +1200 pourrait être une nominalisation du groupe verbal.

\section{Dire blanc}

I. dire (prononcer, voir) blanc et dire (répondre, entendre, faire) noir : dire une chose et son contraire Emploi absolu

+1366 Garde toy de l'oisel flatant, Car il te cuide decepvoir ; S'il te dit blanc, respons lui noir (Eustache Deschamps, Euvres complètes [3 $3^{\mathrm{e}}$ tiers XIV $\left.\left.\mathrm{X}^{\mathrm{e}}\right]\right)$ 
1396 Parlons de ces traitres, et premierement de flateur mensongeur. C'est comme l'enchanteur du dyable qui fait apparoir ce qui n'est pas, dit de blanc noir et de noir blanc, et tourne en folie et frenesie ceulx et celles qui le recoivent, quer il occist Verité ; et quant Verité fault, Erreur et Fausseté s'i boute (Jean Gerson, Sermon pour la fête de l'annonciation)

1623 donques il n'y a point d'escriture saincte, depuis qu'on void un tel desordre parmy les esprits, que les uns disent blanc et les autres noir, que ceux-cy reçoivent ce livre pour canonique, et ceux-là le renvoyent comme estant apocryphe (François Garasse, La Doctrine curieuse des beauxesprits de ce temps)

1701 Souvent, j'ay beau réver du matin jusqu'au soir :

Quand je veux dire blanc, la quinteuse dit noir (Nicolas Boileau, Satires [1664-1701])

1719 C'est bien la peine d'imprimer.

C'est ainsi que chaque rencontre

Vous voit changer de mesure et de poids ; Disant blanc ou noir ; pour ou contre (Antoine Houdar de La Motte, Fables)

1764 Cela seroit contre toute raison quant au législateur ; parce qu'alors toute la solemnité des loix seroit vaine et ridicule, et que réellement l'État n'auroit point d'autre loi que la volonté du petit conseil, maître absolu de négliger, mépriser, violer, tourner à sa mode les regles qui lui seroient prescrites, et de prononcer noir où la loi diroit blanc, sans en répondre à personne

(Jean-Jacques Rousseau, Lettres écrites de la montagne)

1845 - Ceci me fait souvenir, mesdemoiselles, qu'hier vous avez chuchoté tout le long de l'étape... et quand je vous disais blanc, vous me répondiez noir (Eugène Sue, Le Juif errant)

1863 Je suis comme toi, tu vois bien, je perds la boule ; je dis alternativement blanc et noir (Gustave Flaubert, Correspondance)
1875 PATUREL. C'est non quand je dis oui, oui quand je dis non, noir quand je dis blanc, blanc quand je dis noir... une contradiction perpétuelle, une bataille de tous les instants... si nous allons au théâtre ensemble, elle trouve bête la pièce qui m’amuse, elle s'amuse à la pièce qui me paraît idiote (Henri Meilhac et Ludovic Halévy, La Boule)

1914 Non contents de différer sur des points graves, les deux ministres se contredisaient, l'un disant blanc, l'autre disant noir, et leur lutte intestine naturellement ignorée du peuple français, c'est-à-dire du maître et du souverain, était connue de toute l'Europe (Charles Maurras, Kiel et Tanger)

1918 Alors le général vit qu’ils étaient trop nombreux. Il avait nom Peyre; on en a dit blanc et noir, comme de tous les hommes qui tinrent la queue de la poêle en ce temps-là, mais il était honnête et avait des moyens. Voyant donc le nombre des brigands, il fit sonner la charge pour les effrayer et battit en retraite (Anatole France, Le Petit Pierre)

1954 On préfère l'aveu. " Vous avez dit blanc, vous ne pouvez plus dire noir » et personne ne songe que c'est précisément parce qu'on a dit blanc qu'on peut dire noir et zut (France observateur, 25 février 1954 / Grundt : 251)

1960 FRANTZ. (très sec) Sais-tu qu'il m'arrive de dire blanc quand je veux leur faire entendre noir? (Jean-Paul Sartre, Les Séquestrés d'Altona)

2012 C'était à qui crierait le plus fort. Quand les uns disaient blanc, les autres répondaient noir, un ton au-dessus (Stéphane Osmont, Éléments incontrôlés)

II. Dire sciemment le contraire de quelque chose

Emploi absolu

1863 Il n'y a pas d'art sans liberté, car l'art est une expression de la pensée ; et qu'est-ce donc que l'expression de la pensée, si vous êtes contraint à répéter ce que dit votre voisin, ou à dire blanc quand vous voyez 
noir ? (Eugène Viollet-Le-Duc, Entretiens sur l'architecture)

1896 C'est ainsi qu'aujourd'hui, comme nous nous levions

Après une nuit belle, et que nous nous devions,

Depuis trois fois que nous étions forcément sages,

Tu t’avisas, dans le plus prude des langages Mitigé d'ailleurs par ton air naïf et franc, De me blâmer de faire noir ayant dit blanc, Et dédier ma chair d'homme à la chair des femmes

En des rapprochements nombreux et polygames

(Paul Verlaine, Euvres poétiques complètes)

CORPUS WEB :

Dire blanc et faire noir : la spécialité de la FDSEA87!

Dans son journal de campagne, la liste FDSEA-JA de la Haute-Vienne fait de la défense du revenu des agriculteurs sa principale préoccupation. La CR87 et ses candidats de la liste « Changer, c'est vital » sont heureux de voir que leur opposants se réveillent enfin! [http://www. coordinationrurale.fr/comment-la-fdsea87-oseparler-de-revenu.html] (1.2.2015)

La gauche clamait sa volonté de rétablir la laïcité bafouée par la droite. Elle n’en fait rien. C'est insupportable. Elle tient des discours de droite pour acheter les voix de la droite. Dire blanc et faire noir, c'est pousser les gens à s'abstenir, ce qui n'est déjà pas bien, ou à voter Front national [http://www.sudouest.fr/2014/12/12/lalaicite-en-debat-ce-vendredi-avec-henri-penaruiz-1766508-3536.php] (1.2.2015)

En société, la Sagittaire adore caracoler, et tant pis si cela doit l'amener à être plus snob que sincère. De toute façon, cette pragmatique sera toujours capable de dire blanc et noir sans s'emmêler dans ses pinceaux [http://www.style listquebec.ca/2014/01/19/horoscope-2014-droleet-cruel-3e-partie] (1.2.2015)

Les couleurs ont un goût de bleu, sentent le jaune, sont rouge au touché, se voient en blanc et parfois elles peuvent s'entendre noir [http://www. saithbautistaart.com] (24.3.2015) oui Il est l'homme du mensonge qui nous dit blanc il faut entendre noir [http://www.bfmtv. com/politique/la-perte-du-aaa-un-obstacle-surla-route-de-nicolas-sarkozy-217779/avis $/$ ?page= 30] (24.3.2015)

Le plus dur est de confronter l'être avec le paraitre, entendre noir alors que l'on ressent blanc est parfois difficile à gérer et croyez moi il faut avoir la foi [http://niombrenilumiere.forum gratuit.org/t1184p30-un-petit-peu-bizarre] (24.3.2015)

REMARQUES : Au figuré, dire blanc s'oppose à dire noir, c'est-à-dire son contraire, formant un schéma lexicalisé qui désigne un comportement contradictoire. (I) désigne le fait d'énoncer un propos et son contraire, celui-ci pouvant être émis par la même personne ou non, les énoncés opposés étant représentés par les antonymes blanc et noir. (II) décrit la situation dans laquelle la chose dite ne coïncide pas avec l'action effectuée (dire blanc et faire noir), ou avec la perception de la réalité (voir blanc et faire noir). Le CW met en évidence la productivité du schéma qui admet aussi d'autres verba dicendi et sentiendi qui s'opposent souvent à ce qui est fait (faire noir). Dire blanc est ainsi mis en opposition avec répondre noir, prononcer noir, entendre noir, faire noir, voir noir. Ces exemples montrent que l'opposition blanc : noir se retrouve dans une série assez ouverte de verbes. Dans le quatrième exemple du CW, s'entendre noir s'emploie dans un sens concret et métaphorique à la fois, évoquant éventuellement des sentiments noirs, sans l'opposition avec blanc (ici : en blanc), dans lesquels se voit baigner celui qui perçoit cette mer de couleurs. Blanc et noir restent invariables. Dire blanc / noir ne se prêtent pas à la modification (* plus blanc / noir), mais on trouve le modifieur alternativement pour les contraster. Notons l'emploi de ressentir blanc. VoIR AUSSI : répondre noir ; d'autres exemples sous dire noir

\section{Dire bref}

Dire brièvement, de manière concise Transitif

1341 SECOND MENESTERÉ. Voirment yrons nous de cuer baut.

Mais, $d y$ nous brief, sanz delaier, Ou l'en doit ainsi festaier : 
Est ce une noce? (Miracle de l'evesque que l'arcediacre murtrit, 635)

-1342 Or te vueil dire brief et court De quoy il servent a ma court (Guillaume de Machaut, Le Dit dou vergier, 629)

+1400 A brief dire, sans jamais le ravoir, Toute m'amour je vous octroye en don (Christine de Pisan, Cent balades d'amant et de dame / Euvres poétiques [début $\mathrm{xV}^{\mathrm{e}}$ ], III, p. 235, 23)

1579 LUCIAN. Le suc de nos melliflus propos est à bref dire ce que chante l'Eclesiaste : Cum sancto sanctus eris, et cum perverso perverteris. Ideo, Cato, cum bonis ambula (Pierre de Larivey, Le Laquais)

1828 FAUST. Monsieur le magister, laissez-moi en paix ; et je vous le dis bref et bien : si la douce jeune fille ne repose pas ce soir dans mes bras, à minuit nous nous séparons (Gérard de Nerval, Faust [trad.])

1837 Il m’a donc dit ce matin à l'amphithéâtre que... que... eh bien, que le censeur des études M. C qui [a] une chemise sale, des bas sales, une âme sale, et qui enfin est un salop, il m'a dit bref qu'il avait été surpris dans un bordel et qu'il allait être traduit devant le conseil académique (Gustave Flaubert, Correspondance)

CORPUS WEB :

Tout ça pour dire bref, que contrairement à ce que tu penses, je ne suis pas une si méchante fille pour t'en vouloir jusqu'à ta mort et comme tu t'es justifié de façon correcte, je passe à mon tour l'éponge [http://forums.mangas-fr.com/index. php?topic=40797.610;wap2] (1.2.2015)

Dsl andie c que je t'ai souvent écrit et j'ai pas eu de réponse pas personnellement juste te dire bref que tu es vraiment une chanteuse ACCOMPLI continue !! [https://fr-fr.facebook.com/ andieduquette/posts/497504850371684] (1.2.2015)

Puis, une de mes amies regarde le prix et me demande, sourir en coin, d'essayer de le deviner... $167000 \$$ !!! (Je crois que l'équivalent en euro soit de +/- 115000 euro) Disons, pour dire bref, que je me sentais presque gêné d'y toucher... Ah oui ! [http://www.pianomajeur.net/forum/viewtopic. php?f=1\&t=859] (1.2.2015)

REMARQUES : Dire bref désigne le fait d'énoncer un propos en employant peu de mots, donc en peu de temps. Notons l'expression à dire bref ainsi que la collocation bref et court, renforçant le sémantisme. Bref (brief) reste invariable. L'exemple de +1400 , à brief dire 'pour tout dire', reflète le développement vers une fonction de marqueur du discours de récapitulation correspondant au français moderne bref (ex. Bref, il n'était pas content) et enfin bref (ex. Enfin bref ! au sens de 'il n'y a rien à faire, c'est comme ça, il faut l'accepter'). Bref reste invariable.

\section{Dire brut}

Dire (quelque chose) sans ménagement, brutalement

入 dire $\mathrm{cru}$

\section{Dire clair}

Dire clairement, distinctement, explicitement

Transitif

1100 Cler en riant l'ad dit a Guenelun :

« Tenez m'espee, meillur n'en ad nuls hom ;

Entre les helz ad plus de mil manguns.

Par amistiez, bel sire, la vos duins,

Que nos aidez de Rollant le barun,

Qu'en rereguarde trover le poüsum » (Chanson de Roland, 619)

+1100 Ele avoit le chief blondet,

Si faisoit un chapelet

Et disoit ceste chancon

Molt haut et seri et cler

« Robeconet, la matinee

Vien a moi joer » (Romances et pastourelles

françaises des XII et XIII ${ }^{e}$ siècles, p. 283)

1365 La Royne i entra, puis prist à apeller

Son gentil maronnier, si li dist haut et cler : Biaus maistrez, je vous pri que nous voelliez mener

Droitement à Boulongne, car g'i voel arriver (Li Romans de Bauduin de Sebourc, Chant III, 193)

1450 SAINT PIERRE. Si grant courroux en moy se boute 
Que boire ne mengier ne puis.

Pour Dieu, mon maistre, se je suis

Celuy qui vostre mort procure,

Dictes le au plain [variante : dictes le cler],

car je n'ay cure

Que me cellez ung tel meffait,

Affin, se j'ay vers vous meffait

Tous mes compaignons me destruisent

(Arnoul Gréban, Le Mystère de la Passion, 18132)

1538 Lors Renommée avec ses esles painctes Ira volant en bourgs et villes maintes, Et sonnera sa trompette d'argent,

Pour autour d'elle assembler toute gent ;

Puis hault et clair de cent langues qu'elle a

Dira ta vie ; et puis deçà et là

Ira chantant les fins tours dont tu uses,

Tes laschetez, tes meschances et ruses

(Clément Marot, Élégies)

1560 Qui plus est, que plaidons-nous du sens de ces parolles, comme s'il estoit obscur ou douteux, veu qu'on ne sauroit rien dire plus clair ne plus certain? (Jean Calvin, Institution de la religion chrestienne)

1604 Tu le dis haut et clair et d'une voix certaine, En branlant le Laurier dont ton chef est orné (Antoine de Montchrestien, Hector)

1866 J'aime cette vie saine et franche, et cet homme droit et naturel, qui raconte ses trente années de paysannerie et ses vingt et une années de régisseur rural, suivies de la période d'instituteur et d'écrivain chasseur, et raconte tout cela sans gloriole ni fausse honte, d'un parler sobre et net, qui va droit au but et dit clair ce qu'il veut dire (Henri-Frédéric Amiel, Journal intime de l'année 1866)

1920 Le meilleur repas m'est, je vous le dis tout clair, une chose odieuse, s'il me faut l'avaler, par exemple, sur l'air de la " veuve joyeuse » (Raoul Ponchon, La Muse au cabaret)

\section{CORPUS WEB :}

Pour dire clair, on aura du mal à cerner toutes ces comptines, et c'est tant mieux, car notre bonhomme n'aime rien tant que ces mots impressionnistes, comme lorsqu'on fixe de très près une tache sur le sol, et que la couleur finit par perdre ses contours [http://www.amazon.fr/ Clair-Jp-Nataf/dp/B002OFG5LC] (1.2.2015)

Ils ne font qu'exécuter un ordre qui leur est transmis par le parquet. Donc pour le dire clair et net : eux n'y sont pour rien! [http://www.ances. lu/index.php/55-radelux/166-le-placement-desenfants-et-l-intervention-des-forces-de-l-ordrela-force-de-la-loi-ou-la-loi-de-la-force] (1.2.2015)

Résolument installé dans la mouvance des penseurs au dire clair et franc, ses thèses proposent une véritable armature de compréhension du fait négrier et colonial à la base du peuplement nouveau des Caraïbes [http://www. rogertoumson.com/2.html] (1.2.2015)

Je vais te la dire clair et net, la Russie n'est pas une democratie, les droits de l'opposition n'y sont pas du tout respectés et Poutine fait ce qu'il veut dans le pays ! [http://forum. olweb.fr/showthread.php?152439-Actualit\%E9sinternationales/page27] (1.2.2015)

Certes il est plus facile de communiquer le commun et donc de prétendre à une idée claire puisquechacuns'accordera àla dire claire [https:// www.google.fr/\#q=\%22la $+<$ dire $+<$ claire $\% 22$ ] (1.2.2015)

Remarques : Dire clair désigne le fait de communiquer quelque chose, d'énoncer un propos à quelqu'un d'une manière claire, que ce soit en prononçant distinctement ou en tenant des propos sans ambiguïté. Notons la collocation haut et clair, traduisant l'idée d'élévation de la voix pour que ce soit entendu de tout le monde. L'usage actuel dans le CW tend à employer la collocation clair et net, avec la variante analogique clair et franc. Clair reste invariable et est modifié par moult, plus, tout. Il s'accorde cependant avec l'objet au féminin dans le dernier exemple du CW ; clair insiste alors sur la clarté de l'idée. Le même effet s'observe avec le masculin dans l'exemple de 1560 , où le français moderne pourrait remplacer ne saurait rien dire plus clair par ne saurait rien dire de plus clair. Ces deux exemples marquent le passage de la fonction d'adverbe de manière dans dire clair à la modification de l'objet direct, ce qui explique aussi la flexion dans le dernier exemple, qui met en avant la clarté d'une idée. Notons la nominalisation des verbes dans 
le troisième exemple du CW. Notons également l'emploi absolu dans le premier exemple du CW. Mentionnons également l'emploi de aller droit au but. VoIR AUSSI : confesser clair

\section{Dire compréhensible}

S'exprimer clairement

$\pi$ dire juste

\section{Dire court}

I. Dire rapidement, brièvement, simplement Emploi absolu

1340 Je me rens confesse et coupable A Dieu le pére esperitable, Qui pour nous en croiz mort souffri, Et a sa doulce mére aussi Et des cieulx a toute la court, Sire, et a vous, pour dire court, Conme celle qui a meffait Contre Dieu trop vilain meffait (Miracle de l'abbeesse grosse, 1121)

Transitif

-1342 Or te vueil dire brief et court De quoy il servent a ma court (Guillaume de Machaut, Le Dit dou vergier, 629)

1364 Se savoir vuelz pour quel raison Je fui bannie de sa court, Je le te dirai brief et court (Guillaume de Machaut, Le Livre du voir dit, 7816)

+1480 A le vous dire brief et court, Parleray je de gens de court $\mathrm{Ou}$ praticiens en court laye ? (Sermon nouveau d'ung fol changant divers propos [ 1480-1490], 123)

1500 La court est une estrange beste : Pour le vous dire brief et court, Il est bien fol qui la acourt Pour y trouver tous les jours feste (Antitus, Poésies)

1560 Il ne nie pas que ce ne soit un Concile légitime, mais il dit plat et court qu'il a peu errer (Jean Calvin, Institution de la religion chrestienne)

1601 et, pour le dire plus court et plus clairement, c'est que le temperament du cerveau, duquel a esté tant parlé cy-des- sus, par lequel et selon lequel l'ame agist, est divers et changeant ; et estant bon pour une fonction d'ame, est contraire à l'autre (Pierre Charron, De la sagesse)

II. dire tout court : Dire sans plus, tout simplement; nommer tel quel

Transitif

-1456 Les seigneurs françois que le roy lui avoit bailliés pour lui servir ne l'en peurent destourner, lors lesdits seigneurs poulains lui dirent tout court qu'ilz ne le serviroient plus en tel estat (Antoine de la Sale, Jehan de Saintré, p. 157, 29)

1515 Et ce fait, s'en alla au lict, auquel il ne fut pas demeye heure que le ventre petit à petit luy racommence à faire mal et tant que aprés pluseurs parolles qu'ilz eurent, luy et sa femme, il luy dit tout court qu'il estoit force qu'il allaist encor au retraict (Philippe de Vigneulles, Les Cent Nouvelles nouvelles, $\mathrm{p} .315,140$ )

1619 Mais je vous dis nettement et sans exception, ne vous courroucés point du tout, s'il est possible, et ne recevés aucun pretexte quel qu'il soit pour ouvrir la porte de vostre cour au courroux ; car saint Jacques dit tout court et sans reserve, que l'ire de l'homme n'opere point la justice de Dieu (Saint François de Sales, Introduction à la vie dévote)

1669 MONSIEUR DE SOTENVILLE. Doucement, mon gendre. Apprenez qu'il n'est pas respectueux d'appeler les gens par leur nom, et qu'à ceux qui sont au-dessus de nous il faut dire "Monsieur » tout court (Molière, George Dandin)

1704 puisque lui-même qui n'ignoroit rien et surtout, qui n'ignoroit pas cette heure dont il estoit le dispensateur, ayant trouvé un costé par où il pouvoit dire qu'il l'ignoroit, parce qu'il l'ignoroit dans son corps et qu'il estoit de son dessein que son dessein que son Église l'ignorast, il dit tout court qu'il l'ignore et nous enseigne à ne rougir pas de nostre ignorance (Jacques-Bénigne Bossuet, Méditations sur l'Évangile) 
1842 Solange est très orgueilleuse de dire Pauline tout court en parlant de vous (George Sand, Correspondance)

1956 Et, renonçant aux moyens dont seul le roman dispose, ils renoncent à ce qui fait de lui un art à part, pour ne pas dire un art tout court (Nathalie Sarraute, L'Ėre du soupçon)

1983 Il aimait apprendre (On disait apprendre tout court, comme boire ou manger) (Annie Ernaux, La Place)

CORPUS WEB :

Et pourquoi doit-on identifier quelqu'un selon sa nation ? Pourquoi pas selon sa citoyenneté et dire tout court qu'il est canadien ? [http:// fr.wikipedia.org/wiki/Discussion:Marc_Favreau] (1.2.2015)

Assumez vos responsabilités jusqu'au bout pour dire tout court, je suis charlie et je ne suis pas musulman [http://senego.com/2015/01/16/ macky-sall-je-ne-peux-pas-cautionner-lapublication-de-charlie-hebdo-dans-mon-paysmusulman-a-95_210600.html] (1.2.2015)

Du coup, Monseigneur Dagens aurait mieux fait de ne rien dire tout court ! ça dénote ces paroles hors coup médiatique.... [http://www. charentelibre.fr/2015/01/12/1-eveque-d-angou leme-scandalise-par-les-bancs-grillages, 1934660.php] (1.2.2015)

Si on n'aime pas la verite soi meme, on a du mal souvent a la dire tout court [http://jesus isthehealer.les-forums.com/topic/123/les-epouxdoivent-tout-se-dire/goto/231] (1.2.2015)

REMARques : Court est un adjectif-adverbe de dimension. Relatif au temps, dire court désignait le fait d'énoncer un propos brièvement, en employant peu de mots ou de dire quelque chose simplement, sans pédanterie, notamment dans la collocation usitée jusqu'en moyen français bref et court. À partir du XVII ${ }^{\mathrm{e}}$ siècle, tout court se lexicalise au sens de 'sans plus, tout simplement', seul présent dans le CW. Dans l'emploi moderne, il peut s'associer syntaxiquement au nom ou au verbe qui le précèdent immédiatement : Pauline tout court (1842), un art tout court (1956), dire « apprendre » tout court (1983). Court reste invariable et est modifié par plus, tout. Notons les variantes dire plat et court, et dire plus court et plus clairement. Ce dernier souligne la fonction adverbiale de court.

\section{Dire cru}

Dire directement les choses, dire directement ce qu'on pense, sans ménagement

Transitif

1781 Voici autre chose, M. le Turc, tous les mouchars, ou, si vous aimez mieux, tous les Mandrins font aux trousses d'un autre sublime Linguet, barbouilleur, qui barboüille à merveille ! qui dit tout cru ce qu'il pense (Mercure Turc)

1823 C'était pour lui un jour d'étonnement : il fut surpris de mon grec. Il me montra luimême un morceau de la Couronne qu'il avait traduit. Nous parlâmes encore de politique et de religion ; et je lui dis tout cru ce que je pensais (Jules Michelet, Écrits de jeunesse)

1831 Je te le dis net et cru, une telle neutralité est à mes yeux un crime envers soi-même, une blessure inguérissable à sa conscience (Alphonse de Lamartine, Correspondance générale)

1836 Je dis tout net et tout cru ce qui me vient (George Sand, Correspondance)

1935 Oh ! à certains moments, oui, ils se surveillent, ou plutôt ils parlent comme on leur a appris qu'il était convenable de parler. Mais à d'autres ils disent tout cru ce qu'ils pensent, ce qu'ils sentent (Jules Romains, Les Hommes de bonne volonté)

1984 Lalaire, à qui j’avais dit tout cru ma façon de penser, avait tenu à nous accompagner à Orly (Evane Hanska, Les Amants foudroyés)

1994 Mais tout cela était assez confus dans sa tête et si quelqu'un s'était avisé de le lui dire tout cru, Francis aurait répondu qu'un couple devait vivre comme cela, que c'était évident, et qu'il était inutile et inconvenant d'en parler (François Delivré, Le Pouvoir de négocier) 


\section{Corpus Web :}

Non mais c'est dur de te dire tout cru comme ça si pour toi c'est une bonne affaire ou non... [http://forum.macbidouille.com/index.php?sho wtopic $=339608 \&$ pid $=3386819 \&$ mode $=$ threaded $\&$ start=] (1.2.2015)

je ne suis pas le genre à mettre les pieds dans le plats, vous me connaissez tout en tact et délicatesse, mousse et pampre... mais là, l'honnêteté m'oblige à vous le dire tout $\mathrm{cru}$, ça sent le gars qui veut se faire sucer [http://www.planete-ducati. com/forum/index.php?topic=18927.10;wap2] (1.2.2015)

En fait, je vais vous le dire tout cru et brut de coffrage : c'est de l'animisme revêtu d'un langage chrétien! [https://actualitechretienne.wordpress. com/2014/07/18/remy-bayle-au-cameroun-il-ya-une-forme-devangile-qui-nest-pas-levangile] (1.2.2015)

le mieux c'est que tu étudies plus sérieusement toutes ces questions de "terrorisme", bien entendu pas sur tfi fr2 etc, la vérité sur le terrorisme, mon petit poulet, je vais te la dire tout cru et tanpis pour tes illusions de justicier à deux balles [https://fr.answers.yahoo.com/question/ index?qid=20070605082656AAtdhdY] (1.2.2015)

le meilleur moyen de cacher la vérité, c'est de la dire toute crue! [http://forum.macbidouille. com/lofiversion/index.php/t31534.html] (1.2.2015)

REMARQUeS : Employé presque exclusivement dans la collocation dire tout cru, le groupe désigne le fait d'énoncer un propos sans altération et sans détours, d'exprimer les choses telles qu'elles sont, sans fard, ni affectation, avec franchise et naturel. Notons les collocations dire net et cru, et cru et brut, renforçant le sémantisme. $\mathrm{Cr} u$ reste invariable dans la plupart des cas. Il s'accorde cependant avec l'objet au féminin dans le dernier exemple du CW, se rapprochant ainsi d'un prédicat second orienté vers l'objet ; l'accord y est appuyé par le féminin toute.

\section{Dire direct}

Dire directement, sans ambages

$\lambda$ aller direct

\section{Dire droit}

I. Dire le droit (substantif)

Transitif

$\sim 1160$ As ne sorent trover nul home

Qui miauz en sache dire droit

que Paris, qui el bois estoit (Eneas, 115)

+1233 Seignor, fet il, dites me droit [variantes, éd. Constans : direz me drois / dites ent dreit]

De cest mien traïtor revoit, Savoir qual justice en ferai Ferai le pendre, ou se l'ardrai (Roman de Thèbes [ $2^{\mathrm{e}}$ tiers XIII $]$ ], 7801)

Emploi absolu

1370 Semblabement en ceste vie humaine, ceulz qui font operacions de bonnes choses et de tres bonnes œuvres, il sont $a$ droit dire nobles, excellens et beneurés (Nicole Oresme, Le Livre de Ethiques d'Aristote, I, p. 126)

II. Dire directement, avec franchise, ouvertement, honnêtement

Transitif

1480 A parler de la fureur et violences de leurs bonbardes, ne s'en pourroit droit dire ce qui en est, car c'est la chose la plus impétueuse et mervilleuse qui jamaiz fust ne de quoy on oyt oncques parler a grant paine le peut l'en croyre (Pierre Barbatre, Le Voyage à Jérusalem en 1480)

1844 Pour moi, je ne sais rien inventer et je vous dis tout droit la vérité, vous laissant le choix du mensonge (George Sand, Correspondance)

1850 Pourquoi ne pas dire tout droit à ce Monsieur V. Henry, que je n'agis que par vos conseils et que vous ne me conseillez pas de me fourrer dans sa bagarre ? (George Sand, Correspondance)

1911 Comme il dit tout droit ce qu'il lui importe de dire! (Maurice Barrès, Greco ou Le Secret de Tolède)

1958 Pour soutenir l'histoire [...] on n'a point fait d'effort littéraire. Ça dit, tout droit, tout gros, ce que ça a à dire, strictement (Sélection du Monde, 2-7 mai 1958 / Grundt : 383) 
Pronominal

1701 Tierce, Sexte et None se diront en mesme ordre ; la priere, c'est à dire, le Verset, Deus in adjutorium, puis les Hymnes des mesmes Heures, les trois Pseaumes, la Leçon, le Verset, Kyrie eleison; et ainsi on finira. Si la Congregation est grande, que ces Heures là soient chantées avec Antiennes : et si elle est petite, qu'elles se disent tout droit (saint Benoît, La Regle du bienheureux pere saint Benoist)

\section{CORPUS WEB :}

Fin 2002, Ferrat disait tout droit à rfimusique.com : "Ce qui est pour moi un sujet de satisfaction, c'est d'avoir mis dans la rue des chansons issues de la grande poésie française, en particulier Aragon » [http://www.petitions24. net/forum/15254/start/30800] (2.2.2015)

Nous prenons la parole pour qu'elle sonde, pour qu'elle s'affranchisse, pour qu'elle emporte avec elle le secret des mots anciens, ceux qui pesaient comme la pierre, ceux qui ne se cachaient pas, ceux qui disaient tout droit le poids de leur sens [https://nantes.indymedia.org/ articles/23824] (2.2.2015)

c'est clair que si tu vas chez Cit avec une panne hydrau, il te disent tout droit : « faut pas insister mon bon monsieur ! qd ça commence, on ne sait pas qd ça s'arrête - voyez donc là-bas notre nouvelle C5 à $25000 \mathrm{E}$ ! » [http://www. yaronet.com/posts.php?s=80583] (2.2.2015)

@Akina, je me disait droit la même chose au niveau densité rien qu'un pied à la taille d'un lingot de $20 \mathrm{~kg}$ en plus les reflets ça fait plus feuille d'or que lingot fondu [http://lelombrik. net/12266] (2.2.2015)

REMARQUES : Dire droit (I), où droit est un substantif, ne devrait pas figurer dans ce dictionnaire, en principe, mais les trois citations mettent en évidence une possible transition au sens (II). $\mathrm{Au}$ figuré, dire droit (II) désigne le fait d'énoncer un propos sans altération et sans détours, d'exprimer les choses telles qu'elles sont, sans fard, ni affectation, avec franchise et naturel. Notons les locutions à dire droit ou à droit dire ainsi que l'emploi analogique de dire gros dans l'exemple de 1958, dans un registre populaire. Droit reste invariable. Dans l'emploi moderne, il est générale- ment modifié par l'adverbe d'intensité tout, mais le dernier exemple du CW renoue clairement avec l'usage vieilli (possible régionalisme).

\section{Dire dur}

S'exprimer avec dureté

$\lambda$ dire sec

\section{Dire faux}

I. Dire une chose non conforme à la vérité, mentir

Emploi absolu

1370 Teles vertuz selon lesquelles l'ame dit verité, ou en affirmant ou en noiant, il sont .v. en nombre et sont cestes : art, science, prudence, sapience, entendement. Car suspicion et opinion ne sont pas de cest nombre, pour ce que il avient aucune foiz que par suspicion et par opinion l'en dit faux (Nicole Oresme, Le Livre de Ethiques d'Aristote, II, p. 334)

1601 Et Charles incertain s'ils disoyent faux ou vray, les tenant en son pouvoir, estima qu'il pouvoit mettre en deliberation s'il devoit faire le voyage d'Espaigne, ayant la paix tout par tout : et qu'aussi bien il luy convenoit rompre son armée (Claude Fauchet, Fleur de la maison de Charlemaigne)

1655 Le Diable (dites-vous) est Père de mensonge. Pourquoy donc, l'autre jour, fistesvous brûler ce Magicien, qui ne fut accusé que par le Diable? Car je responds comme vous : « le Diable est Père de mensonge ». Avoüez, avoüez, mon Révérendissime, que le Diable dit vray ou faux, selon qu'il est utile à vostre malicieuse paternité (Savinien Cyrano de Bergerac, Les Lettres)

1668 Mercure, au lieu de donner celle-là, Leur en décharge un grand coup sur la tête.

Ne point mentir, être content du sien, C'est le plus sûr : cependant on s'occupe À dire faux pour attraper du bien : Que sert cela? Jupiter n'est pas dupe (Jean de La Fontaine, Le Bûcheron et Mercure / Fables) 
1684 Cependant, demesme que de deux hommes, dont il y en a un qui dit, Corisque joue, l'autre Corisque ne joue pas, ou dont il y a un qui dit, Corisque joüa hyer, l'autre Corisque ne joua pas hyer, l'un dit vray, et l'autre faux, encore que je ne puisse pas dire lequel des deux dit vray, lequel dit faux, acause que presentement je suis, ou que je fus hyer absent (François Bernier, Abrégé de la philosophie de Gassendi)

1715 - Je ne veux pas m'opiniâtrer contre vous, ajouta Danhasch ; le moyen de vous convaincre si je dis vrai ou faux, c'est d'accepter la proposition que je vous ai faite de venir voir ma princesse, et de me montrer ensuite votre prince (Antoine Galland, Les Mille et une nuits)

1762 Mais quand trompé par son jugement il va plus loin, et qu'après avoir affirmé qu'il voit un bâton brisé, il affirme encore que ce qu'il voit est en effet un bâton brisé, alors il dit faux : pourquoi cela ? (JeanJacques Rousseau, Émile ou De l'éducation)

1774 Car tant que vous ne détruirez pas les faits articulés dans mon supplément : tant que vous ne prouverez pas que j'ai dit faux sur les débats de notre confrontation, sur vos aveux forcés, sur les contradictions de vos interrogatoires ; tant que vous ne laverez pas M. Goëzman de l'infamie d'avoir suborné Lejay, d'avoir minuté la déclaration chez lui, dans sa maison, à son bureau, avant qu'il y eût de procédure entamée, et d'avoir fait et nié les faux remarqués dans ces déclarations [...] je ne suis pas tenu d'user mon temps à vous répondre (Pierre-Augustin de Beaumarchais, Mémoires contre M. Goëzmann)

1776 Allez, allez, leur dit Joseph ; vous êtes des espions. Envoyez quelqu'un de vous chercher votre petit frere ; et vous resterez en prison, jusqu'à ce que je sache si vous avez dit vrai ou faux (Voltaire, La Bible enfin expliquée par plusieurs aumoniers de S.M. L.R.D.P.)

1822 Si l'on m'a dit vrai, que toute ta trace de toi soit séparée, que toute nouvelle de toi soit ensevelie. Si l'on m'a dit faux, je ne fais rien de mal en enfouissant un coffre : ce n'est que du bois enterré (Stendhal, De l'amour)

1835 - Dis-tu vrai ? Répondit Sanréal, enchanté.

- Dans ces choses-là, mon cher, répliqua Roller d'un ton sec et piqué, tu dois savoir que je ne dis jamais faux.

- Est-ce que tu vas me faire des phrases, à moi ? Répondit Sanréal d'un air de spadassin. Nous nous connaissons (Stendhal, Lucien Leuwen)

1851 « Tu veux m’attraper ou tu veux rire, Denise ; ça n'est pas bien ; tu sais qu'il ne faut pas badiner avec les aveugles, parce qu'ils ne peuvent pas voir si on dit vrai ou faux. " Puis, se tournant de mon côté en entendant rire la jeune fille : " dis-moi, Claude, comment elle est " (Alphonse de Lamartine, Le Tailleur de pierre de SaintPoint)

1905 Tenez, voilà qui est décidé, je ne veux plus me « fouiller » l'âme ainsi, vous ne pouvez deviner comme cela me fatigue, m'énerve, m'exaspère dans le doute où je flotte, ne sachant si je dis vrai ou si je dis faux, si je me trompe moi-même en m'excitant aux mots, aux injures que je prodigue à mon esprit et qui une fois votre lettre écrite me laisseront face à face avec mon bleu défraîchi (Georges Bernanos, Lettres inédites)

1936 Occasion encore de se tromper. Ce serait trop beau si les menteurs mentaient toujours ; et il n'y a point de vraisemblance pour qu'un homme que je n'aime point dise toujours faux. Et certes cela s'explique assez déjà par les passions. Nous n'aimons point contredire quand nous aimons, ni approuver quand nous haïssons (Alain, Propos)

1987 - Ça peut aller ? y me colloque, ce vieux singe.

Je dis oui comme quand on sort de chez l'arracheur de crocs, si t'en reste... Mais lui, y se demande pas si je dis vrai ou faux. 
S'assoit à côté. Il est lourd pour un paquet de tibias. Les os morts pèsent peut-être plus que les autres. Va savoir (Jean-Louis Degaudenzi, Zone)

II. Dire avec des intonations fausses, en manquant de naturel

Emploi absolu

1426 Maiz, quant des choses composées

Et à ce propos disposées, Est le triacle, pour certain, Moult précieux et souverain, Maiz qu'il soit fait depuiz dix ans, Ou les acteurs sont faulx disans, Duquel fault prendre chascun moiz, Ou par quinzaines une foiz (Olivier de La Haye, Poëme sur la grande peste de 1348)

\section{CORpus Web :}

Le principe qui déternime le mensonge est non de dire faux, mais l'intention de tromper en disant faux. Il faut donc faire une distinction entre erreur (involontaire) et mensonge (volontaire) [http://www.etudier.com/dissertations/ Qu'Est-Ce-Que-Mentir/95593.html] (2.2.2015)

Mais... c'est bien, nous sommes forcés, ce qui prouve que nous ne pouvons pas dire faux, hein ? C'est que nous sommes forcés d'énoncer des propositions dont nous ignorons nous-même le sens... [http://www2.univ-paris8.fr/deleuze/ article.php3?id_article=266] (2.2.2015)

Quelque sinistre urluberlu pourrait s'amuser à montrer, en mentant, que dire faux et dire vrai sont la même chose ou même que dire faux par intention est préférable à dire faux par erreur [http://www.franceculture.fr/emissionle-gai-savoir-le-mensonge-la-querelle-kantconstant-2013-06-02] (2.2.2015)

REMARQUeS : Dire faux (I) désigne le fait d'énoncer un propos contraire à la vérité ou qui contredit l'existence de quelque chose, la vérité étant connue par celui qui écoute ce propos (l'autre se trompe) ou celui qui le dit (ment). En (II), il renvoie à une certaine fausseté dans le discours, à un manque d'authenticité. Il peut également connoter la fausseté de quelqu'un. Notons la collocation contrastive dire vrai et faux. Faux reste invariable. Il est modifié par jamais, toujours.

\section{Dire ferme}

I. Dire avec fermeté, dire avec certitude ; confirmer fermement

Transitif

1698 Avez-vous dit cela à Dona Juana, dit Isidore ? Je n'y ai pas manqué, répliqua Don Louis, et je lui ai trouvé quelque répugnance à les renvoyer : mais je lui ai dit si ferme qu'il le falloit, et que j'en prendrois le soin, qu'ayant peur que je ne les maltraite, elle m'a dit qu'elle veut le faire ellemême (Marie-Catherine d'Aulnoy, Finette Gendron)

1842 On pourrait bien objecter, pour le fond, que saint Thomas vient là un peu en contrebande, que Saint-Cyran ne l'y aurait pas mis, que Jansénius et lui n'auraient pas dit si ferme que c'était là leur créance ; car ils croyaient que les justes n'ont pas toujours ce pouvoir (Charles Sainte-Beuve, Port-Royal)

1952 ESTRAGON. Il devrait être là.

VLADIMIR. Il n'a pas dit ferme qu'il viendrait (Samuel Beckett, En attendant Godot)

II. Discuter vivement

Emploi absolu

1934 Tout ça, c'est des histoires de femmes, et les histoires de femmes, pour bien les comprendre, faut connaître ce qui se passe sous les jupes de celles qui en débitent. Enfin, ça disait ferme, en pleine rue. Elles en disaient à peu près comme elles tricotent, sans plus d'effort, et sans mettre plus de bon sens dans une parole que dans une maille, comme des poules après l'œuf, ça pouvait se comparer (Gabriel Chevallier, Clochemerle)

\section{Dire fort}

I. Dire en élevant fortement la voix Transitif

+1350 .I. chevalier i ot c'om apeloit Bruiant, Que Butor tenoit bien a tout le plus sachant ;

Si a dit a Butor moult fort en soupliant : " Baro[n], sire Butor, et qu'alez vous pensant? »

(Brun de la Montaigne [2e moitié XIV $]$ ], 505) 
1450 BELZEBUTH. Sathan, tu nous metz en grant doubte

Et sur le point de desconfort.

SATHAN. Encor vous diray je plus fort :

Ceste vierge a eu ung enffant,

Et si n'ay sceu comment ne quant (Arnoul

Gréban, Le Mystère de la Passion, 7325)

1882 Sa voix montait peu à peu, emplissait la pièce de cris aigus, lorsque tous deux entendirent brusquement, derrière leur dos, quelqu'un dire très fort :

- Madame ! (Émile Zola, Pot-Bouille)

1893 Quand messieurs les journalistes sont forcés de me nommer, de rompre, une minute, le silence concerté qu'ils croient si mortel, ils n'ont à dire que cela et ils le disent le plus fort qu'ils peuvent (Léon Bloy, Journal 1 : Le Mendiant ingrat)

1931a Comme ça on a monté la montée du village au plateau et tout le long, à tous ceux qu'on rencontrait on disait bien fort : «Bonjour, monsieur ! (Jean Giono, Le Grand troupeau)

1931b Et j'y ai pensé, patron, je te le dis, tant fort, que ça m’a brûlé (Jean Giono, Le Grand troupeau)

1995 De son coin, assez fort, il dit : « Bonjour !» Les gendarmes, occupés à secouer la neige de leurs bottes, n'avaient pas remarqué sa présence et cherchèrent des yeux qui avait parlé (Emmanuel Carrère, La Classe de neige)

2005 J'ai soudain une envie folle de refaire de l'équitation.

Suit le deuxième message.

Vous dites assez fort : « Moi, accessoirement, je t'aime. »

Je ris (Anne Brochet, Trajet d'une amoureuse éconduite)

2011 Et elle disait tout fort, à celles qui l'accompagnaient, que c'était un cousin ; assez fort pour que moi je l'entende, et tous ceux qui attendaient les bus de Voracieux-les-Bredins (Alexis Jenni, L’Art français de la guerre)
Emploi absolu

1963 MARIE. Ne dites pas si vite, ne dites pas $s i$ fort (Eugène Ionesco, Le Roi se meurt)

II. Insister, dire avec force, emphase

Transitif

1405 Et non obstant que de Dieu viengne la grace d'en hault, je suis celle qui la mets a œuvre ou cuer de la personne, et sans moy riens ne prouffiteroit. Et te dis plus fort que, se je n'estoie avec Foy, Esperance et Charité, point ne seroit es humains (Christine de Pisan, Le Livre de l'advision Cristine, p. 55, 41)

1584 Il seroit bon y adviser de bonne heure, Sire, car nostre trafic se pourroit bien perdre et aneantir par ceste negligence et faineantise, et fault que je vous die, puis qu'il vient à propos que vostre bien se diminue : ce que je ne vous voulois aussi plus celer, estant vostre principal serviteur, en qui vous avez le plus de fiance, et vous diray plus fort, j'ay entendu qu'il commence à s'endetter (François d'Amboise, Les Neapolitaines)

1654 Pour nouvelles chacun dit fort

Que le Duc Charles est d'accort,

Landrirette,

La neutralité fait grand bruit, Landriry (Vincent Voiture, Poésies)

1686 Le P. Rapin et vous m'avez si fort dit que j'avois de l'esprit, que je vous offenserois d'en douter (Roger de Bussy-Rabutin, Les Lettres de messire Roger de Rabutin)

1888 BOILEAU. Ce qu'on dira contre moi, je le dirais plus fort encore (Ernest Renan, Drames philosophiques)

Emploi absolu

1515 « Hé ! fait il, cecy n'est rien, et vous direz bien plus fort, car j'ay veu ung poisson qu'on appelle bachet prendre ung lievre sans aultre aide que de luy mesme et le proverés bien, et est tout vray » (Philippe de Vigneulles, Les Cent Nouvelles nouvelles, p. 231, 14)

1648 Si on m'eust laissé en ma liberté, j'eusse pris le grand chemin, avec la mesme fran- 
chise et la mesme seureté que tousjours, et je fusse allé d'icy droit au Bourg la Reine. $\mathrm{Au}$ moins j'eusse eu le plaisir de passer encore une nuict à Paris, et j'avois resolu de vous donner en passant de la ravegarde, et de la raoussette ; mais je vous dis fort fort, ma foy. Je pense qu'en me dissuadant ce dessein, et en ayant peur pour moy, on a eu peur de moy aussi, et que l'on s'est imaginé que l'on le sçauroit au bureau d'adresse, et que je me fourrerois estourdiment parmy tout le monde (Vincent Voiture, Lettres)

Pronominal

1671 Ce mot de gens tout seul est un vieux mot que nous avons renouvellé. Je me connois un peu en gens; vous n'avez gueres de charité pour les gens.

Seûr et Seûreté se disent fort. C'est un coup seûr (Le père Dominique Bouhours, Les Entretiens d'Ariste et d'Eugène)

1748 Je fais bien ici vos affaires, car j'ai parlé de vous à Mme la comtesse de Senecterre, qui se dit fort de vos amies (Montesquieu, Correspondance)

1913 Presque tout occupé de notre véhicule qui semblait lui-même effrayé des efforts qu'il fallait faire pour avancer dans la seule voie ouverte aux charrettes, aux voitures, aux troupeaux de brebis, de chèvres et de pourceaux, je me disais plus fort que jamais encore : Oh ! Non, tu n'es pas Sion (Maurice Barrès, La Colline inspirée)

\section{CoRpus WeB :}

La solution de base indispensable - Se rendre disponible pour son ado et le lui dire fort et clair [http://www.hommepage.fr/enfants.php? article=98] (4.2.2015)

Aujourd'hui, quand tu oses dire fort ce que tous pensent tout bas, tu te fais accuser étymologiquement d'autocratie [https://www.facebook. com/patback2thelight/posts/10151561459598220] (4.2.2015)

Les enfants sont installés sur deux lignes face à face et éloignées d'une dizaine de mètres. Un des groupes va s'approcher lentement de l'autre en répétant une phrase (ex. : " Holà, braves gens, venez donc boire un coup »). Ils devront la dire fort et bien articuler quand ils sont loin, puis de plus en plus faiblement en s'approchant [http://www.educ-envir.org/ euziere/ internetlivre/annexe13.html] (4.2.2015)

Catarina on a rien vu d'elle on peut pas la dire forte. Je te parle des femmes qu'on a vu en actions jusqu'à présent tu me cite des inconnu $>\mathrm{D}$ [http://www.forums-mx.com/index. php?topic=7481.810; wap2] (4.2.2015)

Cela va de paire avec la force physique. On ne peut pas se dire fort tout seul mais par rapport à d'autres ou à une échelle prédéfinie. Celui qui soulève $200 \mathrm{~kg}$ aux altères (exemple pris au hasard) ne peut se dire fort que parce que les autres font moins [http://www.atoute.org/n/ forum/showthread.php?t=176436] (4.2.2015)

REMARques : Dire fort (I) désigne le fait de communiquer quelque chose à quelqu'un en élevant la voix afin d'être entendu d'une ou de plusieurs personnes. (II) réfère au fait d'énoncer un propos en insistant, voire en exagérant, en le considérant comme vrai et digne de crédit. Sous sa forme pronominale, il peut renvoyer au fait de penser, de se dire quelque chose à soi-même avec force, de se considérer fortement comme tel ; il peut également avoir un emploi passif, référant alors à l'emploi oral d'un terme, d'une expression. En dernier lieu, l'exemple de 1671 met en évidence la fonction de fort comme quantifieur au sens de 'beaucoup', voire d'adverbe de temps signifiant 'souvent'. Notons la réduplication de fort dans l'exemple de 1648. Fort reste invariable mais l'accord est fait dans le quatrième exemple du CW (prédication seconde); fort a alors le sens de 'qui a de la force' (v. dernier exemple du CW). Fort est modifié par assez, bien, bien plus, le plus, moult, plus, si, tant, tout, très. Mentionnons également l'emploi de penser bas.

\section{Dire franc}

Dire franchement, sans détour, avec sincérité Transitif

1656 Souvent la cour, peu courtoise, La traite en dame bourgeoise, Et l'huissier du cabinet Luy dit souvent franc et net, Retournez, pauvre ingenüe, Par où vous estes venüe, Car avec gens comme nous 
Il ne fait pas bon pour vous

(Georges de Brébeuf, Lucain travesti)

1666 Le corsaire apprend d'abord

L'aventure de la belle ;

Et, la tirant à l'écart,

Il en veut avoir sa part.

Elle fit fort la rebelle.

Il ne s'en étonna pas,

N'étant novice en tel cas.

Le mieux que vous puissiez faire,

Lui dit tout franc ce corsaire,

C'est de m'avoir pour ami ;

Je suis corsaire et demi (Jean de La Fontaine, La Fiancée du roi de Garbe)

1669 MARIANE. Vous m'avez dit tout franc que je dois accepter

Celui que pour époux on me veut présenter :

Et je déclare, moi, que je prétends le faire, Puisque vous m'en donnez le conseil salutaire (Molière, Le Tartuffe)

1736 Parmi ces gens, étoient, disoit-il, le procureur du roi, une bonne partie des procureurs, le maire de ville... comment, corbleu, s'écria là-dessus Phocion, ces messieurs ne perdent pas leur bonnet quarré, plutôt que de ne pas se ranger de vôtre côté : il faut que vous ne vaillez rien, je vous le dis tout franc (Pierre de Marivaux, Le Télémaque travesti)

1944 Il fit un effort pour se maîtriser :

- Mais dis-moi franc ce que tu veux faire (Jacques Roumain, Gouverneurs de la rosée)

1970 MAGNY, duc de Plaisance. Mon cher Vastey, je suis un vieux soldat. J'ai commandé sous Toussaint et Dessalines et je vous dirai tout franc que je suis mal fait à ces manières courtisanesques dont vous avez l'air de faire vos délices! (Aimé Césaire, La Tragédie du roi Christophe)

Emploi absolu

1896 Pourtant, c'est trop beau, pour dire franc... Un pressentiment fait comme une ombre À ce tableau d'extases sans nombre, Et du noir rampe au nuage blanc! (Paul Verlaine, Euvres poétiques complètes)
1911 Devant cette merveille de goût, je suis capable de me hausser au bien-être, à l'apaisement que nous donne la beauté, bref de goûter l'art pour l'art mais à dire franc, ce n'est pas ce plaisir sensuel qui me retient ici (Maurice Barrès, Greco ou Le Secret de Tolède)

CORPUS WEB :

Résolument installé dans la mouvance des penseurs au dire clair et franc, ses thèses proposent une véritable armature de compréhension $\mathrm{du}$ fait négrier et colonial à la base du peuplement nouveau des Caraïbes [http://www.roger toumson.com/2.html] (1.2.2015)

Pour dire franc, on pensait qu'en ce vendredi 9 août, le petit garage de Longvilliers serait fermé [http://www.lavoixdunord.fr/region/lapres-inondations-ils-pataugent-dans-1incomprehension-ia0b0n1477093] (4.2.2015)

Et ce n'est qu'en entrant dans son secteur, son quartier, et en ces lieux communs où l'on retrouvait les personnes de confiance avec lesquelles on pouvait se lâcher, le naturel revenait, pour dire franc et fort, le fond de sa pensée, et ainsi donner libre cours à ses sentiments réels [http:// www.lejourdalgerie.com/Editions/Speciale/ Contribution\%20Decembre\%201960.htm] (4.2.2015)

C'est facile de se dire franc hein! Mais un peu moins de l'être vraiment [https://twitter. com/patoucathy/status/542947361614745600] (4.2.2015)

C'est bien beau de se dire franche et directe, comme 95\% des gens [http://www.genaisse.com/ forums/viewtopic-44213.html] (4.2.2015)

REMARques : Dire franc désigne le fait d'énoncer un propos de manière sincère, ouvertement et sans dissimulation. Notons l'expression $\grave{a}$ / pour dire franc, synonyme de à dire vrai / à vrai dire, s'employant pour introduire une restriction et signifiant 'franchement' ou 'en réalité' (v. dire vrai). Dans le premier exemple du CW, le groupe est nominalisé (un dire franc). Franc reste invariable et est modifié par souvent, tout. Notons les collocations franc et net, clair et franc, franc et fort. Franc (et direct) remplissent la fonction de prédicat second orienté vers le sujet dans les deux derniers exemples du CW, ce qui entraîne l'accord (elle se dit franche est synonyme de elle 
dit (prétend) qu'elle est franche). Mentionnons également l'emploi de faire fort.

\section{Dire gros}

Dire grosso modo, en gros

Transitif

1958 Pour soutenir l'histoire [...] on n'a point fait d'effort littéraire. Ça dit, tout droit, tout gros, ce que ça a à dire, strictement (Sélection du Monde, 2-7 mai 1958 / Grundt : 383)

CORPuS WEB :

J'ai actuellement ma jument dans une écurie de propriétaire qui est en fait une association. Pour dire gros, je paye $110 €$ par moi pour « simplement " bénéficier des installations [http:// www.1cheval.com/membre/forum/general/sujet2724073-1-projet-ouverture-ecurie-de-proprio-endordogne] (4.2.2015)

Dire tout gros ce que tout le monde pense tout gras [http://phippopotame.blogspot.com/ 2015/09] (4.2.2015)

Elle dit tout gros ce que les Québécois pensent tout gras [http://www.cliqueduplateau. com/2012/10/11/si-tu-veux-sauter-sur-moe-tuvas-avoir-du-fun] (4.2.2015)

REMARQUES : Au figuré, dire gros désigne le fait d'énoncer un propos sans détours, sans égards, d'exprimer les choses telles qu'elles sont, sans entrer dans les détails. Notons dans le CW l'expression en l'occurrence probablement québécoise dire tout gros ce que (tout le monde) pense tout gras, basée sur dire tout haut ce que l'on pense tout bas, a sonorité proverbiale. Gras est employé ici au sens trivial de 'vulgaire'. Dans le premier exemple du CW, dire gros prend l'acception de 'grosso modo, en gros, approximativement', avec peut-être la connotation de payer gros (d'argent). Gros reste invariable.

\section{Dire haut}

I. Dire à voix haute

Transitif

+1100 Ele avoit le chief blondet, Si faisoit un chapelet

Et disoit ceste chancon

Molt haut et seri et cler

« Robeconet, la matinee

Vien a moi joer » (Romances et pastourelles françaises des XII ${ }^{e}$ et XIII ${ }^{e}$ siècles, p. 283)
1225 Et quant il parla, si dist si haut que cil de laienz le porent bien oïr : « Gauvains Gauvains mis m'avez le grant corroz ou cuer donc jamés ne me porrai esbatre devant que je sache veraiement a quele fin ceste queste porra torner, car trop ai grant doute que mi ami charnel n'en reviegnent ja » (Queste del saint Graal, § 23, 31)

1275 Corsols entre en la tente qui estoit de sami, L'amustant salua et l'amirant aussi, Si haut dist ses nouveles que chascuns l'entendi (Adenet le Roi, Buevon de Conmarchis, 1483)

1365a Il ont panceit et dit mauuistieit et malice. et contre lou tres hault ont dit iniquiteit et blasme (Psautier lorrain, p. 73)

1365b La Royne i entra, puis prist à apeller Son gentil maronnier, si li dist haut et cler : Biaus maistrez, je vous pri que nous voelliez mener

Droitement à Boulongne, car g'i voel arriver (Li Romans de Bauduin de Sebourc, Chant III, 193)

1372 Il avoit la un amiraut Qui respondi et dist tout haut : «Sire, j'en diray mon penser : Vous devez bien considerer .v. choses qui sont a ce fait, Si les vous diray tout a fait » (Guillaume de Machaut, La Prise d'Alexandrie [(1370-)1372], 2640)

1460 Quand elle se trouva leens, elle cuida bien enrager, et dist tout haut : " Et que fays ceens? " (Les Cent Nouvelles nouvelles, p. 341, 105)

1538 Lors Renommée avec ses esles painctes Ira volant en bourgs et villes maintes, Et sonnera sa trompette d'argent, Pour autour d'elle assembler toute gent ; Puis hault et clair de cent langues qu'elle a Dira ta vie ; et puis deçà et là Ira chantant les fins tours dont tu uses, Tes laschetez, tes meschances et ruses (Clément Marot, Élégies) 
1550 Sur la roche thespienne,

Des Sœurs la plus ancienne,

Qui de tes faits a souci,

Me garde une melodie,

Afin qu'un jour je la die

Bien plus haut que celle-ci

(Pierre de Ronsard, Les Odes, p. 131)

1559 Ce temps pendant, frappoit le mary à la porte, appellant le plus hault qu'il pouvoit sa femme. Mais elle faignoit de ne le congnoistre poinct, et disoit tout hault aux varletz de leans : «Que ne vous levez vous et allez faire taire ceulx qui font ce bruict à la porte ? » (Marguerite d'Angoulême, Heptaméron, p. 47, 25)

1568 « Pource (dit-il) que je n'entrois mie en colère ; mais toutes et quantes fois, disoit-il en continuant son propos, on voudra confesser verité, on dira haut et clair que les Italiens ont plus souvent porté les marques des François colerez que les François n'ont porté les marques des Italiens desesperez »

(Bonaventure des Périers, Les Nouvelles Récréations et joyeux devis)

1575 Et mesmes le vendredi $11^{\text {e }}$ de ce mois, jour de Sainct Martin, on lui donna advis d'un capitaine de Provence qui s'estoit eslevé et faisoit comme un parti à part ; ce que le Roy aiant entendu, comme il alloit à la messe, dit assez haut ces mots. « Voilà que c'est des guerres civiles ; un Connestable, Prince du sang, jadis ne sceut faire parti en France : maintenant les valets y en font » (Pierre de L'Estoile, Registre-Journal $d u$ regne de Henri III)

1656 Et il [= le père Filiutius] y donne encore [...] un autre moyen plus sûr d'éviter le mensonge. C'est qu'après avoir dit tout haut, «Je jure que je n'ai pas fait cela », on ajoute tout bas : « aujourd'hui », ou qu'après avoir dit tout haut, "Je jure ", on dise tout bas, « que je dis »; et que l'on continue ensuite tout haut, « que je n'ai point fait cela ». Vous voyez bien que c'est dire la vérité (Blaise Pascal, Les Provinciales)
1752 Un vieux péripaticien dit tout haut avec confiance : l'ame est une entéléchie et une raison par qui elle a la puissance d'être ce qu'elle est (Voltaire, Micromégas)

1755 Ô chère Miss Grandisson! Ai-je dit assez haut pour être entendue (abbé Prévost, Nouvelles Lettres angloises [trad.])

1831 Elle se regarda dans la glace et dit tout haut, d'un air de mauvaise humeur :

- Je n'étais pas jolie ce soir !... Mon teint se fane avec une effrayante rapidité... Je devrais peut-être me coucher plus tôt, renoncer à cette vie dissipée... Mais Justine se moque-t-elle de moi ?

(Honoré de Balzac, La Peau de chagrin)

1832 LOUIS. D'un chevreuil je veux suivre la trace.

Dis bien haut que le roi va partir pour la chasse (Casimir Delavigne, Louis XI)

1907a (La porte de la salle à manger s'ouvre et Charles fait une fausse entrée ; mais on entend la voix de Courpière qui dit, très haut:) « Charles, je vous défends expressément d'aller ouvrir » (Abel Hermant, Monsieur de Courpière)

1907b - Il disait tout haut : « celui qui a fait cela est un mauvais ouvrier. » Et ni les ricanements, ni les grognements, ni les injures ne le faisaient se déjuger (René Bazin, Le Blé qui lève)

1966 Comme la caissière le regarde, interdite, il lui dit, assez haut pour que Thomas Pezner l'entende :

- Méfiez-vous de mon ami, il va essayer de vous vendre un aspirateur

(Robert Sabatier, Le Chinois d'Afrique)

1987 La plupart de ces fabricants de croûtes ont dit partout haut et fort, et très franchement, qu'ils voulaient enculer le catholicisme et foutre les églises en l'air (Philippe Sollers, Le Cour absolu)

1995 Faut pas gamberger... entrevoir la poloche et se prendre la fantaisie de le dire tout haut ou de l'écrire (Alphonse Boudard, Mourir d'enfance) 
2006 un Papa auquel je peux dire alors, l'embrassant de toute la force qui unit les enfants à leurs papas et que j'ai aussi, moi, Stéphane, baptisé « Stéphane » par Papa et Maman, un Papa auquel je peux dire haut et fort, auquel je peux crier sans plus avoir peur cette chance incroyable que j'ai eue d'échapper à la morsure à coup sûr gravement mortelle des crocodiles (Stéphane Crémer, Comme un charme)

Pronominal

1869 Si l'on se mettait à se dire tout haut les vérités, la société ne tiendrait pas un seul instant (Charles Sainte-Beuve, Mes poisons)

II. Dire publiquement

Transitif

1235 Se vous estes a cele presse,

Vous i orrés mainte confesse.

Car chascuns dit haut ses peciés,

Dont ce jor se sent entechiés ;

Puis s'est assaus de tous ses fais

Dont il se sent cel jour confès

(Philippe de Remi, sire de Beaumanoir, La Manekine, 6887)

1675 Vous pouvez croire que ma joie n’a pas été médiocre d'entendre dire tout haut cela de vous (Mme de Sévigné, Correspondance)

1829 Je chantais, lorsqu'un long rire

D'épouvante m'a glacé ;

Puis tout haut j'entends dire :

Notre règne est passé

(Pierre-Jean de Béranger, Chansons)

2007 Je continue bien sûr à imaginer des choses : un ballet de regards, des sourires discrets, un clin d'œil entre filles ; un rire étouffé, peut-être un fou rire, peut-être un acting out carabiné ou alors un scandale, pourquoi pas ? Quelqu'un qui dit haut et fort que c'est dégoûtant et qu'il n'achète pas le journal d'Hubert Beuve-Méry pour y lire des cochonneries pareilles (Emmanuel Carrère, Un roman russe)
III. Dire franchement

Transitif

+1400 Pour Dieu ne me vueilliez nuire, Trés doulce estoille de mer Par qui je me vueil conduire ; Vous seule vueil reclamer, Vueillez moy ami clamer, Ou je vous diray tout hault Que vigour et cuer me fault (Christine de Pisan, Cent balades / Euvres poétiques [début $\mathrm{XV}{ }^{\mathrm{e}}$ ], I, p. 71, 13)

\section{CORPUS WEB :}

Je ne saurai trop vous conseiller de dire haut et fort ce que vous m'avez écrit, c'est à dire que vous n'avez pas de projet de domination, et que les banquiers ne vous représentes pas [http:// www.leava.fr/questions-reponses/non-juifs-2/ je-ne-saurai-trop-vous-conseiller-de-dire-hautet-fort-ce-que-vous-mavez-ecrit-cest-a-dire-quevous-navez-pas-de-projet-de-domination-et-queles-banquiers-ne-vous-representes-pas-il-estevide.php] (4.2.2015)

Idée $\mathrm{N}^{\circ} 38$ : Dire haut et fort que le projet de société du Front National est sexiste et réactionnaire [http://laregledujeu.org/2012/03/21/9358/ idee-n\%C2\%B0-38-dire-haut-et-fort-que-leprojet-de-societe-du-front-national-est-sexisteet-reactionnaire] (4.2.2015)

François Fillon, à droite, rejoint Manuel Valls, à gauche, sur l'idée que dire la vérité, et la dire haut, est la seule façon d'enrayer le vote Front national [http://www.lesechos.fr/07/10/2013/ LesEchos/21537-006-ECH_la-politique-en-modefortissimo.htm] (4.2.2015)

REMARQues : Dire haut (I) désigne le fait de communiquer quelque chose à quelqu'un en élevant la voix afin d'être entendu d'une ou de plusieurs personnes. (II) signifie 'proclamer, déclarer quelque chose publiquement, officiellement'. (III) réfère au fait de dévoiler quelque chose, de dire ce qu'on pense, avec sincérité, franchise, droiture. Notons la collocation haut et clair (aussi : haut et seri et clair), ajoutant l'idée de limpidité du message, et la collocation, plus moderne, haut et fort, renvoyant à l'intensité de la voix ou au fait de dire quelque chose publiquement. Haut reste invariable et est modifié par assez, bien, bien plus, moult, partout, si, tout, très. Mentionnons égale- 
ment l'emploi de appeler haut ; ajouter bas. VoIR AUSSI : annoncer / parler haut

\section{Dire juste}

Dire avec raison, justesse, véridicité

Transitif

$\sim 1450$ BOSO. Cela ne puis je pas nyer.

ANSELME. Nous ne trouvons nulz qui soit par dessus tout quenques n'est pas Dieu, fors que Dieu.

BOSO. Il est vray.

ANSELME. Il s'ensuit dont que nulz ne peult faire satisfacion du pechié de l'omme se non Dieu.

BOSO. La consequence est bonne.

ANSELME. Et nulz ne doit faire ceste satisfacion fors que l'omme.

BOSO. Riens ne peulx tu dire plus juste

(Pierre Crapillet, Le «Cur deus homo » d'Anselme de Canterbury [trad.], p. 212, §125)

1876 Toutes les expressions de la sainte Écriture, celles spécialement du Cantique des Cantiques, conviennent d'une manière étonnante à cette perfection... Elles disent juste ce qui est, ce qui fut et dut être (Mgr Félix Dupanloup, Journal intime)

Pronominal

1696 Douloureux ne vient pas plus naturellement de douleur que de chaleur vient chaleureux ou chaloureux, celui-ci se passe, bien que ce fût une richesse pour la langue, et qu'il se dise fort juste où chaud ne s'emploie qu'improprement (Jean de La Bruyère, Les Caractères)

Emploi absolu

1733 LISETTE. Mais il dit qu'il n'a pas lieu d'être content, et je crois qu'il dit assez juste : qu'en pensez-vous, Madame ? (Pierre de Marivaux, L'Heureux Stratagème)

1865 Ce grand bon bêta de Nieuwerkerke nous disait, en fumant, qu'il manquait une certaine tendresse à nos œuvres, ce que donne à l'homme la fréquentation de la femme. Il disait vrai et juste. Mais il faut bien se garder de guérir de cela (Edmond et Jules de Goncourt, Journal)
1887 - Madame Moraines a eu la bonne idée de me garder une place...

- Dans votre loge... reprit Paul qui ne croyait pas dire si juste

(Paul Bourget, Mensonges)

1933 Pour dire juste, il n'y avait pas grand monde dans le paradis, et c'est peut-être ce qui m’a le plus surpris (Marcel Aymé, $L a$ Jument verte)

1936 Ah j'allais oublier : encore une ressource du magasin, celle-là une fois par an seulement, au printemps, les brassards de première communion. [...] Une fois par an, ce n'est peut-être pas dire juste : faut pas oublier la confirmation (Louis, Les Beaux Quartiers)

1976 Bien des choses qu'il avait dites, en étant certain de dire juste mais sûrement sans penser que c'était à la lettre qu'elles devaient être prises, il s'affligeait maintenant de ce qui lui montrait qu'elles avaient tout le poids de vérités d'expérience (Michel Leiris, La Règle du jeu 4 : Frêle Bruit)

2005 C'est une écriture à laquelle toutes les procédures ordinaires du travail sont interdites : le diariste ne peut ni composer, ni corriger. Il doit dire juste du premier coup (Philippe Lejeune, Signes de vie)

\section{CORPUS WEB :}

Peut-on tout dire à l'enfant ? Deux extrêmes sont à éviter, nous fait remarquer J. HARDUIN, « D'une part, la croyance fausse que l'enfant peut tout entendre. D'autre part, le rien dire qui ne peut que générer de l'angoisse. Il ne s'agit pas de tout dire ou de ne rien dire, mais de dire juste, de trouver la parole authentique et vraie que l'enfant peut entendre " [http://www.ram68.fr/index.php?option=com content\&view=article\&id=106:le-langage-chezlenfant\&catid=41:lenfant\&Itemid=64] (4.2.2015)

Cette image est forcément vraie tant l'obsession de dire et de dire juste, ne peut laisser place à la tricherie [http://www.loeilebloui.fr/wp-con tent/uploads/les-e\%CC\%81ditos.pdf] (4.2.2015)

où les mots vous échappent et vous êtes là à chercher ces mots - et la manière de les dire juste et compréhensible, pour viser le sujet que vous 
vous voulez aborder ? [https://fr.answers.yahoo. com/question/index?qid=20140323002830AAHL gsk] (4.2.2015)

«Sa fermeture n'est pas en lien avec la perte des habitants ", a insisté le maire, adressant cette remarque à l'élu absent : «Quand on dit des choses, il faut les dire justes " [http://www.lejsl. com/edition-de-chalon/2011/05/21/une-dettemaitrisee-et-des-taux-moderes-a-0-5] (4.2.2015)

REMARQues : Dire juste désigne le fait d'énoncer un propos fondé, sensé, judicieux, véridique. Sous sa forme pronominale, il réfère à l'emploi oral correct d'un terme, d'une expression. Juste reste normalement invariable et est modifié par assez, fort, plus, si. Juste s'accorde cependant avec l'objet au pluriel dans le dernier exemple $\mathrm{du} \mathrm{CW}$, où il permet également une analyse de prédicat second orienté vers l'objet. Notons l'adjectif-adverbe compréhensible dans le troisième exemple du CW, où l'absence de l'accord peut surprendre. Mentionnons également la collocation vrai et juste. VoIR AUSSI : jouer juste

\section{Dire laid}

Dire des choses désagréables, blâmer

Emploi absolu

+1150 Toutes gens set lait dire et reprouer (Aiol et Mirabel [ $2^{2}$ moitié XII $]$, 2590)

\section{CORPUS WEB :}

Le blobfish est ainsi une espèce menacée de disparition à cause de captures accidentelles dans les filets des pêcheurs : " Certains le disent laid, mais je pense que la face triste du blobfish cache un cerveau malin et gentil », a expliqué le président de l'association, Simon Watt [http:// www.20minutes.fr/planete/1222327-2013091220130912-animal-plus-laid-monde-est-blobfis] (4.2.2015)

Ceci dit, quelques sites anti-moi étaient apparus, critiquant le fait que nous ayons un enfant hors-mariage, et que je n'étais même pas célèbre, et beaucoup me disaient laide comme un poux [http://dict.leo.org/frde/index_de.html\#/ search $=$ poux\&searchLoc $=0$ \&resultOrder=basic\& multiwordShowSingle $=$ on] (4.2.2015)

REMARQues : Dans l'exemple de +1150 , dire laid désigne le fait d'énoncer un propos déplaisant, produisant un effet désagréable chez le locuteur.
Laid reste invariable. L'emploi adverbial de laid était usuel en ancien français. Cette fonction disparaît en français moderne où le CW ne documente que celui de 'dire que quelqu'un ou quelque chose n'est pas beau', d'un point de vue esthétique, ce qui entraîne l'accord (prédication seconde).

\section{Dire long}

I. en dire long sur quelque chose (sujet animé): dire, raconter beaucoup sur quelque chose Intransitif

1760 Si j'y trouvois une lettre de vous, je remplirois la demi-page qui me reste et qui ne me resteroit pas, car je l'aurois remplie tout en disant que je ne voulois pas en dire plus long, si l'on ne m'invitoit pas à descendre. Je vais voir ce qu'on veut... (Denis Diderot, Lettres à Sophie Volland)

1775 De plus, vos parents arriveront qu'il n'y aura plus ni vert ni feuille. Cette belle vue, ce joli jardin seront tristes, et leur maison serait affreuse si le vent y venait de partout, et elle serait dangereuse s'il y avait des plâtres neufs. J'en dis bien long parce que j’ai réellement fort à cœur que vous évitiez d'avoir un repentir qui troublerait votre vie (Julie de Lespinasse, Lettres à Condorcet)

1830 Je ne t'en dis pas bien long car je suis toujours éreintée et endormie en rentrant, et c'est presque le seul moment où je puisse écrire (George Sand, Correspondance)

1886 - Oh ! Nous... c'est différent ; ça nous est défendu de faire du bruit. (Il avait répondu cela avec un air de sous-entendre quelque mystère noir ; avec un sourire drôle, qui, par la suite, revint souvent en tête à ceux de la Marie et leur donna à penser beaucoup.) Et puis, comme s'il en eût dit trop long, il finit par cette plaisanterie :

- Notre corne à nous, c'est celui-là, en soufflant dedans, qui nous l'a crevée (Pierre Loti, Pêcheur d'Islande)

1892 Il ne put d'ailleurs tirer aucun détail précis de ceux qu'il s'efforça d'interroger : les uns répondaient, hébétés, qu'ils ne savaient pas ; les autres en disaient si long, dans 
une telle furie de gestes, une telle exaltation de paroles, qu'ils ressemblaient à des fous (Émile Zola, La Débâcle)

1920 Qu'il soit permis de n'en dire pas plus long sur ce difficile sujet (Alain, Système des beaux-arts)

1925 Et elle parla, et elle en dit rudement long (Maurice Genevoix, Raboliot)

1943 - Eh ! ma pauvre dame, vous nous en dites bien plus long qu'on ne vous en demande (Colette, Le Képi)

Emploi absolu

1847 Vendredi saint. Je ne dirai pas long ce soir, étant fatiguée de ma journée d'église (Eugénie de Guérin, Lettres)

II. en dire long sur quelque chose (sujet inanimé) : être révélateur, significatif Intransitif

1874 Il ne se plaignait pas, mais il avait des pincements de lèvres qui en disaient long (Émile Zola, La Conquête de Plassans)

1922 - Les mots ne nous trahissent pas tant qu'ils ne nous trahissent : l'erreur du langage en dit long sur notre pensée cachée (Louis Aragon, Les Aventures de Télémaque)

1926 Chose incroyable ! Pas un instant, Gallet ne douta qu'elle eût dit vrai. Dès les premiers mots, il l'avait crue, tant le regard en dit plus long que les lèvres (Georges Bernanos, Sous le soleil de Satan)

1963 Sous l'angle de la curiosité, un cabaret vaut bien une cathédrale, et m'en dit parfois bien long sur la cathédrale elle-même (Albert T’Serstevens, L'Itinéraire espagnol)

1993 Comme ces phrases en disent long sur les soi-disant élites du temps et leurs minables ruminations de l'ombre! (Philippe Sollers, Le Secret)

2000 Les regards, fermés, goguenards, les yeux des femmes qui estimaient le prix des plis savants de Mme Grès drapés sur Elsa, en disaient long. Je prenais goût à susciter cette réprobation. Il me plaisait de partager cette sorte d'exil intérieur où était alors maintenu Aragon (François Nourissier, À défaut de génie)

2004 Écrite avec une rigueur fantaisiste qui rappelle les romans d'un écrivain d'une génération précédente, cette fable légère et profonde en dit plus long que bien des reportages sur le désordre, mais aussi l'intensité qui souffle dans le pays (Édouard Levé, Journal)

CORPuS Web :

C'estfou commeparfois un simpleregard peut en dire long... [https://fr-fr.facebook.com/pages/ Cest-fou-comme-parfois-un-simple-regardpeut-en-dire-long/10150106008015203?sk=info] (5.2.2015)

Les pupilles peuvent en dire long lors de vos phases de séduction [http://forum.psychologies. com/psychologiescom/rencontres-et-seduction/ seduction-pupilles-peuvent-sujet_8122_1.htm] (5.2.2015)

REMARQues : En dire long (I) désigne au figuré le fait de raconter quelque chose, d'informer quelqu'un, de rapporter avec beaucoup de détails et de précision. En (II), le sujet étant inanimé, il se dit de quelque chose ayant une grande signification, étant porteur de sens, dont l'analyse peut s'avérer révélatrice. Long reste invariable et est modifié par bien, bien plus, parfois, plus, rudement, si, trop. Sémantiquement, long est un adjectif de dimension qui se transpose métaphoriquement au domaine de la quantité 'beaucoup', de l'intensité 'avec plus de détail' et du temps 'longuement', sans qu'il soit possible de les démêler clairement, mais le côté quantitatif prédomine dans les exemples.

\section{Dire net}

I. Dire directement, franchement

Transitif

1573 Puis luy dirent tout net, qu'ils voyoyent bien que de nopces il n'en failloit plus parler (Blaise de Vigenère, Les Chroniques et annales de Poloigne)

1668a CLÉANTE. Et je vous ai trouvé, Monsieur, fort à propos,

Pour vous en dire net ma pensée en deux mots (Molière, Le Tartuffe) 
1668b DOM PÈDRE. Et vous voulez du bien à tous ceux qui prennent ce soin?

ISIDORE. Assurément.

DOM PÈDRE. C'est dire fort net ses pensées (Molière, Le Sicilien)

1693 Je me rapporte aux yeux d'une Ourse mes amours.

Te déplais-je ? va-t'en, suis ta route et me laisse :

Je vis libre, content, sans nul soin qui me presse ;

Et te dis tout net et tout plat :

Je ne veux point changer d'état

(Jean de La Fontaine, Les Compagnons d'Ulysse / Fables)

1732 Ce secrétaire m'a dit tout net : Seigneur gentilhomme, ne vantez pas tant votre zèle et votre fidélité (Alain-René Lesage, Histoire de Gil Blas de Santillane)

1773 GLYCĖRE. Je ne puis te souffrir : je te l'ai dit, je pense,

Assez net, assez clairement.

Va-t'en, ou je m'en vais

(Voltaire, Les Deux Tonneaux)

1833 Mais ne le lui dites pas si net et ménagez son amour propre (George Sand, Correspondance)

1854 Si bien qu'en soulevant ma valise après votre départ, l'aubergiste inquiet a soupçonné une partie de la triste vérité, et m'est venu dire tout net que j'étais un prince de contrebande (Gérard de Nerval, Les Filles $d u f e u$ )

1907 Je dis non, très net, m'attendant toutefois au pire (Claude Farrère, L'Homme qui assassina)

1918 C'est dit trop sec et trop net, mais je vois cette opération se faire sous mes yeux (Maurice Barrès, Mes cahiers)

1962 Aussi, ma foi, La prochain' fois

Qu'on mariera Jeannett',

On s'pass'ra d'vous,

Tonton, je vous,

Je vous le dis tout net
(Georges Brassens, "Tonton Nestor »/ Poèmes et chansons)

2004 Ça me pèse... Moi aussi, j’ai ma famille, mes soucis et mes petits ennuis de santé alors, je te le dis tout net : tu dois prendre tes responsabilités maintenant... (Anna Gavalda, Ensemble, c'est tout)

Emploi absolu

1936 Ou plutôt, et pour dire net, il n'y a pas de littérature parlée, improvisée, il n'y a que de la littérature écrite (Albert Thibaudet, Réflexions sur la littérature)

\section{Dire explicitement}

Transitif

1656 Cela veut dire tout net, Adieu soutane et bonnet, Flamberge contre écritoire Emportera la victoire (Georges de Brébeuf, Lucain travesti)

\section{CORPUS WEB :}

Ils ne font qu'exécuter un ordre qui leur est transmis par le parquet. Donc pour le dire clair et net : eux n'y sont pour rien! [http://www.ances. lu/index.php/55-radelux/166-le-placement-desenfants-et-l-intervention-des-forces-de-l-ordrela-force-de-la-loi-ou-la-loi-de-la-force] (1.2.2015)

Je vais vous dire net et clair. Nous, nous sommes contre l'émigration massive des Camerounais à l'étranger, et spécialement dans les pays européens. Pour la simple raison que, vu les conditions dans lesquelles ces Camerounais vivent en Europe, c'est impensable [http://www. cameroon-info.net/stories/0,16866,@,anicetekane-president-du-manidem-nous-sommescontre-l-emigration-des-camerounai.html] (5.2.2015)

Je vais te la dire clair et net, la Russie n'est pas une democratie, les droits de l'opposition n'y sont pas du tout respectés et Poutine fait ce qu'il veut dans le pays ! [http://forum. olweb.fr/showthread.php?152439-Actualit\%E9sinternationales/page27] (1.2.2015)

REMARQUES : Dire net (I) se dit pour énoncer un propos sans altération et sans détours, pour exprimer les choses telles qu'elles sont, sans fard, ni affectation, avec franchise et naturel. Dire net (II) désigne le fait de dire quelque chose claire- 
ment, d'avoir une signification claire. Net reste invariable et est modifié par assez, fort, si, tout, très, trop. Notons la collocation tout net et tout plat, ainsi que celle de clair et net dans le CW, qui prédomine dans l'usage actuel. Notons l'emploi de dire sec.

\section{Dire noir}

faire blanc et dire noir : dire une chose et faire son contraire

Emploi absolu

1846 Votre intention est excellente, et j'en prends acte : mais j'ajoute que vous vous êtes trompé de boule, que vous avez voté blanc quand vous vouliez dire noir, que la société a été prise par vous pour l'égoïsme, et réciproquement l'égoïsme pour la société (Pierre-Joseph Proudhon, Système des contradictions économiques)

\section{Corpus Web :}

Quand a ton BF no comment. Je ne sais même pas comment ils font ces gens la. Faire blanc et dire noir a la rigueur qu'il se tait se fasse petit etc. [http://forum.doctissimo.fr/grossessebebe/grossesse-libre/marsette-complet-angessujet_210738_470.htm] (5.2.2015)

C'est ça kes femme un jour blanc un jour noir, défois elles pensent blanc et disent noir [http://www.forum-algerie.com/humour/37840delirez-ici-764.html] (5.2.2015)

il ne faut pas s'etonner aussi de voir des gens avoir un peu la rage de lire ici des questions ou des affirmations (bien que ce ne soit pas tton cas precis) de gens qui font blanc et disent noir apres pour moi, y'a plus de question a se poser, y’a juste a jouer [http://forums.jeuxonline.info/ showthread.php?t=540801\&page=4] (5.2.2015)

REMARQUeS : Dire noir s'oppose à dire blanc. Les adjectifs-adverbes noir et blanc restent toujours invariables. Notons l'emploi de faire blanc, penser blanc, voter blanc. Voir commentaire sous dire blanc.

\section{Dire plat}

Dire franchement, dire simplement

Transitif

1515 Et aprés pluseurs prepos et d'ung costez et d'autre l'ostesse leur dit tout plat qu'elle n'en laisseroit rien de chascune .v. groz de Mets à leurs faire tres bon marchez (Philippe de Vigneulles, Les Cent Nouvelles nouvelles, p. 355, 217)

1560 Il ne nie pas que ce ne soit un Concile légitime, mais il dit plat et court qu'il a peu errer (Jean Calvin, Institution de la religion chrestienne)

1693 Je me rapporte aux yeux d'une Ourse mes amours.

Te déplais-je ? va-t’en, suis ta route et me laisse :

Je vis libre, content, sans nul soin qui me presse;

Et te dis tout net et tout plat :

Je ne veux point changer d'état

(Jean de La Fontaine, Les Compagnons d'Ulysse / Fables)

\section{CORPUS WEB :}

mais un peu de cheveux sur les bords.. c'est un signe héréditaire de con sur les bords. Il faut parfois vous le dire tout plat pour que vous compreniez votre débilité cellulaire...devant un forum audacieux [http://www.agri-web.eu/2013-01-02_ tarir-sans-antibiotiques-cest-possible] (5.2.2015)

Etant un habitant des EU maintenant, si je le rencontrais je le remercierais de ne pas m'avoir fait trop de promesses en l'air et en me disant, tout plat, que c'est au peuple de se reveiller et de faire quelque chose [http://www.lapresse.ca/ debats/vos-reactions/200902/16/01-827686-sivous-rencontriez-obama.php] (5.2.2015)

J'ai moi même une série de pigeons de courant sanguin Aarden et van Wanroy.... mais ce sont des Beijers car les croisements ont été réalisés par cet amateur et c'est lui qui a réalisé des résultats avec ses pigeons... Celui qui dit aujourd'hui vendre de vrais Aarden est je le dis tout plat un arnaqueur [http://mondialpigeons.forumpro.fr/ t2013-race-jan-aarden\#31202] (5.2.2015)

REMARques : Dire plat désigne le fait d'énoncer un propos sans altération et sans détours, d'exprimer les choses telles qu'elles sont, sans fard ni affectation, avec franchise et naturel. Au vu des sites cités dans le CW, dire plat pourrait être un régionalisme (Canada, Belgique). Plat reste invariable et est modifié par l'adverbe d'intensité 
tout. Notons les collocations dire plat et court et dire tout net et tout plat. VOIR AUSSI : perdre plat et court

\section{Dire sec}

Dire sèchement, froidement

Transitif

1782 Le curé, qui se trouva là, prit la liberté d'approcher de sa voiture, pour lui demander ce qu'il vouloit ordonner à l'égard de ce petit malheureux. « Moi ! dit l'homme sec et dur, que voulez-vous que je fasse d'un estropié ? » (Robert-Martin Lesuire, L'Aventurier françois ou Mémoires de Grégoire Merveil)

1925 Le vieux Tancogne, sans avoir frappé, poussa la porte de Volat.

- Bonjour, dit-il, tout sec

(Maurice Genevoix, Raboliot)

1947 J'étais inquiet en face de tant de joie. Je sentais qu'elle était dirigée contre mon bonheur et je lui fis un mauvais accueil. Je dis encore très sec :

- T’as pas besoin de faire du théâtre, ça me touche pas. Fous le camp, les gâfes vont radiner.

Il partit, léger, sans cesser de sourire (Jean Genet, Miracle de la rose)

1985 Elle arrondit ses yeux noisette très ordinaires. Toute sa figure est butée, avec deux grandes rides de mépris de chaque côté de sa bouche tombante. Elle dit, sec :

- Je fournis pas ce genre de choses.

- Comment, ce genre de choses? Mais les roses, c'est des fleurs ! Vous êtes fleuriste ou boulangère? Manivelle sourit un peu (Victoria Thérame, Bastienne)

\section{CoRpus Web :}

jvais te le dire sec tu me plait beucoups :\$ [http://ask.fm/Jouustine7/answer/102765988916] (5.2.2015)

Incapable de lui dire sec de même que je la trouve pas belle [https://twitter.com/kefosch/ status/376525971169345536] (5.2.2015)

Je reprends le discours relevé sur le document [1], et le commente sommairement. Ces idées n'engagent que moi, et je peux me tromper, mais quand même... Je préfère le dire tout sec [https://www.facebook.com/avantimegamaths/ posts/548848721918205] (5.2.2015)

REMARQues : Dire sec désigne le fait d'énoncer un propos sèchement, crûment, d'exprimer les choses telles qu'elles sont, sans sensibilité ni tendresse, avec indifférence. Sec reste invariable et est modifié par tout, encore très. La syntaxe de l'exemple de 1782 est ambiguë, mais l'interprétation de sec et dur comme adjectifs adnominaux d'homme n'a pas de sens.

\section{Dire seri}

Dire, réciter agréablement, paisiblement

Transitif

+1100 Ele avoit le chief blondet,

Si faisoit un chapelet

Et disoit ceste chancon

Molt haut et seri et cler

« Robeconet, la matinee

Vien a moi joer »

(Romances et pastourelles françaises des $\mathrm{XII}^{e}$ et XIII ${ }^{e}$ siècles, p. 283)

REMARQUES : L'ancien français dire seri signifie ici 'dire d'une voix claire, sereine'. Notons sa collocation avec haut et clair traduisant l'idée de limpidité de l'énoncé.

\section{Dire soef}

Dire doucement, calmement

Transitif

1170 Mout par li fait Jason grant joie ; Soëf, basset, que l'om ne l'oie, [variante : bassez]

Li dist : Vassaus, ne tenez mie

A mauvaistié n'a legerie, Se a vos me vieng acointier (Benoit de Sainte Maure, Le Roman de Troie, 1312)

+1175 Venuz s'en est aeschariz. «Lasse, fait ele, mes amis Est trovez, mes sires l'a pris!» Souef le dit entre ses denz (Béroul, Tristan [ $4^{\mathrm{e}}$ quart $\mathrm{XII} \mathrm{I}^{\mathrm{e}}$ ], 3165)

-1200 Et Franchois furent coi et mu et taisant ; De lui aidier, n'i a nul ki s'en vant. Li uns a l'autre le souef disant : Quex vis deables porroient soffrir tant? (Aliscans [fin XII ${ }^{\mathrm{e}}$, 2694) 
1235 Effreez sunt paens de ço e esbaiz,.

Le poer Jesu prisent volentris u enviz ;

Li un en sunt joius e li autre mariz.

Dient entre eus suef : N'est droitz k'il seit despiz,

Li Deus Auban pur ki mortz est e escharniz (La Vie de seint Auban, 921)

REMARQUES : Dire soef désigne en ancien français le fait d'énoncer un propos doucement, agréablement, avec calme, voire précaution. Soef reste invariable.

\section{Dire vrai (voir)}

I. Dire la vérité Emploi absolu

$\sim 1100$ « Vers Carlemagne li durrai bon conseill : Cunquis l'avrat d'oi cest jur en un meis. De Sarraguce les clefs li portereiz, Pui li dites il n'en irat, s'il me creit. » Cil respundent : "Sire, vus dites veir» (Chanson de Roland, 2754)

1119 Or oez sun sermun

Cum le met a raisun, Icil Deus ki tut fist

E ki tuz jurz veir dist, Il guart l'anme de tei (Philippe de Thaon, Comput [1119 ou 1113], 16)

$\sim 1160$ Et ne fist il, il a voir dit, Car il n'i fu, n’il ne la vit ; Ne sai coment il i morust, Car ainz que la bataille fust, Li fist Nisus lo chief voler : Ce ne sot il pro deviner (Eneas, 5069)

1170 Onques mes, fet il, n’oï tel. Mainne moi dons a son ostel ; Que certainnemant vuel savoir Se tu me diz mançonge ou voir (Chrestien de Troyes, Erec et Enide, 3254)

1177 Or si vos dirai la androit, Ou Meleaganz est venuz, Que oiant toz, gros et menuz, Dist a son pere molt en haut : Pere, fet il, se Deus me saut, S'il vos plest, or me dites voir, Se cil ne doit grant joie avoir Et se mout n'est de grant vertu, Qui a la cort le roi Artu
Par ses armes se fet doter?

(Chrestien de Troyes, Lancelot ou Le Chevalier de la charrete, 6277)

+1200 a « Gauvains, ce n'est mie novele, Tuit sevent que la damoisele Perdi par toi en ton servise Son ami. Or sez qu'ele est prise Par toi ; quant tu ne la secors, Tu es honiz en totes corz. » Mes sire Gauvains sanz respit Demande se cele a voir dit (Raoul de Houdenc, Meraugis de Portlesguez [début XIII'], 5152)

+1200b « Sire, de chou que vous savés ne vous puis jou faire menchoingne a croire. Ne autre chose ne vous dirai je mie, mais pour Dieu aiiés mierchi de moi ; car je vous dirai merveilles et voir, se vous m'asseurés que vous ne me lairés mie » (Merlin [1 ${ }^{\mathrm{er}}$ quart XIII'], p. 121)

1225a Par foi, fet li rois, je sai bien que vos dites voir (Queste del saint Graal)

$+1225 \mathrm{~b}$ Je cuit bien que vous dites voir, Dist il, et mout bien avés dit. Ne demeure que mout petit K'il sont a l'ostel venu (Le Chevalier as deus espees [ $2^{\mathrm{e}}$ quart $\left.\mathrm{XIII}^{\mathrm{e}}\right]$, 5268)

1285 Et je cuit bien que nus fors il Ne se metroit en tel peril, Et pour ce ne sai que j'en die. Voir me dites, je vous en prie (Adenet le Roi, Cleomadés, 3214)

1339 LA DAME. Il dirent, si disoient voir, Que le terme demain cherroit Du respit qui donné m'estoit, Et je tant prié et requis Qu'a huit ans me ront terme mis (Miracle de l'enfant donné au diable, 598)

+1400 Tiens ta promesse et petit jure, Gard ne soies trouvé parjure, Car le menteur est mescreü Et, quant voir dit, il n'est creü. (Christine de Pisan, Les Enseignemens moraux / Euvres poétiques [début XVe], III, p. 32) 
+1415 Alors mon cueur, pour dire voir, De joye souvent soupiroit, Et, combien qu'il portast le noir, Toutesfoiz pour lors oublioit Toute la doleur qu'il avoit, Pensant de recouvrer briefment Plaisance, Confort et Liesse.

Et d'avoir en gouvernement Tresor d'amoureuse richesse (Charles d'Orléans, Poésies [ 1415-1440], I, Ballade XXXVII, p. 57)

1450 Pandaro dist : " Je congnois que vous dictes vroy ; mais souventesfoiz advient que tel ne se scet garder du venin, qui par son advis en garde bien ung aultre. Et autresfois c'est veu celui qui avoit la lumière en la main esgaré, et celui qui n'en avoit point alloit le droit chemin » (Roman de Troilus et Cressida, p. 137)

+1489 Beaucoup furent esbahiz de ceste fantaisie, qui blasmèrent ce cas, disant qu'ilz avoyent faict pour bien, et disoyent vray (Philippe de Commynes, Mémoires [14891498], VI)

1495 « Vrayement, ma fille, » dit le roy, « vous dictes vray. Si envoyray devers ses gens qui sont venus, pour les faire fornir de linge, vaixelle et tapisserie, et de tout ce que leur sera necessaire » (Roman de Jehan de Paris, p. 52)

1562 L'ADVocAT. Tu dis bien vray, Marion ; mais Magdelon est-elle contente ? (Jacques Grévin, Les Esbahis)

1696 Il ne vous dirait point plus vrai que moi sur ma jambe (Mme de Sévigné, Correspondance)

1701 Du soin d'aider le pauvre on dispensa l'avare ;

Et même chez les Rois le superflu fut rare. C'est alors qu'on trouva pour sortir d'embarras,

L'art de mentir tout haut en disant vrai tout bas.

C'est alors qu'on aprit qu'avec un peu d'adresse,
Sans crime un Prêtre peut vendre trois fois sa Messe

(Nicolas Boileau, Satires [1664-1701])

1715 - Je ne veux pas m'opiniâtrer contre vous, ajouta Danhasch ; le moyen de vous convaincre si je dis vrai ou faux, c'est d'accepter la proposition que je vous ai faite de venir voir ma princesse, et de me montrer ensuite votre prince (Antoine Galland, Les Mille et une nuits)

1722 JAQUELINE. [...] après ça, ma tante disait toujours qu'un amant, c'est comme un homme qui a faim : pû il a faim, et pû il a envie de manger, pû un homme a de peine après une fille et pû il l'aime.

PIERRE. Parsanguenne, il faut que ta tante ait dit vrai ; car je meurs de faim, je t'en avertis, Jacquelaine

(Pierre de Marivaux, La Surprise de l'amour)

1734 On dit bien vrai, lorsqu'on assure qu'en dormant nous dépendons si peu de nousmêmes, que l'objet du monde qui nous est le plus odieux, triomphe de notre répugnance (Alexandre Dumas fils, L'Écumoire)

1745 SIDNEI. Je ne dis que trop vrai : plaignez mon sort funeste (Jean-Baptiste Gresset, Sidnei)

1812 - Vous dites plus vrai que vous ne croyez, répondis-je (Étienne de Jouy, L'Hermite de la Chaussée-d'Antin)

1836 À vrai dire, je ne suis rien moins que sûr d'avoir quelque talent pour me faire lire (Stendhal, Vie de Henry Brulard)

1899 Je veux croire, jusqu'à la fin, que nous n'aurons pas le spectacle de Picquart condamné pour avoir dit vrai (Georges Clemenceau, Vers la réparation)

1978 Poussé par Ėve, Adam se décide. Il mord dans le fruit. Et il ne meurt pas. Ses yeux s'ouvrent au contraire, et il connaît le bien et le mal. Yahvé avait donc menti. C'est le serpent qui disait vrai (Michel Tournier, Le Coq de bruyère) 
1989 Le mort dit vrai en ne disant plus et si, sur lui, l'on jette tant de silence, c'est pour ne rien entendre (Christian Bobin, La Part manquante)

1997 - Essayé, vous dites vrai, mais il ne l'a pas fait ! (Patrick Rambaud, La Bataille)

II. Dire franchement, avec sincérité

(introduisant une restriction)

Emploi absolu

1450 Et en tant que sa bonne renommée appetisseroit, à vous dire vray, il m'en desplairoit ; mais, au fort, elle s'en passera comme fist Helène ; si faittes tant seulement que voustre desir soit accomply (Roman de Troilus et Cressida, p. 218)

1566 Et pour dire vrai il m'eust fasché que tant de livres indignes et pernitieux, comme les Amadis, Tristans, et autres de mesme farine, c'est à dire, ou inutiles, ou indoctes, ou deshonnestes, tant en vers qu'en prose, eussent eu plus de credit et de vogue que telle chose que mes longues veilles et mon bien grand et bien long travail eussent taillé pour servir à la chose publique (André de Rivaudeau, Aman)

1587 Si le feu n'eust pris à l'amorce, Il n'eust tiré le pistollet ;

Et, à vrai dire, un cabasset

Est fort propre pour la cervelle

(Pierre de L'Estoile, Registre-journal du regne de Henri III)

1664 FLAVIE Il lui parle à présent. Qu'en ditesvous, madame,

Et de cet entretien que souhaite votre âme? Voulez-vous qu'on l'accepte, ou qu'il n'obtienne rien?

PLAUTINE. Moi-même, à dire vrai, je ne le sais pas bien (Pierre Corneille, Othon)

1824 Vous n'avez donc nulle preuve, et n'en sauriez avoir, de ces sentiments que vous attribuez au premier ministre ; mais quand vous en auriez, quand nous serions certains (comme, à vous dire vrai, j'y vois de l'apparence) que M. Decazes au fond n'a pas pour nous beaucoup de considération, faudrait-il nous en plaindre et nous en étonner ? (Paul-Louis Courier, Pamphlets politiques)

1863 Cette nouvelle entrevue, la première, à vrai dire, qui m’ait donné entrée dans la maison des Trembles, n'eut rien non plus de bien mémorable, et je n'en parlerais pas si je n'avais à dire un mot tout de suite de la famille de $\mathrm{M}$. Dominique (Eugène Fromentin, Dominique)

1895 Vous étiez utiles alors, vous étiez nécessaires ; vous n'étiez pas invincibles. $A$ dire vrai, dans ces vieux âges, et pour longtemps encore, il vous manquait le charme (Anatole France, Le Jardin d'Épicure)

1937 À dire vrai, elle n'avait guère besoin de l'amour de son mari (et moins encore, grand Dieu ! de la corvée sexuelle, par bonheur de moins en moins fréquente) (Henry de Montherlant, Le Démon du bien)

+1963 Pour dire vrai, il n'y passait jamais personne et le vieux chat n'avait à signaler que quelque commandeau de renards (Antoine Blondin, Ma vie entre les lignes [1963-1970])

2000a Ton corps agit comme toi. Pour l'heure vous agissez séparément, vous tirez à hue et à dia, chacun de son côté, vous disputant votre héritage commun, absolument commun et unique. Les frères ennemis. Et donc ton corps te fait comme tu le fais. Pour dire vrai, il te fait mal comme tu lui fais mal. Agissez ensemble, soyez-un et tu paries que tout va changer? Un corps, un seul corps, un tout corps (Richard Morgiève, Ton corps)

2000b CATHERINE. Oui. Pardon. Ce que je disais, il s'appelle comme vous, mais, à vrai dire... ANTOINE. Je m'excuse. Ça va, là, je m'excuse, je n'ai rien dit, on dit que je n'ai rien dit, mais tu ne me regardes pas comme ça, tu ne continues pas à me regarder ainsi, franchement, franchement, qu'est-ce que j'ai dit ? (Jean-Luc Lagarce, Juste la fin du monde) 
CORPUS WeB :

Quelque sinistre urluberlu pourrait s'amuser à montrer, en mentant, que dire faux et dire vrai sont la même chose ou même que dire faux par intention est préférable à dire faux par erreur [http://www.franceculture.fr/emissionle-gai-savoir-le-mensonge-la-querelle-kantconstant-2013-06-02] (2.2.2015)

"C'est un combat difficile. Et pour dire vrai, Papa Sow m'empêche de dormir. A chaque fois que j'y pense, je me dis que ce duel est capital pour moi. C'est un combat de vie ou de mort et je vendrai chèrement ma peau ", avoue-t-il dans un entretien avec "L'As » [http://www. seneweb.com/news/Sport/lac-de-guiers-2-laquopour-dire-vrai-papa-sow-m-rsquo-empeche-dedormir-raquo_n_143081.html] (5.2.2015)

Si je dis : « Tout est faux.»

Et bien, je me contredit derechef : pourquoi ?

Parce que je considère que la phrase participe au vrai pour la dire vrai.

Donc tout n'est pas faux [http://www. sens-de-la-vie.com/forums/view topic. php?topic=1743\&forum=8] (6.2.2015)

- Le monde, la vie, c'est ma consommaction.

- Ma consommaction est une proposition apophantique : on peut la dire vraie ou fausse visà-vis du monde [http://spqrepublicaine.blogspot. co.at/2014/04/consommaction.html] (6.2.2015)

REMARQues : Dire vrai (I) désigne le fait d'énoncer un propos conforme à la réalité, à la vérité, le fait d'être honnête. Dans à dire vrai, à vrai dire et pour dire vrai (II), la préposition transforme la collocation en adverbe de phrase portant sur la vérité de la proposition, introduisant une restriction équivalant à 'en réalitế. Vrai reste invariable. Dans le CW, dire vrai s'oppose à dire faux. Dans le troisième exemple, vrai reste invariable en tant que modifieur du verbe (malgré l'objet au féminin), tandis que dans le quatrième exemple, les adjectifs-adverbes s'accordent avec l'objet féminin pronominal antéposé au verbe, en se prêtant à une analyse de prédicat second orienté vers l'objet : dire que quelque chose est vrai. Dans les exemples de $\sim 1170$ et $1200 \mathrm{~b}$, voir est employé comme adjectif substantivé au sens de 'vérité' et est coordonné avec respectivement mançonge et merveilles, tous deux substantifs. Ceci constitue un argument en faveur des linguistes qui considèrent certains adjectifs-adverbes comme étant des « compléments légers » (v. Introduction $§ 6.3$ ). En effet, ceci est possible, du moins occasionnellement, avec des verbes fortement transitifs tels dire, faire. Il est intéressant d'observer que la coordination avec des substantifs est caractéristique de l'ancien français. On peut y ajouter le fait que l'afr. voir n'est jamais modifié. Par contre, son équivalent moderne vrai se combine facilement avec des adverbes de degré (bien, plus, trop). On peut en conclure que la perception de vrai est plutôt celle d'un adverbe, tandis que l'ancien français emploie voir (aussi) comme un « complément " que l'on peut coordonner avec des substantifs. Mentionnons également l'emploi de jouer petit ; mentir haut.

\section{Diriger bas}

Diriger vers le bas

$\lambda$ diriger haut

\section{Diriger droit}

I. (Se) diriger en suivant une ligne droite Transitif

1560 Maintenant ayant plus clairement revelé la grace de la vie future par l'Evangile, il dirige noz entendemens tout droit à la meditation d'icelle (Jean Calvin, Institution de la religion chrestienne)

1684 Cela fait que les rayons du Soleil, et des autres Astres, qui viennent de cette Region Etherée tres rare et tres pure, tombant obliquement sur l'Atmosphere, se rompent vers le rayon perpendiculaire, c'est à dire vers ce rayon que le Soleil dirige droit au centre de la Terre, qui est le mesme avec celuy de l'Atmosphere (François Bernier, Abrégé de la philosophie de Gassendi)

1937 Qu'a-t-elle [= Mouchette] en effet de commun avec ce que les gens appellent l'amour, et les gestes qu'elle sait ? Elle ne peut que continuer à diriger tout droit, sans trembler, le jet de la lampe sur la main blessée.

- Ouvre la porte, commande-t-il. Je m'en vas jeter les cendres (Georges Bernanos, Nouvelle Histoire de Mouchette) 
1989 Les bustes des quatre musiciens aux têtes d'épouvantails sont absolument droits, les quatre masques absolument parallèles aussi, leurs regards endormis d'aveugles dirigés droit devant eux (Claude Simon, L'Acacia)

Pronominal

1899 Puis, entraîné par le mouvement naturel de sa pensée, songeant qu'il faut, pour se diriger droit, le point de repère d'abord : « Il est des circonstances, » a-t-il dit [= le général Derrécagaix], " où la notion du juste s'obscurcit, où les caractères bien trempés hésitent » (Georges Clemenceau, Vers la réparation)

1966 Son sac en cuir se balançait au bout de sa main ; elle avançait comme si elle avait eu un moteur caché quelque part au fond de son corps. Sa face se dirigeant droit dans la direction du trottoir, les yeux mobiles, à demi dissimulés par les paupières et les cils, la bouche ouverte pour respirer, et la gorge palpitant régulièrement (Jean-Marie Gustave Le Clézio, Le Déluge)

II. (Se) diriger directement vers quelque chose/ quelqu'un

Transitif

1745 LA FLEUR. Moi.

LE MARQUIS. Mons de la Fleur, vous n'aurez plus la bourse.

Va.

LA FLEUR. Droit au cabinet dirigeons notre course.

Et vîte et vîte, allons nous payer par nos mains (Pierre Claude La Chaussée, L'École des mères)

1945 Le Survenant cessa de percher et Didace plaça les rames dans les tolets. Il venait d'apercevoir son canot de chasse, avec un homme à l'aviron. Il dirigea droit à lui l'embarcation qu'il colla à côté (Germaine Guèvremont, Le Survenant)

1946 Lalagüe, Récayte, qui aviez de si belles voix de soprano, Etchecopar le sentencieux, avare de paroles qui ne fussent pas dirigées droit sur l'essentiel, je ne vous ai pas oubliés, mes camarades ; et ce spec- tacle d'une belle race si fidèle à ses traditions me fut un réconfort dans l'humiliation (Francis Ambrière, Les Grandes Vacances)

2002 La cause principale était un acte de malveillance, dirigé spécifiquement contre elle. Une fenêtre en effet, un haut de fenêtre repliable, dirigeait droit sur elle un courant d'air tenace, pratiquement incessant (Jacques Roubaud, La Bibliothèque de Warburg)

Pronominal

1812 Il y avait déjà une heure que nous courions par un chemin uni qui se dirigeait droit au sud-est, lorsqu'au lever de l'aurore, j'aperçus quelques débris et un long mur de construction antique : le cœur commence à me battre (François de Chateaubriand, Itinéraire de Paris à Jérusalem)

1846 En ce moment, il vit briller comme une étoile le phare de Planier. En se dirigeant droit sur ce phare, il laissait l'île de Tiboulen un peu à gauche ; en appuyant un peu à gauche, il devait donc rencontrer cette île sur son chemin (Alexandre Dumas père, Le Comte de Monte-Christo)

1859 Nous suivons donc la procession chantante par toutes les allées, en nous dirigeant tout droit à travers le jardin vers la solitude, dont nous connaissons la porte rouge : là nous tournons à droite vers les fraisiers, nous passons le pont proche du glacis pour continuer de cheminer tout le long de l'allée de l'ormois jusqu'à la porte à barreaux, par laquelle, rentrés dans le jardin, nous faisons, malgré son vilain nom, toute l'allée des crapauds (Charles Sainte-Beuve, Port-Royal)

1885 Cet homme achevait de boutonner son collet en se dirigeant droit du côté d'Hubert. Ce dernier s'avança aussi et frôla l'inconnu (Paul Bourget, Cruelle Énigme)

1909 À travers le silence des salles d'en haut, voici que nous nous dirigeons maintenant tout droit vers ceux et celles à qui j'ai demandé audience nocturne (Pierre Loti, La Mort de Philæ) 
1967 Le corps a sa voix, le cœur la sienne. Pascal sortait du Gimère-III. Il se dirigeait tout droit vers la table de son ami Vincent. Elle ne le reconnut pas sur-le-champ (Jean-Pierre Chabrol, Je t'aimerai sans vergogne)

1973 Mais le véhicule a fini par me dépasser, un peu avant Alésia et s'est arrêté près du trottoir, dix mètres devant moi, et la portière s'est entrouverte. Je me suis dirigé droit dessus. C'est comme ça qu'on se fait tuer au cinéma. J'ai ouvert la portière et personne ne m'a vidé son chargeur dans les viscères (Jean-Patrick Manchette, Morgue pleine)

2006 Mais ce dernier, après s'être assuré de son départ, au lieu d'escalader les étages, sembla se raviser, se dirigea tout droit vers la loge et y cogna du poing (Anne-Marie Garat, Dans la main du diable)

\section{CORPuS WeB :}

A Destin (Floride), deux touristes étaient en train de baigner à quelques mètres de la plage et n'ont pas vu un requin-marteau qui se dirigeait droit vers eux [http://reunion.orange.fr/ loisirs/videos-reunion/actu-et-politique/deuxbaigneurs-ne-voient-pas-un-requin-se-dirigerdroit-vers-eux.html] (6.2.2015)

L'avion peut se faire tirer par la station ellemême (VDF) dont l'opérateur au sol donne une information radiophonique des caps à prendre pour pouvoir se diriger droit vers la verticale de cette station [http://home.nordnet.fr/dmorieux/ homing.htm] (6.2.2015)

Comme tous les sauts de valse, la clé est au moment du décollage. Glissez sur longue carre arrière droite sans forcer du haut du corps. On voit souvent des gens tirer leur côté gauche vers l'arrière et balancer la jambe en rond plutôt que de la diriger droit devant et en haut [http:// fr.wikipedia.org/wiki/Saut_de_valse] (6.2.2015)

Harry a craché dehors le mot Tom comme une malédiction. Rapidement il a saisi sa baguette magique hors de sa poche, la dirigeant droite chez Voldemort. Mais Voldemort n'a pas semblé s'inquiéter, au lieu de cela ses yeux snakelike débarqués sur les amis de Harry [http://poudlardfutur.nice-board.com/t6p15fanfics-d-harry-potter] (6.2.2015)
REMARQues : (Se) diriger droit (I) désigne le fait d'orienter quelque chose ou de s'orienter vers un but déterminé, le déplacement étant effectué en ligne parfaitement droite. Dans son emploi transitif, l'objet désigne souvent un faisceau ou un rayon de lumière, dont la lueur éclaire de manière longitudinale. En (II), il réfère au fait de diriger ou de conduire, de guider ou de manœuvrer quelque chose directement vers une personne ou un lieu précis. Dans cette acception, droit est toujours suivi d'une préposition (à, vers, sur, etc.) avec laquelle il s'associe au point de faire partie du groupe prépositionnel comme modifieur de la préposition. Droit reste invariable et est modifié par l'adverbe d'intensité tout. Dans le dernier exemple du CW, droit s'accorde avec l'objet. Sans plus de contexte, on ne saurait dire s'il garde son interprétation directionnelle ou s'il désigne la position verticale de la baguette, mais, dans un tel contexte, la baguette magique est habituellement dirigée vers la cible. Droit maintiendrait donc son sens directionnel malgré l'accord. VOIR AUSSI : aller droit

\section{Diriger haut}

S'exercer à un haut niveau hiérarchique Transitif

1815 Ainsi les hommes faibles et les hommes raisonnables, les hommes vénaux et les hommes scrupuleux, se trouveront engagés par des motifs différents à ménager les dépositaires infidèles de l'autorité exécutive. La responsabilité sera nulle, parce qu'elle aura été dirigée trop haut (Benjamin Constant, Principes de politique)

\section{CORPUS WEB :}

Il conclu rapidement que plus on utilisait de cordes plus on projetait l'éclair loin, plus la note était haute plus il était dirigé haut (de bas en haut), les cordes étant de plus en plus aiguës de gauche à droite. Donc corde du milieu grattée rapidement : tir droit devant à hauteur d'homme (buste) $5 \mathrm{~m}$. corde de gauche (basse) grattée rapidement : tir vers le bas (pied) corde de droite (aigüe) grattée rapidement : tir vers le haut (tête) [http://donjonsetdragons.net/viewtopic. php?f=89\&t=844\&start=20] (6.2.2015)

une cartouche tirant 70 plombs est de la simple grenaille « pas réellement dangereuse » 
quoi que si le tube avait été dirigé haut vers la tête... ca serais une autre histoire il s'agit pas d'un tir au double zéro !!!! [http://www.leparisien.fr/ faits-divers/elle-fait-ses-courses-a-la-ferme-etrecoit-70-tirs-de-plombs-13-08-2009-605800.php] (6.2.2015)

« Avancez, » James a indiqué, obtenant à ses pieds, « nous passerons par cette porte. » Il s'est dirigé haut vers le haut de quelques escaliers. «Et laisse juste l'espoir que j'ai sélectionné le droit » [http://poudlardfutur.nice-board.com/t16p45prongs-rides-again] (6.2.2015)

J'ai toujours eu des problèmes avec mes potences. Et j'en ai eu ! 90, 95, 100, 110 j'ai du mal à me decider. Je viens d'avoir pour mes 60 ans un giant defy advanced 3 taille $\mathrm{M}$ et la potence est une 100. La façon dont elle est mise elle fait $104 \mathrm{~mm}$. Tout dépend si elle est dirigée haut ou bas [http://www.velo101.com/forum/voirsujet/ potence-95mm-14801] (6.2.2015)

REMARQUES : Au sens figuré, diriger haut désigne le fait d'assumer les responsabilités d'un pouvoir, d'un commandement à un haut niveau hiérarchique. Haut reste invariable et est modifié par trop. Dans le CW, haut y figure dans son sens concret directionnel. Il reste invariable, malgré le sujet au féminin dans le dernier exemple, tout comme l'adjectif-adverbe bas, avec lequel il est mis en opposition.

\section{Discuter ferme}

Discuter avec énergie, âpreté

Intransitif

1885 On discutait ferme, et un chef d'orchestre fameux, très ardent pour l'œuvre de Wagner (mettons qu'il soit d'Italie) prenait à partie un de nos jeunes confrères (Le Ménestrel)

1936 Cadieux, qui descendait, passa en coup de vent :

- Tu ne montes pas ? Ça discute ferme, là-haut... C'est intéressant : il y a un Autrichien, en mission, le camarade Boehm, qui arrive de Vienne... Il dit que la note autrichienne sera remise ce soir à Belgrade... aussitôt que Poincaré aura quitté Pétersbourg (Roger Martin du Gard, Les Thibault. L'Été 1914)
1958 Nous lui passâmes cette niaiserie. Mais nous n'étions pas toujours aussi accommodantes ; quand un sujet nous intéressait nous discutions ferme. Nous respections beaucoup de choses; nous pensions que les mots patrie, devoir, bien, mal, avaient un sens ; nous cherchions simplement à le définir (Simone de Beauvoir, Mémoires d'une jeune fille rangée)

1996a Essoufflés, nous nous sommes cachés derrière un porche. Des passants se retournaient. Boris et moi voyions nos parents qui discutaient ferme. Et maman, avançant dans cette rue avec ses « Boria, Boria! », tandis que notre père attendait. Nous sommes sortis de derrière notre porche (Boris Schreiber, Un silence d'environ une demi-heure)

1996b Pire encore : cet espoir ne nous alléchait plus. Peut-être fallait-il argumenter ? Le premier pas dans l'aventure, n'était-ce pas plus grisant que dans les normes? Discuter ferme. Elle aurait cédé. Alors? Andrée ouvrit son sac de plage, y prit une feuille qu'elle nous tendit :

- Mon nom et mon adresse. Je voudrais les vôtres, en retour

(Boris Schreiber, Un silence d'environ une demi-heure)

2002 Président du PINGO (Coordination des organisations non gouvernementales palestiniennes), le canon pointé vers la rue par où nous arrivions. Il a fallu discuter ferme pour que ne soit pas refoulé le médecin palestinien, spécialiste en dermatologie, qui nous accompagnait (François Maspero, Les Abeilles et la guêpe)

2005 On lit le compte rendu, on le critique pour la forme et le fond, on pose des questions au lecteur, on propose des rectifications, etc. On discute ferme des mérites du texte, des problèmes existentiels qu'il pose, on le compare à d'autres textes lus précédemment (Philippe Lejeune, Signes de vie)

Transitif

1985 Heureusement, j'avais une certaine habileté pour les soins et j'étais sérieuse dans 
mon travail. En salle de garde, on me discutait ferme, on mettait en boîte la jeune externe qui était en analyse prolongée et qui, à l'hôpital, parlait aux bébés

(Françoise Dolto, La Cause des enfants)

\section{CORPUS WEB :}

« Le douanier m’a indiqué que je n'étais pas en règle, j'ai dû discuter ferme pour qu'il consente à déplacer les plots sur la chaussée pour me faire reprendre la voie de sortie sans m'acquitter de la vignette et me rendre à la piscine par l'ancienne douane »[http://www.estrepublicain. $\mathrm{fr} /$ insolite/2014/12/17/indispensable-vignette (6.2.2015)

L'autre grand cheval de bataille de PSA est bien entendu l'annualisation du temps de travail. Il s'agirait de calculer le temps de travail sur une année entière afin d'intégrer de manière plus souple les aléas de l'activité (un peu comme les cycles agricoles autrefois). Autant prévoir que cela va discuter ferme dans les semaines à venir... [http://www.caradisiac.com/Actu-del-eco-PSA-propose-un-gel-des-salaires-a-sessalaries-89084.htm] (6.2.2015)

Faut les discuter ferme les contrats à st trop ! et c'est surtout difficile mentalement donc, apres faut se reposer ! [http://forum.elprofessor.com/ index.php?topic=9210.15;wap2] (6.2.2015)

Mais je peux vous assurer qu'ils discutent fermes pour trouver des solutions qui puissent relativement réunir tout le monde et qu'ils s'intéressent aux impressions de ceux qui se déplacent pour les shows [http://www.painthorseforum. com/t4747p45-mooslargue] (6.2.2015)

REMARQUes : Discuter ferme désigne le fait de parler avec d'autres en échangeant des idées, des arguments sur un même point, les sujets s'exprimant vivement, voire rudement les uns envers les autres. Dans son emploi transitif, il peut désigner le fait de mettre en doute avec rigueur les compétences de quelqu'un (ex. de 1985). Ferme tend à l'invariabilité. Toutefois, il s'accorde avec le sujet au pluriel dans le dernier exemple du CW, insistant ainsi sur l'attitude du sujet. VoIR AUSSI : disputer ferme

\section{Disputer ferme}

Disputer de manière décidée, résolue, tenace

Pronominal

1943 On se dispute ferme dans le grand monde et alors en avant les âneries (Robert Desnos, Le Vin est tiré...)

1976 Je l'aimais beaucoup. Je me disputais ferme avec lui. Je lui reprochais son mauvais goût en littérature, son indifférence au «style » et le côté bergerie libertaire de sa philosophie (Claude Roy, Somme toute)

2009 Mon père était d'un naturel anxieux. Il n'avait pas accueilli la nouvelle de notre voyage en France avec beaucoup d'enthousiasme. Au contraire, je l'avais entendu se disputer ferme avec maman à ce sujet. Mes parents étaient divorcés depuis deux ans et les vieilles rancœurs refaisaient vite surface lors des grandes décisions me concernant (Angélique Isselin, Ses yeux comme des miroirs)

2012 « Je ne l'ai vue qu'une fois. À la boutique avec Romain. Une présence exceptionnelle. Je ne me souviens plus s'il me l'avait présentée ou non. Je venais juste d'ouvrir le magasin et, ce jour-là, quand ils étaient passés, mes deux premiers clients (pour ainsi dire) se disputaient ferme le même bibelot, au point que j'avais dû les séparer avant qu'ils ne me rompent quelque objet dans la boutique... » (Robert Deleuse, Un dernier coup de théâtre)

\section{CORPuS Web :}

Groupe assez simple pour ManU, qui devrait se qualifier sans soucis. $\mathrm{Ca}$ devrait par contre se disputer ferme pour la deuxième place, mais je vois tout de même les Russes devant [http://www. allocine.fr/communaute/forum/voirmessage gen_refmessage $=15119853 \&$ nofil $=581228 . \mathrm{html}]$ (9.2.2015)

C'est le collectif qui distingue le Maccabi. Haïfa ne dispose pas de vedettes au talent inné, comme Vermouth ou Shechter, à l'Hapoël TelAviv, qui brille en Europa League (l'autre coupe européenne), et qui est bien décidé à disputer ferme le titre de champion d'Israël à Haïfa cette saison [http://www.metulanews.net/article. php?sid=2541] (9.2.2015) 
Les 4 équipes remaniées de la catégorie Atome se disputent ferme les honneurs du championnat terminant les matchs par des marges très serrées [http://www.ahmverdun.com/Nouvelles/ Saison\%202010-2011/2011-03-21\%20les $\% 20$ jeunes $\% 20$ hockeyeurs $\% 20$ verdunois $\% 20$ aux $\% 20$ championnats $\% 20$ maison.htm ] (9.2.2015)

«Messire Cadenwarr, en ces temps troublés où les grands disputent fermes, recevez toutes mes bénédictions quant à votre mariage et votre descendance à venir. » (Il s'inclina légèrement.) $\mathrm{Si}$ je puis m'atteler à un quelconque projet ayant rapport avec vos enfants ou votre ravissante et jeune épousée, j'ouvrerais avec diligence » [http://retrahant.forumactif.com/t3380p1mariage-royal] (9.2.2015)

RemARQues : Disputer ferme désigne le fait d'avoir une discussion vigoureuse, de débattre avec fermeté, les sujets dénotant de l'assurance et de la résolution. Dans l'emploi pronominal (le plus courant aujourd'hui), disputer ferme réfère à une querelle énergique, vive et réciproque. Pour la collocation fort et ferme, v. disputer fort. Ferme tend à l'invariabilité. Dans le $\mathrm{CW}$, ferme reste invariable dans le troisième exemple malgré le sujet au pluriel, tandis qu'il s'accorde avec le sujet dans le dernier exemple, ce qui le rapproche des prédicats seconds orientés vers le sujet. Le CW met en évidence l'emploi dans le domaine du sport où l'on (se) dispute une victoire. Disputer ferme est transitif dans le second exemple du CW. L'emploi absolu apparaît dans le dernier exemple. VoIR AUSSI : discuter ferme

\section{Disputer fort}

I. Disputer, débattre énergiquement, vivement Transitif

1602 Laffaire feust fort disputée de part et d'aultre et ne passa qu'à fleur de corde, car si bien quelques ungz estoyent retenuz de bon zeelle pour ne passer pas outre à la veriffication, ce neanmoingz plusieurs aultres n'en estoient pas d'advis pour d'aultres considerations de moingz de mise, entre lesquelz aucungz avoyent esté d'advis de la veriffication dez la derniere foys qu'on fit l'arrest des remonstrances, lesquelz maintenant estoyent d'advis contraire pour ce que les choses avoyent changé de face, et qu'il y avoit de nouveaux interestz sur le tapis (Nicolas de Peiresc, Lettres à sa famille)

Intransitif

1624 Puisque pour croire en Dieu chacun choisit sa forme,

Et que l'on trouve bon qu'en ce point la loy dorme,

Qu'on ne craint pas icy les inquisitions,

Et qu'on dispute fort sur les traditions,

Que le livre est ouvert où le salut se puise,

Et qu'on voit que chacun l'interprete à sa guise,

Estans par ce moyen de nostre sens conduits,

Je vous laisse à penser où nous sommes reduits,

S'il y a pas autant comme il y a de testes

D'opinions, d'erreurs, excitans des

tempestes,

Et des brouillars obscurs qui ostent à nos yeux,

Il y a trop long tens, le droict chemin des cieux

(Jacques Du Lorens, Premières satires)

1627 Quelques escoliers les soustiendront, et l'on disputera contre eux fort et ferme pour s'exercer l'esprit, et afin que la verité sorte de cette altercation, comme faict une estincelle de feu du heurt de deux cailloux (Charles Sorel, Le Berger extravagant)

1710 Quant à la destination des élus à la vie éternelle, les protestants aussi bien que ceux de l'Église romaine, disputent fort entre eux si l'élection est absolue, ou si elle est fondée sur la prévision de la foi vive finale (Gottfried Leibniz, Essais de théodicée sur la bonté de Dieu)

1749 Ce château ne faisoit presque que sortir de terre, lorsque le roi s'aperçut d'un défaut à une croisée qui s'achevoit de former dans la longueur du rez-de-chaussée. Louvois, qui étoit brutal, et gâté jusqu’à souffrir difficilement d'être repris par son maître, disputa fort et ferme, et soutint 
que la croisée étoit bien (Saint-Simon, Mé moires complets et authentiques du duc de Saint-Simon sur le siècle de Louis XIV et la Régence [1739-1749])

2013 Ah ! nous étions fort loin des sermons incompréhensibles en dialecte taïwanais des églises de Tamsui, mais emportés $\mathrm{au} \mathrm{IV}$ e siècle à l'époque où les pères de l'Église disputaient fort contre d'autres saints hommes - parce que je ne vois pas pourquoi on ne respecterait pas Origène ou Pélage pour leurs efforts (Amélie de La Musardière, Professeur à Tä̈wan)

II. Se quereller

Pronominal

1854 dans l'une d'elles [= chambres] des matelots bronzés et hâlés [...] jouaient avec des cartes rondes représentant des lunes, des croissants, des sabres, des soleils et des étoiles ; des coquilles blanches servaient de jetons. On criait haut et l'on se disputait fort (Maxime Du Camp, Le Nil. Égypte et Nubie)

1863 Victor qui a lu des pages çà et là est dans le ravissement, il ne pouvait ce matin s'arracher du livre, et nous nous sommes fort disputés à qui l'aurait, ma majesté l'a emporté, mais c'est un coup d'état et un acte de tyrannie (Victor Hugo, Correspondance)

2006 - Il y avait des disputes à la maison et tout ça?

- Ouais des trucs comme ça.

- Oui, j’ai connu ça aussi.

- Tapage nocturne.

- Ah, ils se disputaient fort

(Lionel Thelen, L’Exil de soi)

CoRpus Web :

Arrêtez de faire des HS, on va se faire disputer fort après [http://battlelog.battlefield.com/bf4/ fr/forum/threadview/2979150493936541431/2] (9.2.2015)

Et pourtant, par la magie du téléphone, alors que j’appelais simplement pour demander justement 'Ça va ?', et dire 'Ici... Ça va, rien de nouveau, donc ça va', je me suis fait disputer fort, même très très fort par une petite voix, à trois cent soixante-cinq kilomètres de moi, parce que je tousse et que je ne vais pas voir le docteur et que ce n'est pas bien' [http://sylvainbarraux.net/ blog/category/une-histoire] (9.2.2015)

Non, rassure toi, tu n'es pas la seule. Je viens de tomber sur ton blog parceque justement, je me demande ce que cela fait à un bébé de 7 mois de voir ou d'entendre ses parents se disputer fort. Avec un haut volume sonore. Ou avec une grosse grosse tension rentrée quand on essaye de ne pas crier [http://unblogunemaman.blogspot.co.at/ 2008/12/pas-devant-les-enfants.html] (9.2.2015)

Remarques : Disputer fort (I) désigne le fait d'avoir une discussion énergique, de débattre avec fermeté, les sujets dénotant de l'assurance et de la résolution. Dans son emploi pronominal (le plus courant aujourd'hui), il réfère à une querelle vive et réciproque (II). Notons la collocation fort et ferme et l'emploi de crier haut, soulignant l'idée de dynamisme de la discussion. Fort reste invariable. Notons que l'emploi de disputer fort s'applique surtout aux querelles entre parents, entre parents et enfants ou entre mari et femme. Les deux premiers exemples du CW contiennent la variante se faire disputer. Fort est modifié par très. Mentionnons également l'emploi de crier haut.

\section{Donner cher}

I. (au figuré) donner cher pour : donner beaucoup, désirer ardemment

Emploi absolu

1882 Avec un singulier serrement de cœur, je voyais s'envoler ces derniers moments de notre dernière soirée. - J'attendais avec une inexplicable anxiété ; j'aurais donné cher à cet instant pour voir cette créature, dont j'avais rêvé dans mon enfance, et qui était liée au lointain et poétique souvenir de Rouéri (Pierre Loti, Le Mariage de Loti)

1933 Rien qu'à penser le mot de parapluie, une salive de bonne volonté leur venait à la bouche, ils auraient donné bien cher pour l'avoir encore son parapluie (et si le vieux avait essayé de sortir de sa tombe, ils l'auraient peut-être fait rentrer à coups de soulier sur la tête) (Marcel Aymé, $L a$ Jument verte) 
1956 Néanmoins on était persuadé qu’il y avait réellement un monde d'oiseaux qui passaient avec une rapidité déconcertante à des moments où seul Timard levait le nez. - Je donnerais cher pour toucher un de ces oiseaux, disait Timard.

- Les Dassigne sont cette fois complètement ruinés, répondait Fortan.

C'était vers le début de février (André Dhôtel, Le Ciel du faubourg)

1984 On s'en est d'ailleurs vite aperçus, que c'était bruyant, parce que ce soir-là, justement (« Justement ! » jubilait Proccema), ma belle-mère a téléphoné, et... « Fantastique. Je donnerais cher pour qu'il bosse avec moi, ce Rima falot!»

- Eh bien, monsieur Rima, je vous remercie (Anne Vergne, L'Innocence du boucher)

2004 Que vous ayez un mot gentil. Lorsque vous sortez entre amis, vous discutez ensemble alors pourquoi n'est-ce pas la même chose avec moi ? Je donnerais cher pour savoir ce que vous apprenez, ce que vous faites, si vous avez passé un bon après-midi (Valérie Mréjen, Eau sauvage)

II. ne pas donner cher de : ne pas donner de garantie sur (notamment dans l'expression je ne donne pas cher de sa peau 'je pense qu'il / elle va mourir')

Emploi absolu

1886 c'est à cause d'eux que l'empereur a voulu permettre au public de réviser le procès ; ce sont eux enfin qui triomphent... ah ! J'en entends de belles, je ne donnerais pas cher de vos peaux, jeunes gens! Il riait de son grand rire, les bras ouverts, comme pour embrasser toute la jeunesse qu'il sentait monter du sol (Émile Zola, L’Euvre)

1912 Jamais !... et si tu découvres cet autre-là, comme tu m'as découvert, un autre viendra, et un autre ! Et un autre ! Jusqu'à ce que ce Trébassof paie ses crimes ! C'est tout ce que j'ai à te dire, Koupriane !... quant à vous, mon petit, ajouta-t-il en se tournant vers Rouletabille, je ne donnerais pas cher de vos os! Nous ne valons guère mieux tous les deux. Et c'est ce qui me console! (Gaston Leroux, Rouletabille chez le tsar)

1968 Il doit traîner quelque part au fond d'un tiroir une photo de moi oubliée de tous, que Bettina exhumera, agrandira, encadrera. Elle lui vouera un culte. Je ne donne pas cher, moi mort, de la peau de ses amoureux. Comparé à moi aucun ne vaudra la corde pour le pendre (François Nourissier, Le Maître de maison)

1988 Toi, tu risques soit de te faire plomber, soit de terminer en taule. Moi... s'ils estiment que tu m'as tout raconté, et ils n'auront pas tort, je donne pas cher de mes abattis... La seconde diskette, c'est toi qui l'as ? (Jean-Bernard Pouy, La Clef des mensonges)

1993 Je ne donne pas cher non plus de l'École des Beaux-Arts. Un jour, on déplacera les Matisse en herbe sur le plateau de Saclay entre Polytechnique et les Hautes Études Commerciales (Éric Orsenna, Grand Amour)

2006 Ils n'étaient pas des amis, juste des associés. J'ai mis Jean en garde : je ne donnais pas cher de son collègue, moi. Mais il était entiché de lui, vraiment. Que s'est-il passé, une fois là-bas ? (Anne-Marie Garat, Dans la main du diable)

III. Payer cher

Emploi absolu

1936 C'était au fond de la cheminée qu'elle garait la Remington qu'elle l'avait pas fini de payer... Soi-disant. Je donne pas cher pour mes copies, c'est exact, encore... soixante-cinq centimes la page, mais ça cube quand même à la fin... Surtout avec des gros volumes (Louis-Ferdinand Céline, Mort à crédit)

IV. S’investir beaucoup, faire un effort Emploi absolu

1994 En conclusion, Minvelle laissait percer son pessimisme mais n'abandonnait pas la partie. Il était toujours aussi enthousiaste, prêt à donner très cher de lui-même pour apprendre comment Arnaud de Beltram 
et son escorte avaient bien pu quitter Menzalé et se faufiler entre les lignes ennemies en ce début d'été de l'an 1226 (Jacques Lanzmann, La Horde d'or)

\section{CoRpus Web :}

On pourrait ne pas donner cher de la peau de David Ferrer en finale de Bercy [http://www. eurosport.fr/tennis/paris-bercy/2013/bercy-2013les-chiffres-a-savoir-avant-la-finale-djokovicferrer_sto3990917/story.shtml] (10.2.2015)

@Mastakilomaitre @melanie_diams j’aurai donner cher pour vivre ca en studio pendant qu'elle pause son " vous etes trop gentille gentille » [https://twitter.com/romainjeunot/status/ 519042736662773761] (10.2.2015)

Deux jeunes hommes, convaincus de la fidélité des deux sœurs qu'ils avaient fiancées, font un pari avec l'un de leurs amis, un vieux célibataire, qui ne semble pas vouloir donner cher de la fidélité féminine [http://www.corsenetinfos. fr/Ouverture-du-4eme-Festival-Lyrique-de-Calvi_ a4322.html] (10.2.2015)

Si le PSG avait fini 18e, je n'aurais pas donner chère de la peau des Grenoblois [http://www. vaenl1.com/forum/viewtopic.php?f=11\&t=15303] (10.2.2015)

REMARQUES : Au conditionnel, donner cher pour (I) renvoie au fait de souhaiter vivement quelque chose, d'être prêt à faire d'énormes concessions pour obtenir l'objet souhaité. En (II), l'expression ne pas donner cher de se dit quand le sujet n'est pas prêt à donner des garanties sur quelque chose, notamment sur la vie ("la peau ») de quelqu'un. Il renvoie alors au fait d'être persuadé que quelque chose n'a pas d'avenir, pas de chance de fonctionner et, par extension, de ne pas être prêt à y investir son argent, à parier là-dessus. Donner cher (III) désigne le fait de donner beaucoup d'argent pour quelque chose, d'accorder une grande importance à quelque chose, cher se référant à sa valeur. (IV) désigne l'engagement fort d'une personne. Cher reste invariable et est modifié par bien, très. Dans le CW, cher reste également invariable, à l'exception du dernier exemple, où il s'accorde avec le complément indirect (la peau), mais l'orthographe générale de l'exemple ne permet pas d'y voir un effort stylistique. Notons aussi que donner est un verbe dit trivalent qui s'emploie avec un objet direct et un objet indirect (donner quelque chose à quelqu'un), alors que dans les exemples le seul actant est le sujet (emploi monovalent). Il tend donc à l'emploi absolu quand un adjectif-adverbe le modifie.

\section{Donner gagné}

Donner raison, reconnaître

Emploi absolu

1560 Je respon que si le Juge signifie Dieu en ce passage, la partie adverse signifie le diable, le sergeant un Ange, la prison purgatoire, je leur donne gagné (Jean Calvin, Institution de la religion chrestienne)

1645 BEATRIS. Or si vous en tirez la moindre lachrymule, Je vous donne gagné, foy de Beatricule, Vous riez Dom Louis de ce diminutif, Dame nous en usons, et du superlatif (Paul Scarron, Le Jodelet)

1654a Ainsi il [= Victorius] intente un proces contre une possession de seize cens ans ; ne considere ni la faveur d'Auguste, ni l'amitié de Mecenas, ni les applaudissemens de tous les siecles, ni toutes les voix de la renommée, qui donnent gagné à sa partie (Jean-Louis Guez de Balzac, Dissertations chrestiennes et morales)

1654b Mais quand je dis joli, je ne donne pas gagné pour cela, à l'autre que je dis beau : je me conforme seulement à l'opinion d'Aristote, qui assignant à chaque chose les termes qui luy sont propres (Jean-Louis Guez de Balzac, Dissertations critiques)

1734 D'un autre côté, cet honneur plaidait sa cause dans mon âme embarrassée, pendant que ma cupidité y plaidait la sienne. À qui est-ce des deux que je donnerai gagné ? Disais-je ; je ne savais auquel entendre. L'honneur me disait : « tiens-toi ferme » ; déteste ces misérables avantages qu'on te propose ; ils perdront tous leurs charmes quand tu auras épousé Geneviève (Pierre de Marivaux, Le Paysan parvenu)

1824 Nous étions d'une gaîté folle, et, selon ma coutume, c'était moi qui donnais le ton. On parla des prouesses de certains 
mangeurs d'huîtres détérminés. Je fis le pari, pour ma part, d'en manger cent douzaines. Le pari fut tenu, et voilà les ouvreuses à l'œuvre. L'hôte me conseilla de boire du lait au lieu de vin ; j'y consentis, et j'entrai en besogne. J'avais déjà avalé les deux tiers de mes cent douzaines sans que rien annonçât que je serais forcé de lâcher le pied, et j'avalais encore ; mais mes camarades me donnèrent gagné, et ne voulurent absolument pas que j'allasse audelà, comme j'insistais à le faire pour l'acquit de ma forfanterie (Bernard Fonvielle, Mémoires historiques)

1850 Cette dernière bonne raison donna gagné à Madeleine (George Sand, François le Champi)

1936 Car je semble donner gagné à ceux qui disent que la guerre est dans la nature humaine et durera autant que les hommes (Alain, Propos)

Transitif

1563 Quant au premier poinct, je te le donne gagné, mais quant est de ce que tu dis, qu'il est requis un lieu montueux pour edifier jardins, je ne puis à ce accorder (Bernard Palissy, Recepte veritable)

\section{CORpus Web :}

Les Caennais ont toutes les cartes en main pour aller au bout. Ils comptent un match de moins, face à Nîmes, que la Ligue vient de leur donner gagné sur tapis vert, l'appel des Crocos au CNOSF étant probablement vain [http://www. lamontagne.fr/auvergne/sports/actualite/foot ball/2014/04/14/embouteillages-serres-a-tousles-etages_1964763-6671.html] (10.2.2015)

Une petite incompréhension demeure cependant, à savoir pourquoi le match a été reporté dans un premier temps, pour ensuite le donner gagné par forfait? [http://ascm-foot.footeo.com/ actualite/2013/01/04/c-est-reparti-mon-kiki. html?sf_culture=fr] (10.2.2015)

Inconnu dans l'Ouest, sans profondes racines dans ce parti, M. Mulcair avait hésité à se lancer dans cette course que l'on donnait gagnée d'avance à Brian Topp [http://fr.canoe. ca/cgi-bin/imprimer.cgi?id=1141901] (10.2.2015)
REMARQUES : Donner gagné se dit d'une personne qui reconnaît que son adversaire l'emporte, qu'il a gagné, ou simplement qu'il a raison. Gagné reste invariable, sauf dans le dernier exemple du CW, où il est accordé avec l'objet au féminin, ce qui le rapproche d'un prédicat second orienté vers l'objet. Le CW montre l'emploi préférentiel dans le langage du sport.

\section{Donner gros}

I. Donner beaucoup d'argent

Emploi absolu

1749 À la fin, et à force de donner gros, le marché fut conclu (Saint-Simon, Mémoires complets et authentiques du duc de SaintSimon sur le siècle de Louis XIV et la Régence [1739-1749])

1756 le Roi donne gros à la compagnie des Indes pour cette entreprise (René-Louis d'Argenson, Journal et mémoires)

1945 Tu me payeras, je suppose, la semaine des quat'jeudis. Et haut : « Moi, Emma Philibert, je suis pas assez bête pour me faire prendre, va ! Je donne pas gros comme mon petit doigt » (Gabrielle Roy, Bonheur d'occasion)

II. Donner beaucoup, payer cher (au figuré) Emploi absolu

1769 Je suis las de ce métier, et vous conviendrez que c'est le plus plat métier qu'il y ait au monde que celui de lire tous les plats ouvrages qui paroissent. On me donneroit aussi gros d'or que moi, et je ne suis pas des plus minces, que je ne voudrois pas continuer (Denis Diderot, Lettres à Sophie Volland)

1862 L'ex-horloger aurait donné gros pour reprendre ses anciennes occupations (Paul Reider, Mademoiselle Vallantin)

1877 Je donnerais gros pour être à sa place (Émile Zola, L’Assommoir)

1925 Il réfléchissait, ou plutôt il en revenait toujours à ceci, qu'il eût donné gros pour voir Anne-Marie pourvue d'un parti sortable (Henri Pourrat, L'Auberge de la Belle Bergère ou Quand Gaspard de guerre revint) 
1943 - Je te réponds qu'elles donneraient gros, ces petites bonnes femmes, pour ressembler à Harbley ou à Bouget, dit Elizabeth avec aigreur (Simone de Beauvoir, L'Invitée)

1955 De ces lacunes obsédantes - lésions qui sont cause d'inquiétude et qu'il faudrait réparer pour avoir le sentiment euphorique de se posséder en totalité - l'une, peutêtre, me fait sentir son vide de manière un peu plus gênante que les autres et je donnerais gros pour parvenir à la combler (Michel Leiris, La Règle du jeu 2 : Fourbis)

1972 Pas question de labeur honnête, notre vie fallait bien qu'on la vole. À la sueur de nos tripes ! C'est ce qui nous manquait le plus, un bon boulot peinard. On aurait donné gros pour s'établir citoyens modèles. Un petit commerce, tenez... Une rue calme dans un coin chic. Que des hôtels particuliers classés monuments historiques... (Bertrand Blier, Les Valseuses)

III. ne pas donner gros de : ne pas donner de garantie

Emploi absolu

1936 Les voisins eux s'en occupaient, ils se sur passaient en conseils... Ils donnaient pas gros de ma carrière... Même le gardien du Passage, il m'était défavorable... Il rentrait dans toutes les boutiques, au moment de son allumage. Il colportait les ragots. Il répétait à tout le monde que je finirais hareng saure (Louis-Ferdinand Céline, Mort à crédit)

IV. S'investir beaucoup, faire un effort

Emploi absolu

1946 Elle crée et donne sans compter parce qu'elle porte en elle, sinon de la ressource pour donner toujours plus gros, du moins du mouvement pour aller toujours plus loin. Mais en même temps, elle sait pourquoi elle donne, à qui elle donne, et pourquoi surabondamment (Emmanuel Mounier, Traité du caractère)

\section{CORPUS WEB :}

Perso en soft j'utilise maxxbass de chez waves tu peux au choix faire ressortir la frappe ou la basse du kick, pour le metal c'est bien de pouvoir faire les 2, mais si il faut choisir j'préfère la frappe (entre 150 et 200hz généralement) qui va donner gros d'impact à ta gc [http:// fr.audiofanzine.com/techniques-du-son/forums/ t.84760,gros-kick.html] (10.2.2015)

Quelques minutes à peine avant le premier match de Thomas Vanek avec l'équipe, hier soir en Arizona, le directeur général du Canadien a tenu à dire qu'il avait eu à donner gros afin d'aller chercher l'attaquant mécontent des Islanders de New York [http://www.lapresse.ca/sports/ hockey/201403/07/01-4745435-marc-bergevinavait-thomas-vanek-a-loeil.php] (10.2.2015)

De plus, vu leur puissance, c'est un peu normal qui faut donner gros pour les invoquer, c'est impossible de faire la 3ème mission sans s'entrainer par exemple, sauf si on utilise Shiva, et là, elle bat les monstres en deux, trois coups [http://khisland.info/forum-2-241-5-final-fantasytype-0--discussions-impressions.html?PHPS $E S S I D=88 d 5976 f 1 f 6283 b 4 b 7745 d f 4 a 6 b 34173$ ] (10.2.2015)

REMARQuES : Donner gros reprend exactement la polysémie de donner cher (v. ci-dessus). Notons la comparaison donner gros comme le petit doigt. Les collocations gros d'or, gros d'argent (s.v. devoir gros), gros d'impact montrent sa grammaticalisation comme quantifieur équivalent à beaucoup. C'est aussi la fonction qui prévaut dans les deux derniers exemples du CW, où donner gros signifie 'donner beaucoup de soi-même'. Gros est invariable. Il est modifié par aussi, toujours plus.

\section{Donner juste}

Donner peu, donner juste ce qu'il convient Emploi absolu

1963 Mais nous le faisons toutes [= gratter sur les comptes du ménage], dit-elle, comment veux-tu qu'on s'en tire autrement ? Ils [= les maris] nous donnent trop juste (Christiane Rochefort, Les Stances à Sophie)

\section{CORpus Web :}

Et si je donnais trop -> mort des « voraces » par suralimentation.

Et si je donnais trop juste -> discus, scalaires et cardinalis sous alimentés ! [http://dict.leo.org/ frde/index_de.html\#/search=unterern $\%$ C3\%A4 
hrt\&searchLoc=0\&resultOrder=basic\&multiwor dShowSingle $=$ on] $(10.2 .2015)$

Parfois même la batterie qui donne trop juste ce qu'il faut pour demarrer [http://www. auto-evasion.com/forum-auto/aide-mecaniqueet-panne-moto/triumph-bonneville-2001/159487. html] (10.2.2015)

Remarques : Donner juste désigne le fait de donner quelque chose, une somme d'argent, de la nourriture ou tout type d'effort, suffisant à peine pour réussir. Juste reste invariable et est modifié par trop.

\section{Donner mou}

Frapper faiblement ; mollir, perdre de la vigueur Emploi absolu

1933 Après une demi-heure de travail, son fléau donnait mou, perdait la cadence et, à chaque instant, elle manquait de se le cogner sur la tête (Marcel Aymé, La Jument verte)

CoRpus WeB :

Poussez la partie inférieure de l'avant de dérailleur pour donner mou à la chaîne et laisser revenir en arrière dans sa position de repos [http://www.besteartikel.com/sportif/guidepour-lachat-dune-deuxime-main-vtt] (11.2.2015)

sympa les soirées y'en a pour tous les gouts. par contre when you're gone si c'est avril lavigne ca va donner mou [http://www.makinarena.com/ index.php?topic=8657.0] (11.2.2015)

Il me semble que stefspirit a du acheter le sien dans les 400 euros.

En plus ils sont rares.

Les critiques les donnent mou à PO [http:// www.alphadxd.fr/viewtopic.php?f=1\&t=69318 \&start=0] (11.2.2015)

REMARQUES : Donner mou désigne le fait de porter un coup, de battre avec faiblesse, de ralentir la cadence, le sujet étant généralement inanimé (ici : le fléau). Mou reste invariable. Dans le premier exemple du CW, donner (du) mou signifie 'lâcher, laisser une marge de mouvement'. Il est plus difficile de spécifier la signification dans les autres exemples. Dans le dernier exemple, mou appartient au domaine de la photographie et réfère à un objectif (pleine ouverture).

\section{Dormir aise}

Dormir / s'endormir confortablement, sereinement

Pronominal

1235 « Si ferai jou, fait elle, mais moult me duel encore dou cheoir que j'ai fait. " Et il esracha de l'erbe a ses mains et le met desous son chief por chou que elle se dormist plus aise. Et il meismes oste s'espee et son hyaume et son hauberc et remaint en pur cors, et puis se prent des chevaus garde et lour oste les frains et les seles et les laist paistre (La Suite du Roman de Merlin, § 299, 17)

Intransitif

1325 Aise puet dormir et veillier

Pour qui vous voulez travaillier

(Watriquet de Couvin, Dits, p. 132, 19)

1371 LA MÈRE. Mais que nous arons beu, je vueil,

Godeffroy, que couchier le maines,

Et que de li couvrir te paines,

Si qu'il dorme aise

(Miracle de la fille du roy de Hongrie, 1429)

1379 YSABEL. Egar ! qu'il est tart ! Haro ! qu'est ce?

Je croy que j'ay dormi trop aise

(Miracle de la fille d'un roy, 2747)

REMARQUES : En ancien français, dormir aise réfère au fait de dormir dans un état de confiance, avec sérénité, confortablement, le sujet ne ressentant ni crainte, ni malaise. Aise renvoie également aux conditions extérieures. Le français moderne le remplace par tranquille dans cette fonction : dormir tranquille, laisse-moi dormir tranquille 'sans être dérangé'. Aise reste invariable et est modifié par trop.

\section{Dormir calme}

Dormir d'un sommeil calme, non agité

$\lambda$ dormir profond 


\section{Dormir couché}

Dormir dans une position couchée, dormir allongé

Intransitif

1625 Jusques à samedy dernier qu'un païsan me remis l'os de mon espaule fort heureusement, dieu mercy, et aussytost je commançay à remüer mon bras comme auparavant le mal et à pouvoir dormir couché et respirer (Nicolas de Peiresc, Lettres aux frères Dupuy)

1710 CRISPIN. Tu vois ; quoi qu'il m'arrive, Je conserve toujours un embonpoint égal : Chasser le jour, la nuit, à pied comme à cheval,

Le fusil sur l'épaule, en carrosse, en litiere, Forcer chevreuil, cerf, daim, sanglier, sangliere,

Manger froid, boire chaud, dormir couché, debout ;

Un garçon comme moi s'accommode de tout

(Philippe Destouches, Le Curieux impertinent)

1819 Dormir bien couché, vivre à ma fantaisie, travailler selon mon goût, ne rien faire quand je veux, m'endormir sur l'avenir, n'avoir pour compagnie que des gens d'esprit, le petit père compris, et les quitter quand ils me fâchent (Honoré de Balzac, Correspondance)

1840 Les vitraux éclatants ou sombres, Le caveau froid où, dans les ombres, Sous des murs que le temps abat, Les preux, sourds au vent qui murmure, Dorment couchés dans leur armure, Comme la veille d'un combat (Victor Hugo, Odes et ballades)

1908 C'est une chose triste, quand on a descendu le fleuve Rouge des jours et des jours, sur un sampan où l'on ne peut ni se tenir tout à fait debout, ni dormir tout à fait couché, c'est une chose triste de voir des maisons, de sentir l'odeur des cuisines et de ne pas oser pourtant passer une nuit sous un de ces toits (Pierre Mille, Barnavaux et quelques femmes)
1965 - Toi, Urbain et même Aubain, quand le matin, quittant la maison mère, tu agitais la main vers le perron blanc-gris sur la plus haute marche duquel se tenait, noire et droite et debout, ta grand-mère adorée humant le vent du mont, si droite et si debout qu'en ce moment tu te demandes encore si, vraiment, en haut à gauche, ta grand-mère dort couchée (René-Victor Pilhes, La Rhubarbe)

1976 Supports de ces trois femmes : un grand fauteuil Louis XIII pour la première (qui $r \hat{e}$ verait ou dormirait assise, et non couchée, au moment de mon arrivée), un divan recouvert de velours noir pour la deuxième, une couche quelconque mais très basse pour la troisième (Michel Leiris, La Règle du jeu 4 : Frêle Bruit)

2001 Une autre fois, un de mes récits imprudemment détaillé me valut une vengeance moins colérique bien que tout aussi violente : un coup de rasoir donné à l'épaule droite, alors que je dormais couchée sur le ventre, mais non sans que la lame ait été au préalable soigneusement désinfectée à la flamme de la cuisinière (Catherine Millet, La Vie sexuelle de Catherine M. précédé de Pourquoi et comment)

\section{CORPUS WEB :}

Évidemment il faut dormir couché dans un lit confortable, ce n'est pas en restant assis devant un pc que tu t'endormira dans les bras de morphee [http://www.jeuxvideo.com/forums/151-58512225-1-0-1-0-conseils-pour-bien-dormirtuto-pour-ins.htm] (11.2.2015)

Non merci, pour moi, je continuerai à manger à table et à dormir couché dans mon lit [https://fr.toluna.com/opinions/478874/Avezvous-d \%C3\%A9j\%C3\%A 0-mang \%C3\%A9couch\%C3\%A9] (11.2.2015)

D'un point de vue médical et scientifique, il est recommandé de dormir couché sur le dos ou sur le côté, en s'assurant que le cou est maintenu en ligne avec le reste de la colonne, en utilisant un oreiller de dimension appropriée [http:// pilule.telequebec.tv/occurrence.aspx?id=848] (11.2.2015) 
REMARques : Dormir couché réfère au fait de dormir dans une position horizontale. L'accord étant systématique, il se prête à une analyse de prédicat second orienté vers le sujet ; mais à un niveau plus abstrait, on peut dire aussi que dormir couché forme un verbe complexe qui désigne une façon de dormir, par opposition à dormir debout ou dormir assis / rêver assis. Couché est modifié par bien. Notons la série rimée de style populaire dans l'exemple de 1710 : manger froid, boire chaud, dormir couché, debout.

\section{Dormir dur}

I. Dormir fermement, profondément Intransitif

1275 Ne croi qu'il eüst dame de là dusqu'a Delfur

Qui de si grant afaire fust a tel meseür ;

Damedieus par sa grace li renvoit bon eür, Car de tres fin cuer l'aime, de vrai et de meür.

De paine et de travail dort si fort et si dur, Desouz un arbrisel, lez un viés petit mur, Que on ne l'esveillast pas dou son d'un tabur

(Adenet le Roi, Berte aus grans piés, 1007)

1865 Comme il était pas mal sourd et dormait dur, Brulette coucha le petit, nous servit un bout de collation, et se consulta avec nous sur le réveil qu'on lui ferait, avant qu'il eût fini son premier somme (George Sand, Les Maîtres sonneurs)

1947 Il tourna le commutateur, prit son colt d'une main, entra dans la cuisine.

- Ça dort dur dans le coin ! souffla Bernard légèrement anxieux

(René Fallet, Banlieue sud-est)

2005 - Tu parles! Il aurait fallu qu'elle dorme dur en bébite pour ne pas se réveiller avec une explosion pareille, les sirènes et tout. Les pompiers ont vérifié quand même, mais évidemment... (Marie-Danielle Croteau, Un pas dans l'éternité)

2014 Il s'enquit de Thomas qui dormait dur et de Gabrielle qui finalement s'était endormie collée sur Sam mais où était Inndia ? Le corridor baignait dans le noir et les plan- chers craquaient (Rachel Paulin, 6 petits enfants disparus...)

II. Dormir sur un matériel dur Intransitif

1987 Tu sais ce qu'on disait des voyageurs à l'époque, garçon ? Vivent dur, couchent dur, dorment dur, et mangent des chiens ! Ha! (Ronald Lavallée, Tchipayuk ou Le Chemin du loup)

CORpus Web :

Dormir dur, c'est à dire avoir une bonne quantité de sommeil profond, ne peut exister que dans certaines conditions [http://www.brigitte langevin.com/sommeil-et-reves/bulletin-infosommeil/archives/168-bulletin-mars-2011-no-38] (11.2.2015)

J'habite sur Dufferin et j'ai rien entendu. Je dois dormir dur... [http://www.lapresse.ca/latribune/faits-divers/201409/25/01-4803370centre-ville-lorigine-de-la-deflagration-demeureun-mystere.php] (11.2.2015)

Ca m'est arrivée de m'inquietier aussi qqe fois quand je trouvais qu'il était plus tranquille que d'habitude mais ca na jamais durer vraiment longtemps longtemps. des fois je me disais qu'il devait dormir dur ! [http://forum.canalvie.com/ grossesse-et-bebe/232378-mouvements-du-bebeen-fin-de-grossesse-baisse-ou-hausse.html] (11.2.2015)

Remarques : Dormir dur désigne le fait de dormir à poings fermés (I). Dur reste invariable et est modifié par si. Il peut également renvoyer à la dureté du matériel sur lequel on se couche (II). L'exemple sous (II) est en ambiguïté avec (I). Notons l'emploi de vivre dur ; coucher dur.

\section{Dormir faux}

Dormir d'un sommeil artificiel

$\lambda$ habiller faux

\section{Dormir ferme}

I. Dormir profondément Intransitif

1195 PINCEDÉS. Or tost ! fil a putain, larron !

Car li roys dort et si baron

Si ferm que s'il fussent tout mort

(Jehan Bodel, Jeu de saint Nicolas, 997) 
1879 Et, quand elle se fut assurée qu'il dormait ferme, elle souleva sans bruit une portière de velours, et bonsoir !... « où va-telle? » (Léon Cladel, Ompdrailles, le Tombeau-des-Lutteurs)

1887 Villiers de l'Isle-Adam à Marie Dantine vve Brégeras (ce 17 août 1887): ma bonne chère Marie, je suis comme ressuscité : je mange comme quatre ; j'ai dormi ferme ; cet air des bois m'a fait un bien extraordinaire ; je ne souffre plus du tout (Auguste de Villiers de L'Isle-Adam, Correspondance générale)

1936 Carlotta dormait ferme, avec le désespoir des enfants qui savent qu'on les dérangera (Louis Aragon, Les Beaux Quartiers)

1998 Mais elle dormait ferme. La veille elle avait eu des moments difficiles, la visite imprévue d'un Monsieur l'Inspecteur de l'Enseignement secondaire qui ne s'était pas gêné pour critiquer sa façon d'enseigner les sciences. Le sale macho (Annie Saumont, Embrassons-nous)

2014 La montagne respirait au ralenti, par la bouche des racines et les trous des mares qui tardaient à geler. Même si je savais qu'on dormait ferme là-dedans, parce qu'on ne rigole pas avec l'hibernation chez nous, j'imaginais la java sous les flocons (Gautier Battistella, Un jeune homme prometteur)

II. Dormir profondément sur un matelas ferme Intransitif

1997 Dormez ferme (Slogan de la marque de matelas Lattoflex / Noailly 1997a)

CORPUS WEB :

@milou Saint Amand les Eaux, si tu ne mets pas un ou plusieurs secteurs pavés sur le circuit on va dormir ferme pendant 7 heures [http://www.cyclismactu.fr/news-mondiaux2017-france-candidate-pour-l-organisation-25535. html] (11.2.2015)

Nul, en un mot, le spectateur peut dormir ferme sans avoir la moindre envie de regarder le film ! [http://www.allocine.fr/film/fichefilm138301/critiques/spectateurs/recentes] (11.2.2015)
Ils s'endorment dès la tête posée sur l'oreiller et dorment ferme jusqu'au son du réveil matin [http://www.thehozercanada.com/dealer_ inquiries-f.html] (11.2.2015)

REMARQues : Dormir ferme (I) désigne le fait de dormir à poings fermés. En (II), le slogan d'une marque de matelas joue sur l'ambiguïté de ferme qui signifie, au propre 'dormir sur un matelas ferme' et, au figuré, 'dormir profondément'. Ferme reste invariable et est modifié par si.

\section{Dormir fort}

Dormir profondément, éventuellement en ronflant

Intransitif

+1175 Governal vit le forestier

Venir des tres, sor un destrier, Qui vout Tristran livrer a mort En sa forest, ou dormoit fort (Béroul, Tristan $\left[4^{\mathrm{e}}\right.$ quart XII $\left.\mathrm{e}\right], 4048$ )

1195 PINCEDÉS. Qu'est chou ? Qui nous a esvillie?

Dieus ! con je dormoie ore fort ! (Jehan Bodel, Jeu de Saint Nicolas, 1280)

1341 PREMIER CHANOINE. Je ne sçay, par les sains de Romme ;

Mais je vois sa mesnie querre.

Or, sus, seigneurs, or sus, bonne erre!

Trop fort dormez (Miracle de l'evesque que l'arcediacre murtrit, 263)

+1389 et ainsi qu'il fu illec couchié, vit et aperceust que icellui de La Rue dormoit moult fort (Registre criminel du Châtelet de Paris [1389-1392])

1400 Je scey bien que elle vous ame bien, et pour ce que mon seigneur n'y est pas, venez vous en par nostre huis derriere encore ennuyt de nuit, et je vous mectroy en sa chembre, - elle dort bien fort quar el n'est que pas ung enfant -, et vous couchez avecques elle, car aultre remyde je n’y voy (Quinze Joies de mariage, p. 30)

1424 Disoit cellui qu'Amours tenoit En telle pensee amoureuse Que de dormir ne lui tenoit Ne de faire chiere jouyeuse : 
«Ce me semble chose honteuse

Que de dormir tant et si fort ;

Et pour ce m'est elle ennuyeuse

Car il ne sert de riens qui dort »

(Alain Chartier, Le Debat de reveille matin, p. 307, 22)

1515 Et aprés pluseurs complainctes et lamentacions que ladicte sa femme faindoit de faire s'en alla chascun coucher fors que elle et une sienne bonne voisine, et quant se vint entour mey nuict, elle donna à boire audit son mary je ne sçay quelle chose, qui le fist dormir si tres fort, avec ce qu'il estoit si tres colin, tellement que on l'eust bruslez leens, luy et son lict, qu'il n'en eust rien sceu (Philippe de Vigneulles, Les Cent Nouvelles nouvelles, p. 358, 303)

1559 Ce qu'il fist incontinant, et, en montant en hault par ung petit degré de bois, trouva la fille toute seulle dans le lict, qui dormoit bien fort (Marguerite d'Angoulême, Heptaméron, p. 374, 53)

1592 La mort de cet Empereur a beaucoup de choses pareilles à celle du grand Caton, et mesmes cecy : car Caton prest à se deffaire, cependant qu'il attendoit qu'on luy rapportast nouvelles si les senateurs qu'il faisoit retirer, s'estoient eslargis du port d'Utique, se mit si fort à dormir, qu'on l'oyoit souffler de la chambre voisine (Michel de Montaigne, Essais)

1670 PREMIER MÉDECIN. Tant pis : cette grande appétition du froid et de l'humide est une indication de la chaleur et sécheresse qui est au dedans. Dormez-vous fort? MONSIEUR DE POURCEAUGNAC. Oui, quand j'ai bien soupé (Molière, Monsieur de Pourceaugnac)

1715 Et, en disant ces paroles, il la baisa au front, aux deux joues et à la bouche, avec si peu de précaution, qu'elle se fût éveillée si elle n'eût dormi plus fort qu'à l'ordinaire, par l'enchantement de Danhasch (Antoine Galland, Les Mille et une nuits)

1844 Monsieur Léonard jeune, dit-il en secouant Cadet pour l'éveiller, vous dormez trop fort, vous réveillez toute la chambrée (George Sand, Jeanne)

1950 Polo dormait très fort, mais, par contre, il était très matinal (Joseph Zobel, La Rue Cases-Nègres)

2000 Sous la lampe, elles tenaient conciliabule à voix basse, j'avais pris du retard. La petite dormait si fort qu'elle n'a pas bronché dans les tas de chiffons quand je me suis levée (Anne-Marie Garat, Les Mal Famées)

\section{CORPUS WEB :}

Je devais vraiment dormir fort cette nuit pour ne pas avoir entendu la dameuse tasser l'accès au gîte ! Un grand merci au service des pistes ! [https://fr-fr.facebook.com/Oxysports] (12.2.2015)

Aujourd'hui je vais avoir du mal à vous donner un verdict....... je me suis endormie bien avant lui, et j'ai dormir fort toute la nuit...... jusqu'à ce qu'il parte travailler ce matin :D [http:// www.notrefamille.com/forum/Sante/Santegenerale/Douce-nuit-pour-dormir-t344789.aspx] (12.2.2015)

Hein? tu quoi ? tu ronfles?

Non non, je dors fort.

Euh.... (là je ne vois pas trop à quoi ça ressemble de dormir fort)

Ben oui, quand je dors je respire fort ! Oh tu comprends rien toi ! [http://monavis.canal blog.com/archives/2005/01/29/285758.html] (12.2.2015)

REMARQUES : Dormir fort désigne le fait de dormir à poings fermés. Fort reste invariable et est modifié par bien, moult, ore, plus, si, si très, très, trop. Notons l'emploi euphémique pour celui qui ronfle (ex. de 1592, 1844, et le dernier exemple du CW). Mentionnons également l'emploi de respirer fort.

\section{Dormir immobile}

Dormir paisiblement, sans bouger

$\lambda$ dormir profond 


\section{Dormir profond}

Dormir profondément

Intransitif

1847 Cette immense quantité de procès-verbaux des commissaires de police, de rapports, de notes, de dossiers, cet océan de renseignements dort immobile, profond et calme comme la mer. Qu'un accident éclate, que le délit ou le crime se dressent, la justice fait un appel à la police (Honoré de Balzac, Splendeurs et misères des courtisanes)

1950 Ensemble tout le temps qu'il nous fallait pour vivre

Toute une éternité

Et plus je te voyais vivre à côté de moi

Plus je te confondais avec l'aube et l'été

Dormir profond rêver plus haut

Et s'éveiller l'un bien à l'autre

Telle est la loi de l'innocence

Et vivre plus haut que nos rêves

Etre pareils par la confiance

Tel a été notre plaisir

(Paul Éluard, Une leçon de morale)

1967 Il y avait beaucoup de candeur dans ses yeux larmoyants.

- Les béquilles ? lui demanda Ouroz.

- Tu dormais si profond, dit l'homme, que

tu ne m'as pas entendu les déposer. Sur

l'ordre du grand Toursène

(Joseph Kessel, Les Cavaliers)

CoRpus Web :

Mais jvai dormir profond, ils m’ont épuisé [https://twitter.com/SissouCheriti/status/197788 267117158401] (12.2.2015)

Oui Evy !! je pense quettre enceinte moi aussi je ferais la meme chose !! moi je ne massoupie pas jai trop peur de dormir profond ! [http:// www.magarderie.com/forum/archive/index. php/t-34917.html] (12.2.2015)

Le sommeil de votre enfant n'est pas seulement contrarié par cet empêcheur de dormir profond. Il est hanté par des images terrifiantes et parfois très violentes [http://www.vosquestions deparents.fr/dossier/1404/cauchemars-com ment-laider] (12.2.2015)

REMARques : Dormir profond désigne le fait de dormir d'un profond sommeil. Profond reste in- variable et est modifié par si. Notons l'emploi de vivre haut.

\section{Dormir sage}

Dormir sagement, chastement

Intransitif

1896 Car, après tout, l'amour, n'y pensons plus, C'est chimère à notre âge.

On a fixé des vœux irrésolus, On vit calme, on dort sage.

On n'a plus de ces cœurs qu'il ne faut plus. Raison et mariage !

(Paul Verlaine, Euvres poétiques complètes)

1931 - Là, c'est fini, reste tranquille. N'est-ce pas que ça te fait moins mal ? Maintenant tu vas dormir, bien sage. Tu vois, je pousse la porte, mais sans la fermer tout à fait. Je suis tout près, je reviendrai souvent (Maurice Genevoix, Rroû)

1947 Elle s’amusa comme une folle, laissant le petit à l'hôtel, à la caissière, une femme d'âge, qui n'oublierait pas de lui donner ses fioles à l'heure dite. Le soir, il dormait bien sage ; Paulette pouvait aller au théâtre, qu'elle adorait, et elle eut une toquade pour un ténor qu'elle s'en fut écouter dans ses rôles. Admirable dans Le Trouvère (Louis Aragon, Les Voyageurs de l'impériale)

\section{CORPUS WEB :}

Je gémis, m’agitant

A..Arrête... 1..laisse moi sortir...j..je veux pas avec toi... j..je veux juste aller dormir sage.... [http://gothicat-world.com/forum/viewtopic. php?f=43\&t=11184\&start=6070] (12.2.2015)

Il pleure il hurle il est cramoisit.. il tousse a etouffer.. On lui explique il se calme nous dit qu'il va dormir sage... on le remet dans le grand lit et ca recommence... [http://forum.assistantematernelle.biz/viewtopic.php?pid=2360917] (12.2.2015)

@Apu : offre-lui rien.Si elle se plaint tu lui refoutras sa phrase dans la gueule et elle ira dormir sage comme une image. Au pire kebab, c'est bien le kebab [http://www.footmanager.net/forum/letopic-des-histoires-de-coeurs-t15268-1740.html] (12.2.2015) 
REMARques : Dormir sage désigne le fait de dormir calmement, docilement, ou, dans un autre contexte, avec chasteté. Sage inclut donc le comportement du sujet, c'est-à-dire une propriété circonstancielle, à l'instar de dormir aise, tranquille. Notons la collocation avec vivre calme, renforçant l'idée de tranquillité, docilité. Sage est modifié par bien.

\section{Dormir serré}

I. Dormir profondément

Intransitif

1642 CARISALE DOCTEUR. C'est cela, mais Seigneur, souffrez que mon discours

Exalte en vos vertus la gloire de nos jours, Permettez que j’observe avecque diligence, Et vostre extreme soin et vostre vigilence, Surtout quand le grison cet Asne mon pareil

De qui sont descendus les mulets du Soleil, Vous fut volé soubs vous à la montagne noire

D'une façon estrange et dificile à croire.

SANCHE. Je dormois bien serré.

CARISALE DOCTEUR. Plustost en ce moment

Vostre esprit grand et fort pensoit profondement

(Guyon Guérin de Bouscal, Le Gouvernement de Sanche Pansa)

1865 Enfin je dors serré, ce qui m’amuse encore plus, car je rêve beaucoup, et mes rêves sont généralement agréables (George Sand, Monsieur Sylvestre)

1906 Trois heures du matin. L'auberge de la Hourque sommeille quiètement sous le ciel étoile. Dans la pièce réservée aux touristes mâles, Florent Garaudel, étendu sur le lit de camp, dort serré, et sa bouche entr'ouverte semble fleurie par un rêve heureux (André Theuriet, Mon oncle Flo)

II. Dormir blotti l'un contre l'autre Intransitif

1886 Les balles du Barbare ont troué ces poitrines

Et rompu ces cœurs généreux.

La rage du combat gonfle encor leurs narines,
Ils dorment là serrés entre eux (CharlesMarie Leconte de Lisle, Poèmes tragiques)

1907 L'un, à demi réveillé, se grattant le côté $\mathrm{du}$ ventre, nous regarde d'un œil vide et bée d'un air de délice ; l'autre dort si serré qu'on dirait qu'il colle à la pierre (Paul Claudel, Connaissance de l'Est)

1916 Après un couloir, où dorment, serrés, les agents de liaison, une pièce boisée, avec un siège et une table, et, dans le fond, un lit de fer (Henry Bordeaux, Les Derniers Jours du fort de Vaux)

1919 Les autres étaient prêts à dormir, bien serrés pour se tenir chaud (Roland Dorgelès, Les Croix de bois)

1978 Au col sud, nous dormons serrés dans une tente montée par des Allemands. Nuit d'angoisse dans le vent. Nous dormons serrés contre les autres. Tout est hallucinant. Il faut rester assis pour que la tente ne s'envole pas. La peur nous réveille, le froid aussi (Le Point)

1989 Ou alors nous dormions serrés serrés l'un contre l'autre dans ma maison à moi qui était devenue notre maison à nous avec son bon Dieu russe qui nous faisait de larges sourires bénisseurs (Remo Forlani, Gouttière)

2012 Quand je monte à l'étage pour aller me coucher, le chat et le chien dorment serrés l'un contre l'autre dans un coin de la cuisine. Cette image hors de l'ordinaire me hantera toute la nuit (Micheline Duff, Paysages éclatés)

CORPUS WEB :

Close-up d'un koala assis dans un arbre, et dormir serré (jusqu'à 20 heures par jour) [http:// fr.123rf.com/footage_26216143_.html] (4.2.2015)

Boîte à Musique est là pour vous aider ! Oubliez les nuits sans sommeil et la folie d'un bébé qui pleure. Avec cette boîte à musique panda mignon votre bébé va dormir serré et faire de beaux rêves. Avec la berceuse de bébé parfait que vous et votre enfant ne prendrez jamais le sourire de vos visages [http://www.androidpit.fr/ application/com.BabySleepMusicBox] (4.2.2015) 
Une fois que nous sommes assez éloigné, je laisse LightFall nous choisir un endroit où dormir, et constate qu'il ne s'arrête qu'une fois Cepheus et les autres suffisamment loin derrière nous. La pluie glaciale ayant tremper nos fourrures, nous dormons serré l'un contre l'autre [http:// plume-d-orage.skyrock.com/tags/9WejKlWyuQeCepheus_3.html] (4.2.2015)

... en effet, en saison froide, par manque d'autres moyens, il est nécessaire d'améliorer la température en mettant un brasero au milieu de la case souvent exigüe. La nuit les tout-petits dorment serrés contre leur mère et dans le sommeil il arrive parfois que les bébés roulent proche du brasero et se brûlent les extrémités [http:// www.handicapsante.org/nos-actions/chirurgieplastie] (4.2.2015)

REMARQUES : Dormir serré (I) signifie dormir à poings fermés. Dans l'acception (II), serré est un prédicat second qui s'accorde avec le nom dénotant celui qui dort très proche de quelqu'un, laissant peu ou pas de vide entre les deux corps. Il est modifié par bien, là, si. L’accord fait cependant défaut dans l'avant-dernier exemple du CW. Notons la réduplication serré, serré.

\section{Dormir soef (suave)}

Dormir / s'endormir tranquillement, paisiblement Intransitif

+1100 « Chevalier, mult m'en est bel Que reverdissent prael ; Si avront assez a pestre mi aignel, Je m'irai soef dormir soz l'arbroisel » (Romances et pastourelles françaises des $X I I^{e}$ et XIII ${ }^{e}$ siècles, p. 183)

-1200 En ce que li frans dux se dormoit bien soué Li anfes Floovanz l'a formant esgardé ; .I. coutel out ou poig, qui mont trenchoit soué,

Don il se desdusoit a une pome ou pré. Dou coutel ai la barbe a son maitre copé. Li dux si s'esvoilai, qui ot dormi soué, Regardai ses grenons que cil li ai copez, Et de sa barbe a veü tout autretel ; Adonques ot tel doel a pou n'est forsannez (Floovant [fin XII ${ }^{\mathrm{e}}$, 72 / 77)
1794 Souviens-toi que Cybèle est la mère commune.

Laisse la probité que trahit la fortune Comme l'oiseau du ciel se nourrir à tes pieds

De quelques grains épars sur la terre oubliés.

Son épaule pliait sous une outre vineuse. Et le dormir suave au bord d'une fontaine (André Chénier, Les Bucoliques)

Pronominal

1250 Li enfes se dormoit douchement et souef

Et li peres en a Jhesu Crist aoré ;

Belement l'esveilla et si l'a apelé

(Doon de Mayence, p. 55)

REMARques : Dormir soef (suave) désigne le fait de dormir dans un état de confiance, avec sérénité, sans que rien ne vienne perturber le sommeil. Soef reste invariable. Dans l'exemple de 1794, le groupe verbal est nominalisé : le dormir suave. En ce sens, son emploi au XVIII ${ }^{\mathrm{e}}$ siècle est archaïsant. Notons une seconde attestation de l'emploi pronominal se dormir 's'endormir' dans l'exemple de -1200 et la collocation douchement et soef.

\section{Douter ferme}

Douter profondément

Emploi absolu

1936 Et Descartes a même su dire que bien certainement, quand il doutait ferme, Dieu était de son côté (Alain, Propos)

Transitif

2018 Par ailleurs, il doutait ferme de dénicher des survivants (Marianne Stern, Récits $d u$ monde mécanique)

\section{Douter fort}

Douter beaucoup, fortement ; craindre, redouter, se méfier

Transitif

1177 Que trop savoient d'escremie, Et lor escu n'estoient mie Tel, que rien an ostast espee, Tant fust tranchanz et aceree. Et por ce se pooit mout fort Mes sire Yvains doter de mort : Mes adés tant se contretint, 
Que li lions outre s’an vint,

Tant ot dessoz le suel graté (Chrestien de Troyes, Yvain ou Le Chevalier au lion, 5625)

+1250 Li droiz suet les consaz noter Per quoi fort cuers se puet doter : Virge cui l'on uuet faire outraige, Por corrompre son pucelaige (Ysopet de Lyon [2 moitié XIII'], 1546)

1275 Or est Florianz empereres ; Desouz lui est touz li empires Il n'est nus qui l'en face tort. Et il se fet douter si fort Que traïtour ne losengier N'osent la contree aprochier (Floriant et Florete, 8130)

1562 Que si quelcun ainsi contraint vient à croire (ce que toute fois je doute fort s'il le fait), mais s'il vient à croire, cela ne se fait pas par la contrainte (Sébastien Castellion, Conseil à la France désolée)

1578 MALICAN. Ne t'esmerveille de ma crainte, puis que c'est le commun de la condition humaine de jamais ne voir accomply son desir : et sur tout par ce qu'en ce cas je doute fort ton ennuy, et le mien (Jacques de Lavardin, La Celestine [adapt.])

1664 MORON. Ma foi, Madame, vous ne feriez pas mal : il le mériteroit bien ; mais à vous dire vrai, je doute fort que vous y puissiez réussir (Molière, La Princesse d'Élide)

1688 je doute fort que la plupart des gens entrent dans la remarque que je vais faire ; je la ferai cependant pour ceux qui se connaissent en raisonnements, et je puis me vanter que c'est avoir du courage que de s'exposer pour l'intérêt de la vérité à la critique de tous les autres, dont le nombre n'est assurément pas méprisable (Bernard de Fontenelle, Digression sur les anciens et les modernes)

1715 - Je vous le promets, répondit le sultan ; mais je doute fort que nous trouvions personne qui le puisse être (Antoine Galland, Les Mille et une nuits)
1761 Depuis il ne s'est rien passé dans cette négociation. Il a ordre seulement de ces trois Puissances de faire la compagne avec sa Majesté ; mais je doute fort comme on vient de me dire, que le Roi lui accorde la permission (Friedrich Ernst von Fabrice, Anecdotes du séjour du roi de Suède à Bender)

1764 Il faut encourager la jeunesse. Je l'ay engagé à retravailler son ouvrage, et il doit vous être remis. Je doute fort que malgré tous ses soins vous trouviez un libraire qui veuille l'imprimer (Voltaire, Correspondance)

1770 Si mes Lecteurs éprouvaient la même sensation, ce dont je doute fort, j'aurais approché du but où j’aspirais, en me proposant de réunir le pathétique du Thêâtre de Paris à la terreur du Théâtre de Londres (PierreLaurent de Belloy, Gabrielle de Vergy)

1836 Aussi, ne pouvant ni ne voulant faire couper la tête à mes amants au sortir de mon lit, et n'étant pas non plus d'humeur à supporter ce que les autres femmes supportent, il faut que j'y regarde à deux fois avant d'en prendre un ; c'est ce que je ferai plutôt trois fois que deux, si l'envie m'en prend, ce dont je doute fort, après ce que j'ai vu et entendu (Théophile Gautier, $M a-$ demoiselle de Maupin)

1938 Mais à défaut de ces millions, il n'est pas indifférent de sauver mystiquement la dignité humaine, la semence invisible de l'avenir... de cet avenir dont tu doutes si fort maintenant (Jules Romains, Les Hommes de bonne volonté)

1943 On ne peut emporter avec soi que deux mille francs et un peu de monnaie italienne. Me laisserait-on emporter également des manuscrits ? J'en doute fort et supporte mal l'idée de me les voir confisqués. Puis, là-bas, trouverais-je un gîte possible? (André Gide, Journal)

1972 Mélissa finit le brouillon de « King Cohn ». Pierre Grunstein s'accroche. Simultanément, je doute fort de la volonté de 
Vera de monter le film. La seule chance de Jean-Marie est de monter un certain nombre de choses pour forcer la main à Vera. Mais il faut qu'il agisse. Mais il faut qu'il agisse vite ou je vais le lâcher. Je ne compte pas attendre un an pour aboutir à rien (Jean-Patrick Manchette, Journal)

2006 Je connais un écureuil, si du moins c'est tous les ans le même, et si c'est connaître un écureuil qu'apercevoir furtivement de ma fenêtre son nuage roux, vers la fin de l'été, ondulant sur la pelouse et grimpant en vrille aux branches d'un prunier sauvage qui ne lui sert qu'à me narguer, car je doute fort qu'il se nourrisse de prunes. Peut-être y cache-t-il ses noisettes (Gérard Genette, Bardadrac)

Pronominal

+1370 Or se perchust li dis messires Hues le Espenssier de ceste œuvre et comment on murmuroit sur lui et sur son affaire ; si se doubta trop fort que maux ne l'en venissent : si y pourvey tantost de remède moult fellenèse (Jean Froissart, Chroniques $(\mathrm{A}))$

1588 Par ceste parole le Duc se sentant fort offensé, commença à se douter fort de ce costé là : entra en tres grand soupçon, et ne vouloir point de bien au Duc de Bourgongne : lequel estant à sainct Denis, le Duc de Berry et le Roy de Sicile, et autres y allèrent (Bertrand d'Argentré, L'Histoire de Bretaigne)

1666 quant au Cardinal du Bellay, il se doute fort que le premier venu qui le prendra bien à propos, luy tirera les vers du nez (Lettres et mémoires d'Estat)

1776 On se doute fort que M. de Voltaire n'est pas oublié dans l'énumération de nos orateurs modernes (Madame Du Hausset, Mémoires de Madame Du Hausset, femme de chambre de Madame de Pompadour)

\section{CORPus WeB :}

Les arguments présentés par nos instances de santé publique pour nous inciter à passer une mammographie affichent clairement qu'elles doutent fort que nous ayons un cerveau, et encore davantage que nous soyons capables de faire une recherche sur Internet. Dit autrement : on nous prend pour des gourdes [http://www. expertisecitoyenne.com/livres] (4.2.2015)

Gaétan Barrette promet de régler le problème. Par contre, les spécialistes doutent fort qu'il y arrive [http://tvanouvelles.ca/lcn/infos/ national/archives/2015/01/20150124-175621.html] (4.2.2015)

Même si on a eu un brin d'espoir après sa nomination comme chef de gouvernement, la plupart des Guinéens doutent forts aujourd'hui que le changement vienne de lui et de son équipe. Le mode de formation de son équipe... [http://guineeactu.info/HTML/ne-brulez-pasmon-paradis-s\%E2\%80\%99il-vous-plait.htm] (14.2.2015)

REMARQues : Douter fort désigne le fait d'être fortement dans le doute sur l'existence de quelqu'un, la valeur ou la vérité d'une affirmation. Fort reste invariable dans la majorité des cas et est modifié par moult, si, trop. Notons que fort s'accorde avec le sujet au pluriel dans le dernier exemple du CW tout en gardant son interprétation d'adverbe de degré, modifieur du verbe. Mentionnons également l'emploi de l'incise discursive à vous dire vrai.

\section{Douter petit}

Redouter, craindre peu

Transitif

+1200 et cil qui dedenz se sont mis sont si preudome qu'il douteroient petit vostre efforz (Mort Artu [1 ${ }^{\text {er }}$ quart XIII $]$, p. 135, 51)

+1233 Galeran vet avant ses guie, Si en jure le braz s'amie Que s'il ore vis s'en estort, Tendra se mes toz jors a mort. Avant les autres tient sa route, Mes Thideüs petit le doute

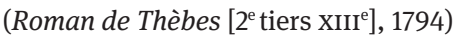

1250 Ains a mis le main a l'espee. A tant conmence la meslee ; Onques hom si dure ne vit. Moult doute l'uns l'autre petit, Au sanlant que cascuns d'ex fait (L’Atre périlleux, 1300) 
REMARQUES : En ancien français, douter petit désigne le fait d'éprouver peu de crainte ou de peur pour quelque chose ou quelqu'un. Petit assumait les mêmes fonctions de quantifieur que peu dans la langue moderne. L'opposition sémantique avec moult dans le dernier exemple souligne la fonction de quantification de petit. Les deux quantifieurs modifient le verbe douter. Petit reste invariable.

\section{Dresser fort}

Dresser avec force

Pronominal

1856 Dans nos antiques forêts de la Gaule et de l'Allemagne se dresse fort et sérieux, lentement, solidement bâti, l'orme ou le chêne, ce héros végétal aux bras noueux, au cœur d'acier, qui a vaincu huit ou dix siècles (Jules Michelet, L'Oiseau)

2010 Mais à présent, face à Moro prisonnier des Brigades Rouges, l'État italien se dresse fort et solennel. Qui ose douter de sa force, de sa solennité ? (Chiara Nannicini, Heinrich Böll et Leonardo Sciasca " ennemis de l'État »)

\section{CORPUS WEB :}

Il se dresse fort et grand, vieillit lentement, Il peuple les forêts, les bois et les marais,

C'est un cœur, un poumon, un si doux battement

Je l'entoure de mes bras, me rapproche tout près [http://www.ipernity.com/blog/192290/ 363083] (2.2.2015)

Les guérisseurs, les artistes et les visionnaires sont souvent nés sous Duir. Le chêne se dresse fort et sage dans le solstice d'été du 21 juin, la plus longue journée de l'année [http:// forums.reblochons.com/viewtopic.php? $\mathrm{f}=1 \& \mathrm{t}=$ 1258\&view=previous] (2.2.2015)

REMARQues : Dresser fort désigne le fait de se soulever, de se redresser en manifestant de la force, notamment en parlant d'un arbre comme le chêne qui symbolise la force et la durée, donc une existence qui résiste aux intempéries. Même si les exemples ne permettent pas l'accord marqué, fort y apparaît comme prédicat second. Notons les adjectifs-adverbes sérieux, solennel, grand et sage coordonnés à fort.

\section{Dresser grand}

(Se) dresser de toute sa grande taille

$\lambda$ dresser fort

\section{Dresser haut}

Élever à un niveau supérieur

Transitif

1553 PROCULEE. Si bien par tout mon devoir se fera,

Que mon Cesar de moy se vantera.

Ô ! s'il me faut ores un peu dresser

L'esprit plus haut, et seul en moy penser :

Cent et cent fois miserable est celuy

Qui en ce monde a mis aucun appuy

(Étienne Jodelle, Cleopatre captive)

1564 Après le siècle d'enfer, de néant, d'abâtardissement que l'humanité vient de vivre, les chrétiens fidèles, que Jésus Christ appelle à être le sel de la terre et la lumière du monde, sauront-ils prendre le temps, avec patience, de dresser haute et claire, la flamme de leur témoignage ? pour que revivent l'Église, les familles et la société (Pierre Viret, Instruction chrétienne)

1876 Renan, dans son histoire du peuple d'Israël, montre les juifs élargissant et dressant plus haut l'idée messianique à mesure qu'ils sont plus vaincus, plus abaissés, plus trompés dans leurs espoirs présents (Louis Ménard, Rêveries d'un païen mystique)

1945 Elle saisit le regard moqueur de M. Létourneau et continua son manège délibérément, la tête dressée haut (Gabrielle Roy, Bonheur d'occasion)

1975 Africains qui veulent une Sainte Vierge négresse, ou les Tibétains qui exigent un Petit Jésus aux yeux bridés, et je n'imagine pas Dieu autrement qu'un pénis dressé haut et dur sur la base de ses deux testicules, monument érigé à la virilité, principe de création, sainte trinité, idole à trompe accrochée au centre exact du corps humain, à mi-chemin de la tête et des pieds (Michel Tournier, Les Météores)

2000 Mais aussi, utopie oblige, dresser haut la statue de ce zombi, afin que tous ne rêvent 
que de cet Homme nouveau, et se précipitent d'eux-mêmes vers l'avenir radieux à lui promis... (Flora Montcorbier, Le Communisme de marché. De l'utopie marxiste à l'utopie mondialiste)

Pronominal

1833 Pourtant, je ne sais pourquoi la grande et féconde idéalité est refusée au génie normand. Il se dresse haut, mais tombe vide. Il tombe dans l'indigente correction de Malherbe, dans la sécheresse de Mézerai, dans les ingénieuses recherches de La Bruyère et de Fontenelle (Jules Michelet, Tableau de la France)

1835 Alors on vit la honte de la France se dresser haute et fière et prononcer sur notre sort, comme si la gloire eût parlé par l'organe de ce sénat (Duchesse d'Abrantès, Mémoires)

1983 « Non, tu ne feras pas ça »... exerçant une douce et ferme et insistante et inexorable pression, celle que j’ai perçue plus tard dans les paroles, le ton des hypnotiseurs, des dresseurs... " Non, tu ne feras pas ça... » dans ces mots un flot épais, lourd coule, ce qu'il charrie s'enfonce en moi pour écraser ce qui en moi remue, veut se dresser... et sous cette pression ça se redresse, se dresse plus fort, plus haut, ça pousse, projette violemment hors de moi les mots... « Si, je le ferai » (Nathalie Sarraute, Enfance)

\section{CORPUS WEB :}

Qu'un arbre, né pour se dresser haut, et grandir compagnon des oiseaux et des astres, se laisse aller à poser genou à terre, à ramper comme un lierre, pour complaire à un très banal et sans doute provisoire réverbère, cela n'arrive pas que dans les jardins de la ville, si l'on y réfléchit un peu [http://www.chemindesjours.com/ article-obsequiosite-98234511.html] (28.2.2015)

Les deux serpents sont de belle taille. Ils enroulent leurs queues faisant une sorte de tresse, ils s'entortillent, dressent leur tête.... C'est étonnant de voir comment ces bêtes qui rampent sont capables de se dresser haut ! [http://groupe naturefaverges.over-blog.fr/30-index.html] (28.2.2015)
Au début, je croyais à une simple force tranquille, mais j'ai vite constaté que l'homme peut être bouillonnant et se dresser haut et fort, pour ses idées, les militants, et plus que tout, pour la cause [http://quebec.huffingtonpost.ca/etienneboudou-laforce/sol-zanetti-nouveau-chef-dop tion-nationale_b_4132776.html] (28.2.2015)

Dresser haut le nom de votre club dans le sens propre du terme. Qui n'a pas un fanion digne de ce nom n'est pas un authentique supporter. Bayern Munich, Schalke 04, Borussia Mönchengladbach ou Bayer Leverkusen ne sont que quelques clubs dans lesquels nos fanions se dressent haut dans le ciel [http://www. fahnenherold.de/info/francais.html.] (28.2.2015)

Elle dresse haut les couleurs de son sport et de son pays [http://philyra-magazine.com/2014/ 03/09/elle-minspire-celine-dumerc] (28.2.2015)

Il y a la rose, et ces roulements de tambour, solennels et graves... Cette même rose dressée haut par François Mitterand il y a déjà 28 ans... L'espoir était " vainqueur » et se voulait être " la chose de France la mieux partagée » [http://archives-lepost.huffingtonpost.fr/ article/2009/05/14/1535893_les-annees-roses-etle-mal-etre-socialiste.html] (28.2.2015)

REMARQUeS : Dresser haut se dit du fait d'élever un objet, inanimé, abstrait (l'esprit, une idée) à un rang supérieur, à un degré plus élevé, devenant ainsi plus noble. Haut reste invariable dans la plupart des cas (ex. de 1945 et 2000), mais il peut également s'accorder avec le sujet (ex. de 1564 et 1835) en se rapprochant d'un prédicat second orienté vers le sujet. Au vu des exemples du CW, il semblerait que la flexion appartienne au style littéraire, soutenu. Il est modifié par plus. Notons les collocations avec dur, fier.

\section{Dresser sage}

(Se) dresser avec sagesse

$\lambda$ dresser fort

\section{Dresser sérieux}

(Se) dresser avec sérieux

$\lambda$ dresser fort

\section{Dresser solennel}

(Se) dresser avec solennité $\lambda$ dresser fort 